\title{
COMPETITIVIDADE E PREDIÇÃO DE PERDAS DE RENDIMENTO DA CULTURA DE FEIJÃO GUANDO EM CONVIVÊNCIA COM Brachiaria plantaginea (Link) Hitchc.
}

\author{
TELMA PASSINI
}

Tese apresentada à Escola Superior de Agricultura

"Luiz de Queiroz", Universidade de São Paulo, para obtenção do Título de Doutor em Agronomia, Área de Concentração: Fitotecnia

P I R A C I C A B A

Estado de São Paulo - Brasil

Outubro - 2001 


\section{COMPETITIVIDADE E PREDIÇÃO DE PERDAS DE RENDIMENTO DA CULTURA DE FEIJÃO GUANDO EM CONVIVÊNCIA COM Brachiaria plantaginea (Link) Hitchc.}

\section{TELMA PASSINI}

Engenheira Agrônoma

Orientador: Prof. Dr. Pedro Jacob Christoffoleti

Tese apresentada à Escola Superior de Agricultura

"Luiz de Queiroz", Universidade de São Paulo, para obtenção do Título de Doutor em Agronomia, Área de Concentração: Fitotecnia

P I R A C I C A B A

Estado de São Paulo - Brasil

Outubro - 2001 


\title{
Dados Internacionais de Catalogação na Publicação (CIP)
} DIVISÃO DE BIBLIOTECA E DOCUMENTAÇÃO - ESALQ/USP

\author{
Passini, Telma \\ Competitividade e predição de perdas de rendimento da cultura de \\ feijão qua ndo em competição com Bra chia ria pla ntaginea (Link) Hitchc. / \\ Telma Passini. - - Piracicaba, 2001. \\ $130 \mathrm{p}$. \\ Tese (doutorado) - Escola Superior de Agricultura Luiz de Queiroz, 2001. \\ Bibliografia.
}

1. Capim mamelada 2. Competição de planta 3. Feijão 4. Índice de área foliar 5. Modelo matemático I. Título

CDD 635.652

\section{"Permitida a cópia total ou parcial deste documento, desde que citada a fonte - $\mathrm{O}$ autor"}




\section{AGRADECIMENTOS}

Ao Instituto Agronômico do Paraná (IAPAR), pela oportunidade de realização deste Curso.

Ao Conselho Nacional de Desenvolvimento Científico e Tecnológico/CNPq, pela de bolsa de estudo concedida.

Ao Prof. Dr. Pedro Jacob Christoffoleti pela valiosa orientação, pela colaboração na realização deste trabalho e sobre tudo, pela amizade.

Ao Prof. Ricardo Victoria Filho pelos conhecimentos transmitidos, atenção e colaboração no trabalho de pesquisa.

À Pesquisadora Inês Fumiko Ubukata Yada (IAPAR), ao Professor Dr. Durval Dourado Neto (ESALQ) e à Professora Sonia Maria de Stefano Piedade (ESALQ) pela orientação na realização e interpretação das análises estatísticas em diferentes fases do trabalho.

Aos funcionários do Departamento de Produção Vegetal da ESALQ/USP, em especial ao Luís Ferrari, Aparecido Mendes e Ony Rodrigues de Campos pela colaboração na realização dos trabalhos, pela alegre convivência e muito mais pela amizade. Agradeço também aos funcionários da horta, em especial ao Aparecido D. Serrano.

Às secretárias do Departamento de Produção Vegetal, Ivete, Bete, D. Helena, especialmente à Maria Célia Rodrigues pela atenção e amizade. 
Ao Hodair Luiz Banzatto Júnior, Técnico em Informática (ESALQ/USP), pela presteza no atendimento e pela amizade .

Aos estagiários do PROHORT pela dedicação na condução dos experimentos preliminares.

Aos funcionários da Biblioteca Central da ESALQ/USP, principalmente à Eliana Garcia pela atenção e colaboração.

A todos os amigos do Curso da Pós-graduação em Fitotecnia e demais cursos da ESALG/USP pela convivência, colaboração e horas de estudo.

A todas as pessoas que contribuíram direta ou indiretamente para a realização deste trabalho 


\section{CURRICULUM VITAE}

Telma Passini, nascida a 29/10/1958 em Piracicaba-SP.

Bacharelado em Engenharia Agronômica, em 1981, pela USP/ESALQ, em Piracicaba-SP.

Mestrado em Fitotecnia, em 1989, pela UFV, em Viçosa-MG.

Professora no período de 1986 a 1987, na UFMS, Dourados-MS, ministrando as disciplinas de Fisiologia Vegetal e Controle de Plantas Daninhas.

Pesquisadora, desde 1988, no Instituto Agronômico do Paraná, em Londrina-PR.

Curso de Doutorado em Fitotecnia iniciado em 1998, na USP/ESALQ, em Piracicaba-SP. 


\section{SUMÁRIO}

LISTA DE ABREVIATURAS.................................................. ix

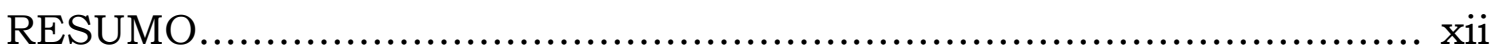

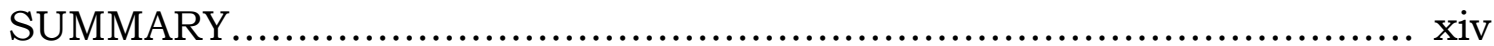

1 INTRODUÇÃO............................................................ 1

2 REVISÃO DE LITERATURA.............................................. 3

2.1 Importância do capim-marmelada (Brachiaria plantaginea) na

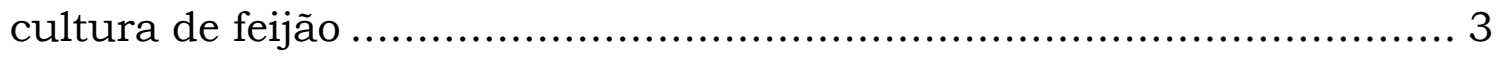

2.2 Métodos de estudo das interações competitivas ........................ 6

2.3 Delineamento substitutivo............................................ 9

2.4 Delineamentos superficie de resposta .............................. 18

2.5 Modelos empíricos de competição entre cultura e planta daninha 18 3 COMPETITIVIDADE DA CULTURA DE FEIJÃO COM A PLANTA DANINHA CAPIM-MARMELADA (Brachiaria plantaginea (Link)

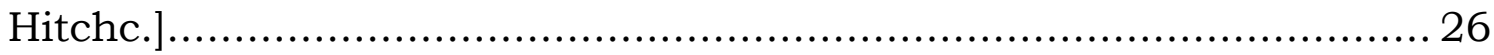

Resumo................................................................ 26

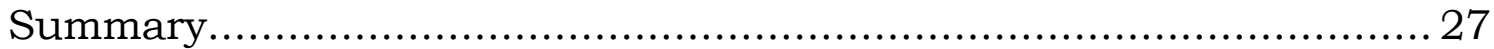

3.1 Introdução ........................................................ 29

3.2 Material e Métodos ...................................................... 30

3.2.1 Densidade na qual as espécies atingem a produção final constante

3.2.2 Determinação da competitividade da cultura de feijão com a planta daninha capim-marmelada ........................................ 35

3.2.2.1 Análise qualitativa da competitividade das espécies ............. 37

3.2.2.2 Análise quantitativa da competitividade das espécies............ 38 
3.3 Resultados e Discussão 40

3.3.1 Densidade na qual as espécies atingem a produção final constante 40

3.3.2 Competitividade da cultura de feijão com a planta daninha capimmarmelada 48

3.3.2.1 Análise qualitativa da competitividade das espécies ............. 48

3.3.2.2 Análise quantitativa da competitividade das espécies ............ 58

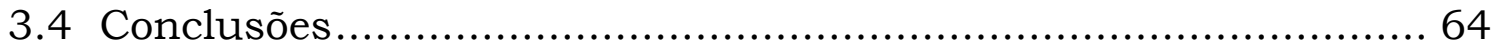

4 MODELOS EMPÍRICOS DE PREDIÇÃO DE PERDAS DE RENDIMENTO DA CULTURA DE FEIJÃO EM CONVIVÊNCIA COM Brachiaria plantaginea (Link) Hitchc...................................66

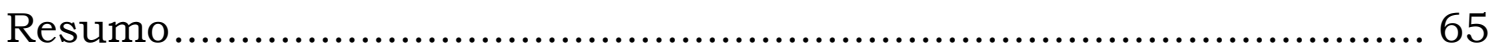

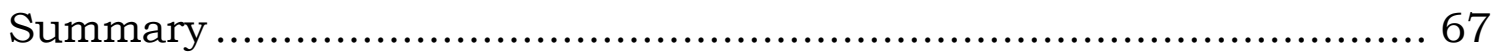

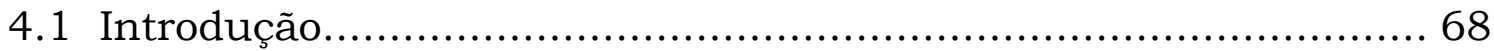

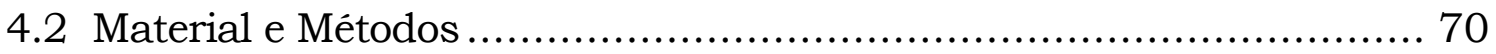

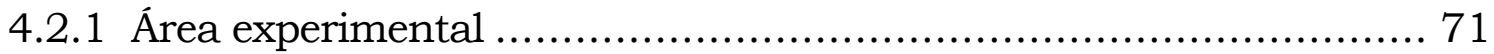

4.2.2 Delineamento estatístico............................................... 72

4.2.3 Preparo da área, instalação e condução do experimento............ 73

4.2.4 Avaliações e cálculos ...................................................... 76

4.2.4.1 Modelos empíricos utilizados ..................................... 78

4.2.4.2 Estimativa dos coeficientes dos modelos empíricos ............... 79

4.2.4.2.1 Modelo de densidade da planta daninha ......................... 80

4.2.4.2.1.1 Método simplificado ............................................. 80

4.2.4.2.1.2 Método completo ................................................ 82

4.2.4.2.2 Modelo de índice de área foliar relativa da planta daninha .. 83

4.2.4.2.2.1 Método simplificado ............................................ 83

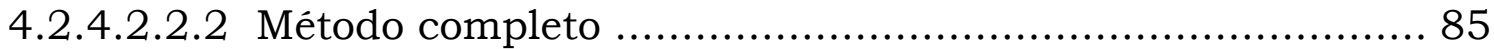

4.2.4.2.3 Modelo de cobertura relativa do solo pela planta daninha ... 86

4.2.4.2.3.1 Método simplificado ............................................... 86 
4.2.4.2.3.2 Método completo .............................................. 87

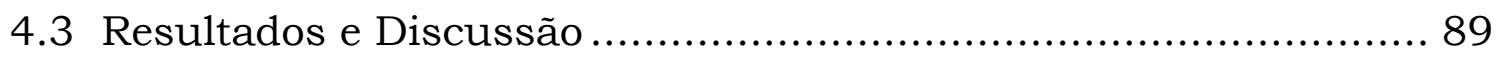

4.3.1 Métodos de ajuste dos dados ....................................... 89

4.3.2 Modelos empíricos .......................................................... 90

4.3.2.1 Modelo de densidade da planta daninha ........................... 90

4.3.2.2 Modelo de índice de área foliar relativa da planta daninha .... 92

4.3.2.3 Modelo de cobertura relativa do solo pela planta daninha.......94

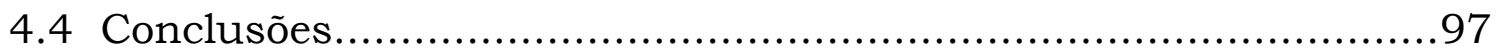

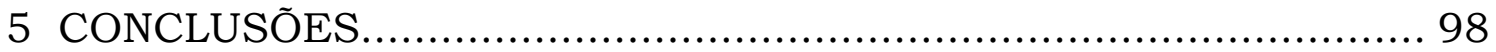

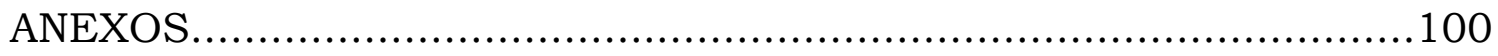

REFERÊNCIAS BIBLIOGRÁFICAS........................................... 124 


\section{LISTA DE ABREVIATURAS}

Y

$Y_{c}, Y_{p d}$

$N, N_{1}, N_{2}, N_{c} \quad$ Densidade - número de plantas por unidade de área $N_{p d}$

$w$

$w_{c}, w_{p d}$

$1 / w, 1 / w_{1}$

$1 / w_{c}, 1 / w_{p d}$

bo

$b_{1}$

$b_{x, y}$

Massa seca da parte aérea das plantas produzida por unidade de área (g.m²).

Massa seca da parte aérea das plantas da cultura e da planta daninha produzida por unidade de área.

$\left(n^{\circ} \cdot m^{-2}\right)$, da espécie 1 , da espécie 2 , da cultura e da espécie de planta daninha.

Massa seca produzida por planta $(Y / N)$.

Massa seca produzida por planta da cultura $\left(Y_{c} / N_{c}\right)$ e por planta da espécie de planta daninha $\left(Y_{p d} / N_{p d}\right)$.

Recíproco da massa seca produzida por planta, da espécie 1 , da cultura e da espécie de planta daninha.

Recíproco da massa seca virtual de uma planta isolada, sem competição intra e interespecífica

Taxa de aumento de $1 / w$, ou de decréscimo de $w$

Coeficientes da regressão linear múltipla do par de equações para duas espécies em competição. $O$ primeiro subscrito refere-se à espécie cujo $1 / w$ está sendo avaliado e o segundo subscrito identifica a espécie associada. 
$b_{1,0}, b_{2,0}, b_{c, 0}$, Recíproco da massa seca teórica máxima de uma planta $b_{p d, 0} \quad$ isolada da espécie 1 , da espécie 2 , da cultura e da planta daninha

$b_{1,1}, b_{2,2}, b_{c, c}$, Coeficientes de competição intraespecífica da espécie 1 , $b_{p d, p d} \quad$ da espécie 2, da cultura e da planta daninha. Indica quanto uma planta afeta outra da mesma espécie, quando na presença de outra espécie.

$b_{1,2}, b_{2,1}, b_{c, p d}$, Coeficientes de competição interespecífica. Quantifica o $b_{p d, c} \quad$ efeito da espécie associada (segundo subscrito) sobre a espécie cujo $1 / w$ está sendo avaliado (primeiro subscrito). Por exemplo, para $b_{1,2}$, o coeficiente indica o efeito competitivo da espécie 2 sobre $1 / w$ da espécie 1 , ou seja, sobre $1 / w_{1}$.

$C R, C R_{1}, C R_{2}$, Índice de competitividade relativa da espécie 1 , da $C R_{c}, C R_{p d} \quad$ espécie 2, da cultura e da planta daninha: é a razão entre o coeficiente de competição intraespecífica e o coeficiente de competição interespecífica. Por exemplo, o indice de competitividade relativa da espécie $1\left(C R_{1}\right)$ é calculado pela razão $b_{1,1} / b_{1,2}$.

IDN Índice de diferenciação de nicho ecológico: é o fator entre os indices de competitividade relativa de duas espécies, por exemplo $C R_{c} \times C R_{p d}$.

$Y_{\text {máx }} \quad$ Produção máxima de massa seca obtida por unidade de área $\left(\mathrm{g} \cdot \mathrm{m}^{-2}\right)$ quando a densidade $\left(N, \mathrm{n}^{\circ}\right.$ de plantas. $\left.\mathrm{m}^{-2}\right)$ tende ao infinito

$K_{n} \quad$ Densidade de plantas com a qual se obtém metade de $Y_{\text {máx }}$

Ro Rendimento da cultura, em grãos (kg.ha-1), na ausência 
de competição com a planta daninha

$R$

PRR

$a$

$m$

$A F_{p d}, A F_{c}$

$I A F_{p d}, I A F$

$F_{p d}$

$q$

$C_{p d}, C_{c}$

$S_{p d}$
Rendimento da cultura, em grãos (kg.ha-1), na presença de competição com a planta daninha

Perda de rendimento relativo (\%) ao tratamento testemunha mantido livre da presença de plantas daninhas

Perda de rendimento causada a cada adição de uma planta de planta daninha por $\mathrm{m}^{2}$

Perda máxima de rendimento relativo

Área foliar média de uma planta da espécie de planta daninha, área foliar média de uma planta da cultura ndice de área foliar $\left(\mathrm{m}^{2} \cdot \mathrm{m}^{-2}\right)$ da planta daninha $\left(A F_{p d} . N_{p d}\right)$ e índice de área foliar da cultura $\left(A F_{c} . N_{c}\right)$ Índice de área foliar relativa da planta daninha $\left[I A F_{p d} /\right.$ $\left.\left(I A F_{p d}+I A F_{c}\right)\right]$

Coeficiente de dano relativo. Expressa a competitividade da planta daninha em relação à cultura e é específico de cada espécie de planta daninha.

Cobertura do solo pela cultura e planta daninha: estimativa visual da porcentagem de área da subparcela coberta pelas plantas da planta daninha e da cultura

Cobertura relativa do solo pela planta daninha: cobertura do solo proporcionada pela planta daninha em relação à cobertura do solo proporcionada pelo total de plantas $\left[\mathrm{C}_{\mathrm{pd}} /\left(\mathrm{C}_{\mathrm{pd}}+\mathrm{C}_{\mathrm{c}}\right)\right]$ 


\section{COMPETITIVIDADE E PREDIÇÃO DE PERDAS DE RENDIMENTO DA CULTURA DE FEIJÃO QUANDO EM CONVIVÊNCIA COM Brachiaria plantaginea (Link) Hitchc.}

Autora: Telma Passini

Orientador: Prof. Dr. Pedro Jacob Christoffoleti

\section{RESUMO}

A predição de perdas de rendimento de uma cultura devido à interferência de plantas daninhas é fundamental para o planejamento e seleção de estratégias de manejo das plantas daninhas na agricultura. Diversos modelos empíricos foram descritos na literatura porém, há necessidade de validá-los e escolher variáveis que possam ser avaliadas de modo prático, sem reduzir a precisão da predição de perda de rendimento da cultura. Os objetivos foram os de avaliar a competitividade da cultura de feijão (Phaseolus vulgaris L.) em relação à planta daninha [Brachiaria plantaginea (Link) Hitchc.]; comparar a eficiência de modelos empíricos em predizer perdas de rendimento da cultura em que a variável independente descreve a população de plantas daninhas em termos de densidade, índice de área foliar relativa e cobertura relativa do solo e propor uma metodologia para estimar os coeficientes dos modelos avaliados. Os experimentos foram conduzidos na Universidade de São Paulo (USP), na Escola Superior de Agricultura "Luiz de Queiroz" (ESALQ), no Departamento de Produção 
Vegetal, em Piracicaba/SP, Brasil. Em casa de vegetação, avaliou-se a resposta de cada espécie à sua própria densidade, determinando-se a densidade mínima de plantas a partir da qual a produção de massa vegetal/unidade de área torna-se independente da densidade e a resposta de cada uma em relação à presença da outra em diferentes densidades e proporções. No campo, avaliou-se a perda de rendimento da cultura devido à densidade e à época de emergência da planta daninha, simulada por diferentes datas de semeadura do capim-marmelada. Em casa de vegetação, o feijão, como espécie competidora, é superior ao capim-marmelada; considerando o efeito da competição sobre a massa seca produzida pela cultura, uma planta de feijão competiu com outra da mesma espécie com a intensidade de 21,3 plantas de capim-marmelada e, o efeito da competição sobre a massa seca produzida pela planta daninha, uma planta de capimmarmelada competiu com outra da mesma espécie com a intensidade de 0,68 plantas de feijão; há diferenciação parcial de nicho ecológico entre as espécies, isto é, ambas utilizam os mesmos recursos do meio mas o feijão evita a presença do capim-marmelada. No campo, o capim-marmelada, como espécie competidora, é superior ao feijão; a perda de rendimento diminui com o atraso na semeadura da planta daninha; o modelo que tem como variável a densidade da planta daninha não descreve a perda de rendimento da cultura causada pela época de semeadura da planta daninha mas aqueles cuja variável é o índice relativo da área foliar da planta daninha ou a cobertura relativa do solo pela planta daninha descrevem; a cobertura relativa do solo pela planta daninha, avaliada visualmente, é uma variável potencial para substituir o índice de área foliar relativa da planta daninha; com o método completo, proposto para estimar os coeficientes dos modelos, obtém-se melhor predição de perdas de rendimento da cultura do que com o método simplificado. 


\section{COMPETITIVITY AND CROP YIELD LOSS PREDICTION OF BEAN (Phaseolus vulgaris L.) IN COEXISTENCE WITH ALEXANDERGRASS [Brachiaria plantaginea (Link) Hitchc.]}

Author: Telma Passini

Adviser: Prof. Dr. Pedro Jacob Christoffoleti

\section{SUMMARY}

The prediction of crop yield losses due to weed infestation is fundamental for the selection of weed management strategies. Several empirical models have been presented in the literature. However, it is necessary to validate them and choose variables, which can be evaluated in more practical way without reducing the precision of the crop yield loss prediction. The goals of this study were to assess the competitive ability of bean (Phaseolus vulgaris L.) relative to the weed alexandergrass [Brachiaria plantaginea (Link) Hitchc.]; to compare the performance of empirical models on predicting crop yield loss based on weed density, weed relative leaf area index and weed relative ground cover and, to suggest a methodology to estimate the coefficients of the tested empirical models. The experiments were carried out at University of São Paulo (USP), Escola Superior de Agricultura "Luiz de Queiroz" (ESALQ), in the Department of Crop Production, in Piracicaba, São Paulo State, Brazil. With the glasshouse experiments the response of 
the species to its own density and, the response of the species to the presence of each other at different densities and proportion between them was assessed. With the field experiment, the crop yield loss, due to weed density and weed emergence relative to the crop emergence, simulated by sowing the weed at different time, was assessed. In the glasshouse experiments, as a competitor species, bean is superior to alexandergrass; the competition as measured by effects on bean biomass, one plant of bean is, to another plant of the same species, competitively equivalent to 21,3 alexandergrass plants and, as measured by effects on alexandergrass biomass, one alexandergrass plant is, to another plant of the same species, equivalent to 0,68 plant of bean; there is partial niche differentiation; the species compete for the same resources however, bean plants avoid the alexandergrass presence. In the field experiment, alexandergrass as a competitor species is superior to bean; crop yield losses decreased with the weed sowing delay; the model which variable is the weed density does not predict de crop yield loss due the relative time of weed sowing however, those models which variable is the weed relative leaf area index or weed relative ground cover, visually estimated, do; the visually estimated weed ground cover is a potential variable to substitute for the weed relative leaf area index; the suggested advanced method for estimating the models coefficients predicts the crop yield loss better than the simple method. 


\section{INTRODUÇÃO}

A competição entre plantas ocorre quando um ou mais fatores essenciais de crescimento encontra-se, no ambiente onde as plantas estão convivendo, em quantidades insuficientes para suprir as necessidades de todos os indivíduos. Nessas condições, ocorre competição tanto intra quanto interespecífica, podendo uma ser mais representativa do que a outra dependendo do nicho que cada espécie ocupa no ecossistema.

No Brasil, as perdas de rendimento das culturas devido à competição com a comunidade de plantas daninhas são quantificadas em função da ocorrência desta em períodos estabelecidos durante o ciclo da cultura. Se por um lado, os resultados assim obtidos são valiosos por indicarem as melhores épocas para o controle das plantas daninhas e o período do ciclo da cultura em que o controle deve ser efetivo, por outro, não permitem avaliar a intensidade das interações intra e interespecífica nem se as espécies envolvidas exploram nichos ecológicos diferentes. Entretanto, tais informações podem ser obtidas com a utilização de delineamentos de tratamentos e métodos de análise apropriados, os quais raramente foram utilizados na condução de experimentos no Brasil.

As plantas daninhas interferem no custo de produção das culturas não só reduzindo o rendimento da porção comercializável mas 
também aumentando o custo das medidas de controle. Para que a relação benefício/custo da medida de controle das plantas daninhas seja positiva, o custo das medidas de controle deve ser inferior ao custo da perda de rendimento na ausência de tais medida. Se for possivel predizer a perda de rendimento devido à presença de plantas daninhas com antecedência suficiente, será possivel decidir pela aplicação ou não de uma medida de controle. No entanto, os modelos de predição de perdas causadas pelas plantas daninhas nas culturas necessitam de uma análise de verificação adequada para as condições de cultivo no Brasil. Sendo assim, a presente pesquisa teve os objetivos de avaliar a competitividade da cultura de feijão (Phaseolus vulgaris) com a planta daninha capim-marmelada (Brachiaria plantaginea); comparar o método qualitativo de análise dos resultados com o método quantitativo proposto por Spitters (1983); comparar a eficiência de modelos empíricos de predição perdas de rendimento da cultura com base na densidade da planta daninha ou índice de área foliar relativa da planta daninha; verificar se a cobertura relativa do solo pela planta daninha, avaliada visualmente, apresenta potencial como variável substituta do indice de área foliar relativa da planta daninha; avaliar se as variáveis utilizadas nos modelos empíricos explicam as perdas de rendimento devido às épocas de emergência da planta daninha em relação à emergência da cultura e propor uma metodologia para estimar os parâmetros dos modelos empíricos avaliados. 


\section{REVISÃO DE LITERATURA}

\subsection{Importância do capim-marmelada (Brachiaria plantaginea) na cultura de feijão}

Papuã, capim papuã, marmelada, capim-marmelada, capim guatemala, grama paulista, milhã branca e milhã são os diversos nomes comuns pelos quais a planta da espécie Brachiaria plantaginea é conhecida nas diferentes regiões brasileiras (Kissmann, 1991). Segundo o autor, sua origem é provavelmente africana e foi introduzida no Brasil na época colonial através dos navios negreiros, nos quais a palha da planta era utilizada como cama pelos escravos. Junto à palha, haviam sementes. Estas, na limpeza dos navios, eram retiradas com a palha, dando início a disseminação da espécie em solo brasileiro.

Na região sul do Brasil, havendo umidade, a germinação das sementes dessa espécie ocorre na primavera e verão, com a chegada do frio, no fim do outono, as plantas terminam o ciclo e morrem (Kissmann, 1991). O desenvolvimento vegetativo se dá até março ou abril e o florescimento e frutificação em maio. Em regiões sem invernos rigorosos o ciclo tende a ser mais alongado. Deuber (1992) cita que o ciclo de vida médio dessa espécie é de 130 dias. O ciclo vegetativo descrito por Kissmann (1991) pode ser comparado aos resultados de um levantamento realizado no Estado do Paraná, em 2.185 lavouras, com várias culturas e sistemas de cultivo (Figura 1) (Kranz, dados não 
publicados). Nesse levantamento, em 253 lavouras das principais regiões produtoras de feijão, capim-marmelada foi a planta daninha mais freqüente, tanto em culturas solteiras como nas consorciadas com milho (Kranz, 1993).

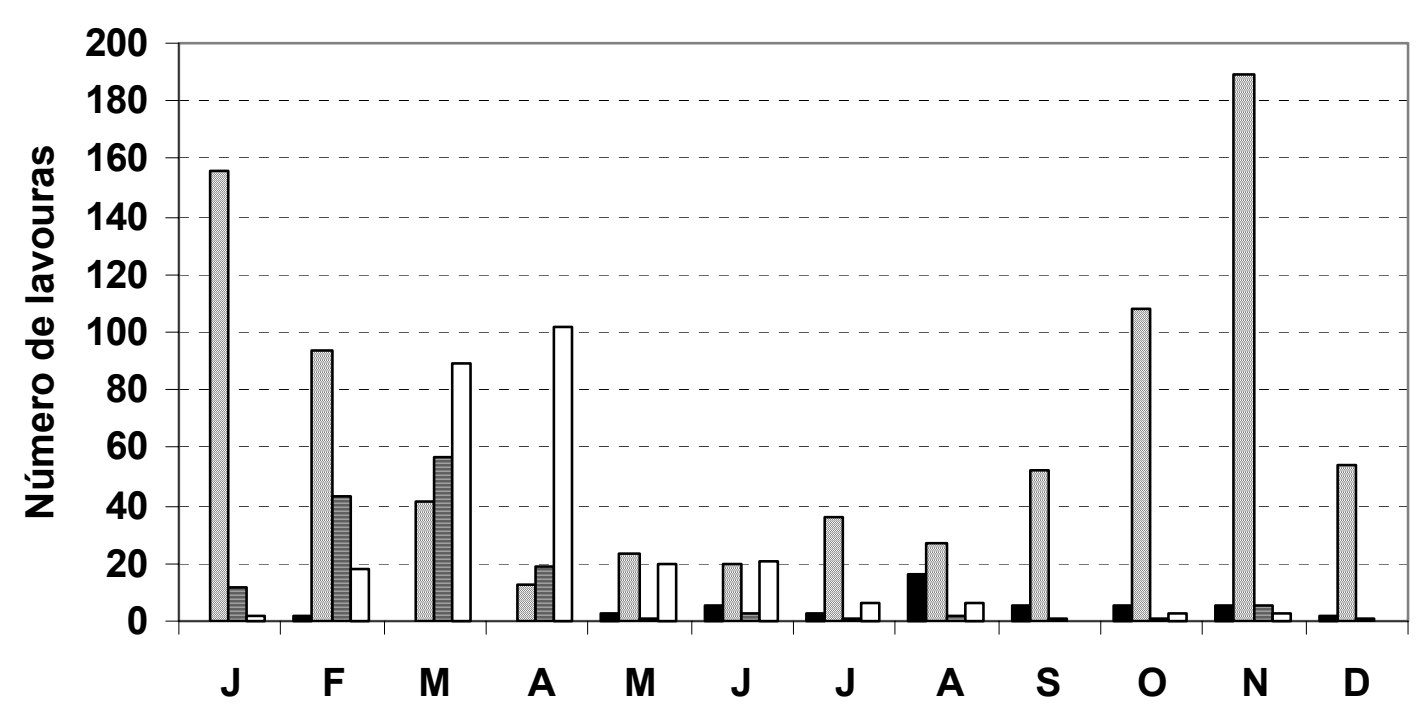

ص Plântula $\square$ Crescimento $\square$ Florescimento $\square$ Maturação

Figura 1 - Estádio de desenvolvimento de capim marmelada (Brachiaria plantaginea) ao longo do ano, expresso pelo número de lavouras em que a espécie foi encontrada em determinado estádio, num total de 2.185 lavouras amostradas no Estado do Paraná, em várias culturas e vários sistemas de cultivo. (Kranz, IAPAR, dados não publicados e apresentados com autorização do autor).

A cultura de feijão pode ser semeada em setembro e colhida em dezembro (feijão das águas), semeada em janeiro e colhida em março (feijão das secas) e semeada em abril e colhida em julho (feijão de inverno). Comparando tais épocas de semeadura da cultura com o ciclo da planta daninha (Figura 1), nota-se que as duas primeiras épocas 
coincidem com a época de germinação das sementes da planta daninha, o que explica a importância de ocorrência dessa espécie na cultura de feijão.

A grande maioria das pesquisas sobre os danos causados pela competição entre culturas e plantas daninhas relacionam o rendimento da cultura ao período em que esta permanece interagindo com a comunidade vegetal daninha presente na área, sendo dificil separar, desses resultados, as perdas causadas por uma única espécie. Os primeiros resultados brasileiros sobre a competição de plantas daninhas com plantas cultivadas foram publicados em 1969 (Blanco, 1982). Esses resultados, segundo o autor, também foram os primeiros para a cultura de feijão, sendo $B$. plantaginea a espécie dominante na área experimental, representando $45,3 \%$ da densidade total de plantas daninhas. Blanco et al. (1969) observaram redução de $23 \%$ no rendimento do feijão das secas (var. Rosinha) quando a cultura, durante todo o seu ciclo, permaneceu em competição com a comunidade de plantas daninhas. Quando B. plantaginea foi a espécie dominante $(92 \%$ do total de plantas daninhas), a ausência de controle durante todo o ciclo da cultura provocou perdas no rendimento de grãos que variaram de 61 a 85\%, dependendo da variedade (Kramm et al., 1990). Os autores também observaram que as variedades mais produtivas foram as que apresentaram maiores reduções no rendimento quando em competição com as plantas daninhas.

De maneira geral, pode-se dizer que quanto maior o período de convivência da cultura com a comunidade de plantas daninhas, maior será o grau de competição Entretanto, há uma fase do ciclo da cultura no qual há maior suscetibilidade da mesma à competição com as plantas daninhas. Para a cultura do feijão está estabelecido que esse 
período ocorre entre 15 e 30 dias após sua emergência mas esse período é dependente da variedade, da comunidade de plantas daninhas, da densidade e distribuição desta na área, das condições edafoclimáticas e dos tratos culturais. Na prática, segundo Lunkes (1997), se a cultura for mantida no limpo durante os primeiros 35 dias ou seja, até a préfloração, que corresponde ao estádio $\mathrm{R}_{5}$ de desenvolvimento, maiores rendimentos serão alcançados.

Devido à importância da cultura de feijão e da importância da ocorrência da planta daninha na cultura, devido às perdas que provoca no rendimento da cultura, é que essas espécies foram escolhidas para a realização da presente pesquisa.

\subsection{Métodos de estudo das interações competitivas}

A determinação das interações competitivas entre espécies de plantas requer delineamentos experimentais e métodos de análise apropriados (Roush et al., 1989). Estas interações competitivas são afetadas por diversos fatores. Dentre os fatores ligados à comunidade infestante, a densidade de plantas é um dos mais importantes, de tal forma que quanto maior for a densidade da comunidade infestante, e portanto maior a quantidade de individuos que disputam os mesmos recursos do meio, mais intensa será a competição com a cultura.

Nas áreas de produção agrícola, a densidade das plantas cultivadas é mantida constante enquanto a densidade das plantas daninhas varia de acordo com o grau de infestação encontrado no local. Desta forma, ocorre também uma variação na proporção entre a densidade de plantas da cultura e de espécies de plantas daninhas, sendo importante, nos estudos de competição, medir não apenas a 
influência da densidade no processo competitivo mas também a influência da variação na proporção entre as espécies.

Dos mais de 600 trabalhos científicos publicados sobre competição entre plantas daninhas e culturas, todos quantificam a interferência que as plantas daninhas provocaram nas culturas, sem se preocupar com a compreensão do processo de competição (Zimdahl, 1980). No Brasil, a maioria das pesquisas sobre competição entre plantas daninhas e cultivadas determinam o período crítico de competição (Christoffoleti, 1988). No entanto, deve-se destacar que existem diversos delineamentos de tratamentos para o estudo da competição entre plantas (Roush et al. 1989) e métodos de análise de resultados que permitem não apenas quantificar as perdas mas também, determinar a competitividade das espécies. Para exemplificar, no Brasil, Christoffoleti \& Victoria Filho (1996) realizaram uma pesquisa com o objetivo principal de descrever as interações competitivas entre plantas de milho (Zea mays L.) e caruru (Amaranthus retroflexus L.) e determinar os índices de competitividade dessas espécies. Os tratamentos foram delineados segundo o método substitutivo e os dados analisados com o método do recíproco da produção recíproca. Determinou-se que o milho foi um competidor mais agressivo que o caruru e que, para a planta cultivada, a competição intraespecífica foi mais importante que a competição interespecífica. Ao contrário, para o caruru, a competição interespecífica foi mais importante que a intraespecífica.

Harper (1977), Oliver e Buchanan (1986) e Rejmánek et al. (1989) descreveram os delineamentos de tratamentos para estudos de competição e (Oliver e Buchanan,1986) ressaltaram suas vantagens e desvantagens. Mais tarde, Cousens (1991) analisou as críticas que 
alguns dos delineamentos vinham recebendo e argumentou que mesmo os mais simples são apropriados, dependendo dos objetivos desejados. Dentre os delineamentos disponíveis, os autores mencionaram os delineamentos aditivo, substitutivo, sistemático, e superficie de resposta. Neste trabalho, o delineamento substitutivo é descrito com mais detalhes.

No delineamento aditivo, a densidade de uma das espécies que convivem numa mesma área é mantida constante e a da(s) outra(s) é variável. Normalmente, a cultura é mantida na densidade recomendada e constante em todos os tratamentos e a densidade das plantas daninhas é variável. Existem variações do delineamento aditivo: convencional, parcelas pareadas, área de influência e microparcelas.

No delineamento aditivo convencional, normalmente, utilizase a infestação natural de plantas daninhas existente na área experimental. Neste caso não se analisa o efeito competitivo de cada espécie de planta daninha sobre a cultura mas o da comunidade de plantas daninhas como um todo. Esse delineamento é mais utilizado para quantificar as perdas de rendimento das culturas em função do período em que plantas daninhas e cultura permanecem em competição.

Para reduzir a variabilidade devido à distribuição espacial das plantas daninhas em uma área, utiliza-se o delineamento aditivo em parcelas pareadas. Este delineamento é assim denominado devido à colocação de uma parcela com a cultura mantida sem a presença da planta daninha (tratamento testemunha) ao lado de cada parcela em que a cultura é mantida em competição.

O delineamento aditivo área de influência é mais utilizado para avaliar o efeito de uma planta daninha na cultura. As plantas 
dessa espécie são espaçadas criteriosamente a distâncias de 2 a 3 metros entre si, de tal forma a não existir competição intraespecífica. As plantas da espécie cultivada são mantidas em seu espaçamento normal. $\mathrm{Na}$ colheita é avaliada a produção individual de plantas da cultura, a intervalos regulares de distância de uma planta daninha, normalmente a 0 a 12,$5 ; 12,5$ a $25 ; 25$ a $50 ; 50$ a 75 e 75 a $100 \mathrm{~cm}$ de cada lado da planta daninha. Este delineamento foi descrito de forma detalhada por Goldberg \& Werner, 1983.

O delineamento aditivo em microparcelas possibilita analisar a massa produzida pela cultura e plantas daninhas em pequenas parcelas, em tratamentos de estande puro e de mistura de espécies. A cultura é plantada em espaçamento mais estreito que o recomendado e as sementes das plantas daninhas são distribuídas uniformemente ou aleatoriamente, porém a uma densidade definida. A análise dos dados da massa vegetal produzida permite a determinação da competitividade relativa ou do índice de competitividade de várias espécies de plantas daninhas.

O delineamento sistemático é utilizado para estudos de competição intraespecífica. Nesse delineamento, dentro da parcela, o número de plantas por unidade de área é variável mas o arranjo espacial é mantido constante.

\subsection{Delineamento substitutivo}

O delineamento substitutivo foi introduzido em 1960 (Wit ${ }^{1}$, citado por Harper, 1977) e tem sido usado principalmente com os objetivos de determinar o melhor competidor entre duas espécies ou

1 Versl. Landbowk. Onderz., v.66, p.1-82, 1960. 
biotipos e compreender como as duas espécies interagem entre si (Cousens, 1991). Nesse tipo de delineamento, a densidade total de plantas é mantida constante enquanto a proporção entre as duas espécies é variável (Harper, 1977). Os tratamentos são estabelecidos a partir do estande puro de uma espécie e, progressivamente, suas plantas são substituídas por outras de uma segunda espécie até se obter o estande puro dessa última (Spitters, 1983) (Figura 2). Além do

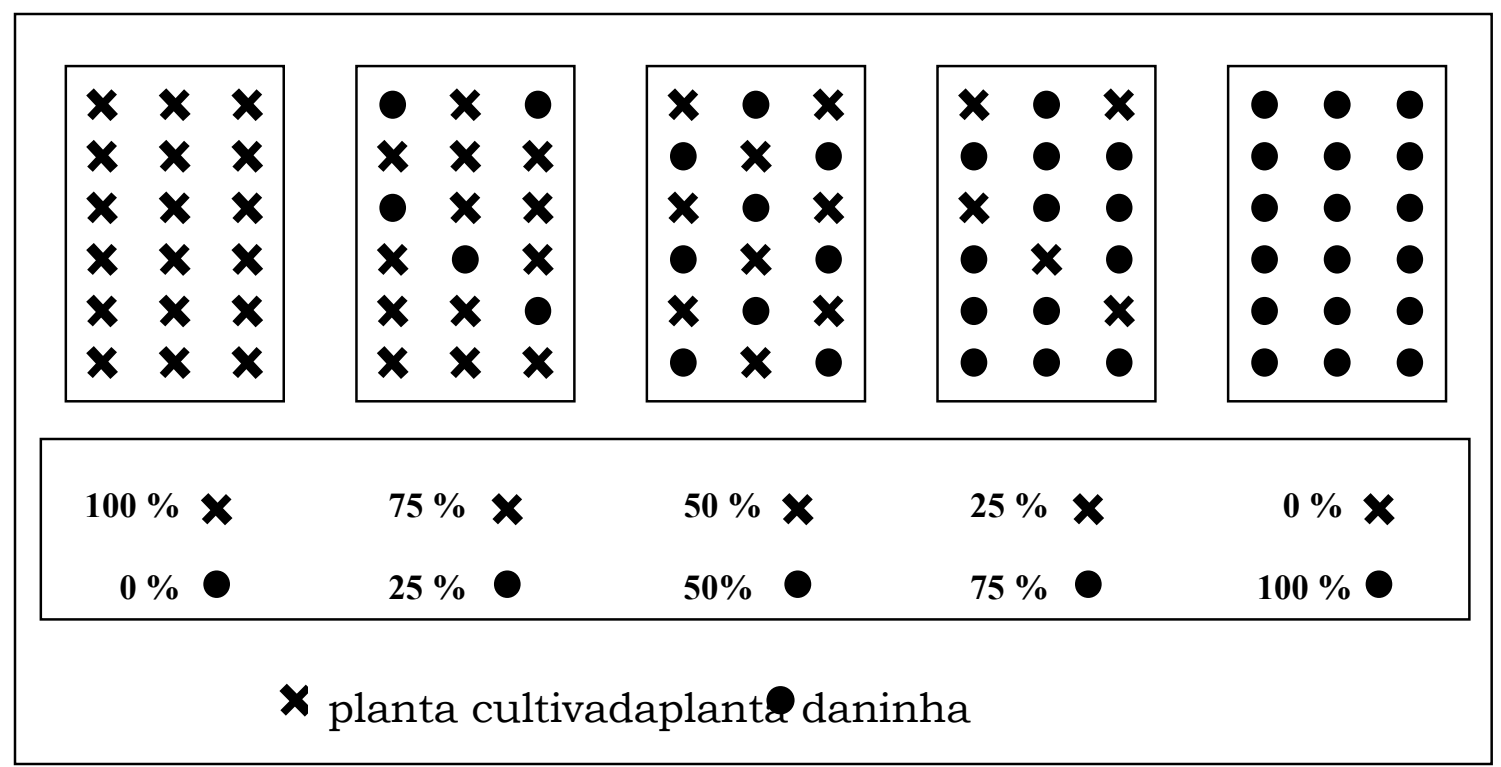

Figura 2 - Delineamento substitutivo. A densidade total é mantida constante em todos os tratamentos enquanto a proporção entre as espécies é variável.

estande puro das duas espécies, na mesma densidade, deve figurar entre os tratamentos a proporção 1:1 (Connoly, 1988). Além disso, assume-se que a densidade total de plantas é suficientemente grande para satisfazer a "lei da produção final constante", ou seja, em densidades acima de determinado valor, a produção de massa vegetal é independente da densidade de plantas naquela área (Figura 3). 


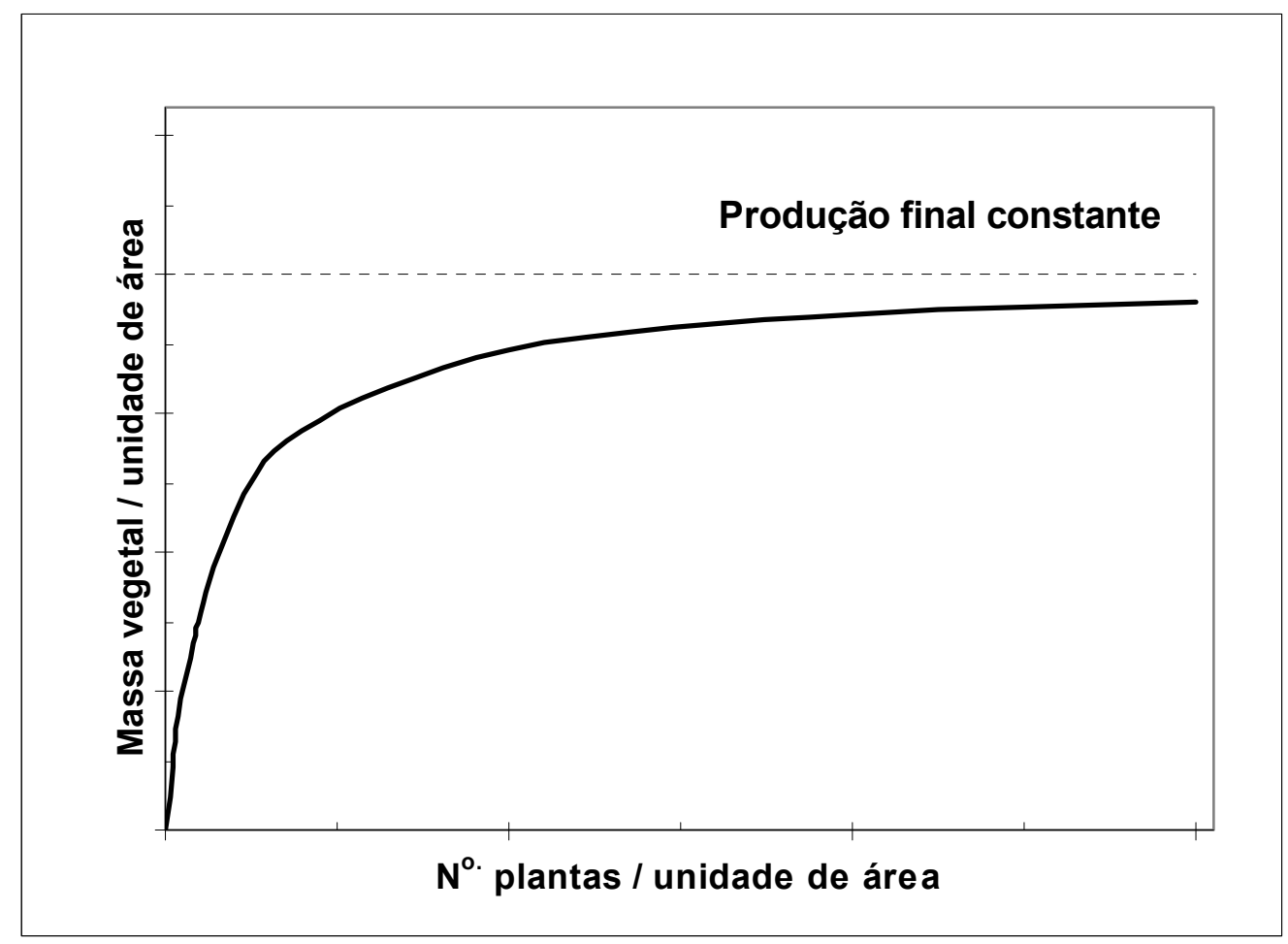

Figura 3 - Representação esquemática da "lei da produção final constante".

A interpretação dos resultados obtidos com o delineamento substitutivo pode ser feita de maneira convencional, qualitativamente, observando a resposta da produção de massa vegetal de cada espécie, devido à variação na proporção entre plantas, em relação à produção de massa vegetal na ausência de competição intra e interespecífica (Figura 4), ou quantitativamente, com o uso de equações matemáticas a partir das quais se estabelecem indices de competição intra e interespecifica e de diferenciação de nicho ecológico (Spitters, 1983 e Joliffe et al., 1984).

Teoricamente, pela interpretação convencional, os resultados dos experimentos substitutivos podem tomar qualquer das quatro formas básicas (Figura 4). A interpretação é feita pela comparação entre a produção obtida e a esperada, sendo esta uma 


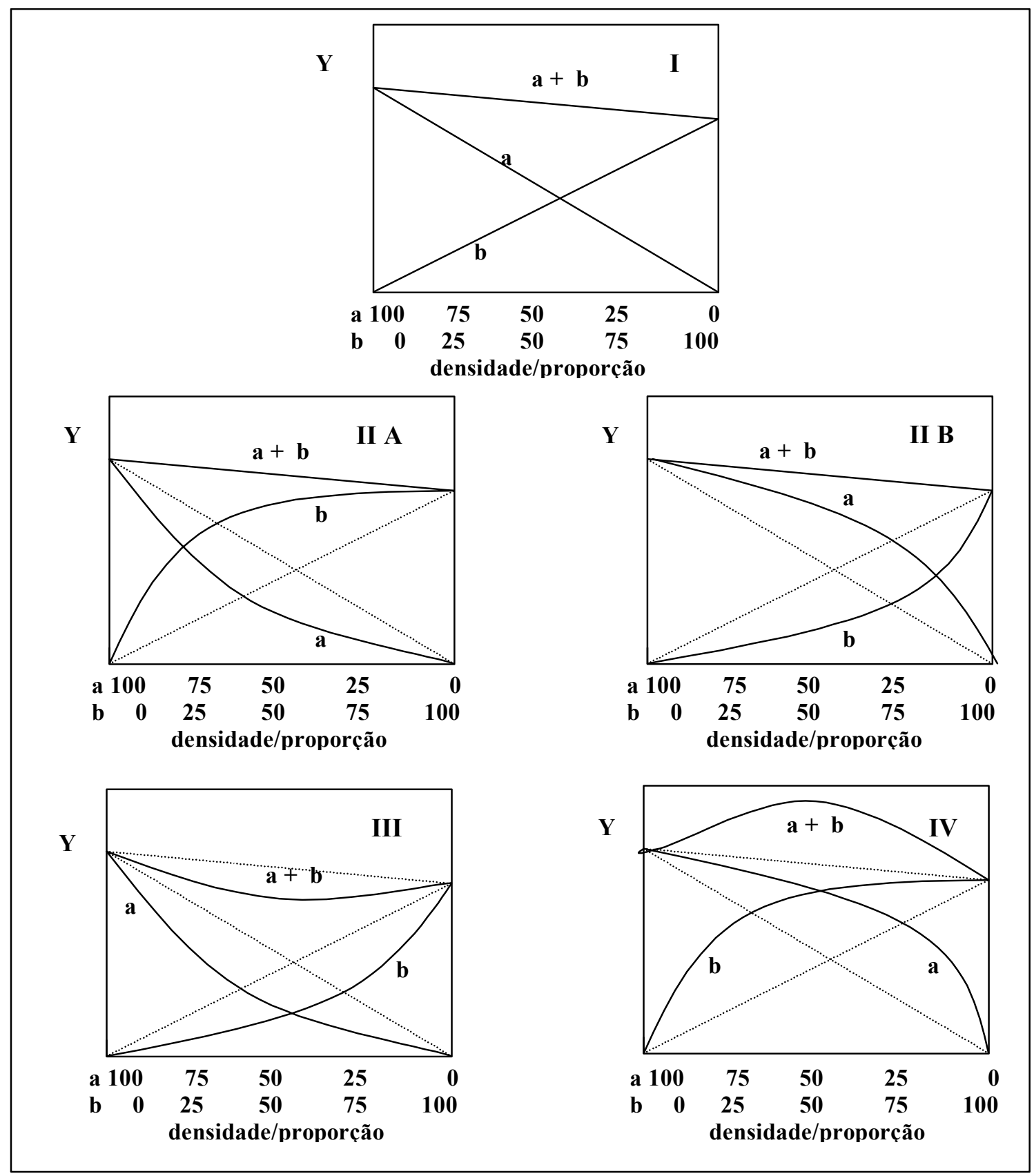

Figura 4 - Possiveis resultados de uma experimento substitutivo (Adaptado de Harper, 1977). $\mathrm{Y}=$ produção, $\mathrm{a}=$ espécie 1 , $\mathrm{b}=$ espécie 2; 100 representa o tratamento em estande puro de cada espécie e os demais valores, a substituição de uma espécie por outra. 
função linear da proporção da espécie na mistura (Rejmánek et al. 1989). A produção esperada é definida pela linha reta que liga o ponto da produção de cada espécie em estande puro (100:0) ao seu ponto de produção zero (0:100). Essa linha é considerada a resposta de competitividade equivalente, isto é, a competição intraespecífica é equivalente à interspecífica. No modelo I, a interpretação é que a habilidade de cada espécie em interferir com a outra é equivalente; isto é, cada espécie contribui para a massa total produzida na proporção direta de sua presença na mistura. Nos modelos II A e II B, uma espécie é mais agressiva que a outra e contribui mais que o esperado para a produção total, enquanto que a outra contribui menos que o esperado. Nas duas combinações, uma curva é côncava e a outra é convexa, indicando que a interação entre as espécies é pelos mesmos recursos e que uma espécie é mais agressiva que a outra na conquista destes recursos. Este é o modelo que normalmente expressa a competição entre plantas daninhas e cultura. No modelo III nenhuma das espécie contribui com a quantidade esperada para a produção de massa vegetal total. A produção das duas espécies na mistura é menor que aquela obtida quando as duas espécies são cultivadas isoladamente. Este tipo de modelo representa um antagonismo mútuo e a produtividade máxima só é obtida com o estande puro de cada espécie. No modelo IV, ambas as espécies produzem mais do que o esperado nos estandes puros, podendo indicar que há benefícios mútuos ou que as espécies tem grande sucesso em evitar uma à outra. Tal situação pode ocorrer entre planta daninha e cultura, mas o ideal é que ocorra em um consórcio de culturas.

A interpretação quantitativa dos resultados de experimentos em delineamento substitutivo teve início no final dos anos 50 quando foi 
determinada empiricamente uma relação linear entre o recíproco da produção por planta e a densidade de plantas (Kira e colaboradores ${ }^{2}$, citados por Rejmánek et al., 1989). Essa relação foi determinada para uma espécie e depois ampliada para duas espécies em mistura, formando um par de equações lineares $\left(\mathrm{Ogawa}^{3}\right.$, citado por Rejmáek et al., 1989). Outros pesquisadores, partindo do mesmo princípio, desenvolveram um par de equações correspondente. Spitters (1983) considerou que a competição intraespecífica pode ser expressa pela produção de massa vegetal por unidade de área ( $Y$ ) em função da densidade de plantas $(N$ - número de plantas por unidade de área), descrita pela equação hiperbólica:

$$
Y=\frac{N}{b 0+b 1 \times N}
$$

e que, o recíproco da massa produzida por planta $(1 / w)$ pode ser descrita pela equação linear:

$$
\frac{1}{w}=\frac{N}{Y}=b 0+b 1 \times N
$$

em que, $b_{0}$ é o ponto em que a reta intercepta o eixo y e representa o recíproco da massa virtual produzida por uma planta isolada; $b_{1}$ é a inclinação da reta e representa a taxa de aumento de $1 / w$ ou de decréscimo em $w$ devido ao aumento em $N$; a proporção $b_{1} / b_{0}$ expressa o aumento de $1 / w$ em relação a seu valor na ausência de competição e portanto mede o estresse da competição intraespecífica. $O$ autor

2 J. Inst. Polytech. Osaka City Univ., D7, p.35-72, 1956 (em japonês) e Physiol. Ecol. Jap., v.8, p.858-860,1958 (em japonês).

3 Experimental studies on the crowding effect in mixed populations of higher plants. Dep. Agric. Thesis, Kyoto Univ. (em japonês). 
assumiu que, se na competição intraespecífica, a adição de plantas da mesma espécie, afeta $1 / w$ aditivamente, a adição de plantas de outra espécie também afetaria $1 / w$ aditivamente. Assim, o par de equações que representariam o inverso da massa produzida por planta seriam, para a espécie 1 :

$$
\frac{1}{w 1}=b 1,0+b 1,1 \times N_{1}+b_{1,2} \times N_{2}
$$

e, para a espécie 2:

$$
\frac{1}{w 2}=b 2,0+b 2,2 \times N_{2}+b_{2,1} \times N_{1}
$$

O primeiro subscrito de cada termo refere-se à espécie cuja massa está sendo avaliada e o segundo subscrito identifica a espécie associada.

O recíproco da massa produzida por uma planta da espécie $1\left(1 / w_{1}\right)$ é descrito pelo recíproco da massa teórica máxima de uma planta dessa espécie $\left(b_{1,0}\right)$, pela sua própria densidade $\left(N_{1}\right)$ e pela densidade de uma segunda espécie $\left(N_{2}\right)$ e, os efeitos da competição intra e interespecífica são quantificados, respectivamente, pelos coeficientes $b_{1,1}$ e $b_{1,2}$ (Spitters, 1983). Na mesma ordem, (1/ $\left.w_{2}\right)$ é descrito pelo recíproco da massa teórica máxima de uma planta da própria espécie $\left(b_{2,0}\right)$, pela sua própria densidade $\left(N_{2}\right)$ e pela densidade da outra espécie $\left(N_{1}\right)$, sendo, os efeitos da competição intra e interespecífica quantificados, respectivamente, pelos coeficientes $b_{2,2}$ e $b_{2,1}$. Dessa forma, densidade total e densidade relativa (proporção) estão incorporadas nesse método para quantificar as interações competitivas 
(Roush et al., 1989) e as competições intra e interespecífica são formalmente separadas (Rejmánek et al., 1989).

A partir dos coeficientes de cada espécie, Spitters (1983) sugeriu a interpretação dos resultados com o uso de índices de competitividade relativa $(C R)$ de cada espécie e do índice de diferenciação de nicho ecológico $(I D N)$ :

$$
\begin{aligned}
& C R 1=\frac{b_{1,1}}{b_{1,2}} \\
& C R 2=\frac{b_{2,2}}{b_{2,1}} \\
& I D N=C R 1 \times C R 2
\end{aligned}
$$

Em termos matemáticos, há diferenciação de nicho quando IDN > 1 (Spitters, 1983).

Outra forma de interpretação dos experimentos com delineamento de tratamentos substitutivo foi proposta por Joliffe et al. (1984), envolvendo comparações entre as produções projetadas das monoculturas, as produções reais das monoculturas e reais das misturas. A equação de resposta da produção em função da densidade das plantas é:

$$
Y=\frac{Y_{\operatorname{má} x} \times N}{K n+N}
$$


e a forma linearizada recíproca dupla:

$$
\frac{1}{Y}=\frac{1}{Y_{\operatorname{máx}}}+\frac{K_{n}}{Y_{\max }} \times \frac{1}{N}
$$

Nessas equações, $Y$ é produção de massa por unidade de área, $Y_{\text {máx }}$ é a máxima produção obtida com um determinado estande de plantas em que a produção final é constante, $\mathrm{N}$ é a densidade das plantas, e Kn representa a densidade em que a produção é $50 \%$ de $Y_{\text {máx }}$. Usando $Y_{\operatorname{máx}}$ e $K n$, Joliffe et al. (1984) propuseram uma linha de produção projetada $\left(Y_{p}\right)$ para indicar uma não-interação "real" que exclui os efeitos das competições intra e interespecífica:

$$
Y=\frac{Y_{m a ́ x}}{K_{n}} \times N
$$

Essa produção projetada serve como referência para comparação com os efeitos das competições intra e interespecífica.

Ao comparar o método proposto por Spitters (1983) [método do recíproco da produção por planta, eq. (3) e eq. (4)] ao proposto por Joliffe et al. (1984) [método do reciproco duplo, eq. (9)] Roush et al. (1989) concluíram que o método do recíproco da produção por planta foi mais simples no que se refere à medir a importância relativa das competições intra e interespecífica e foi mais sensível para medir as interações entre densidade e proporção entre as espécies, na mistura. 


\subsection{Delineamentos superfície de resposta}

Entre os delineamentos usados para descrever uma superficie de resposta estão o delineamento em séries substitutivas e o fatorial ou aditivo completo (Cousens, 1991). O primeiro descreve uma porção triangular das combinações de densidade (Figura 5A) e o segundo, todas as combinações possiveis entre as densidades de cada espécie (Figura 5B).

\subsection{Modelos empíricos de competição entre cultura e planta daninha}

A habilidade em predizer perdas de rendimento devido à presença de plantas daninhas possibilitaria, aos produtores, comparar o custo de controle com o valor da produção, caso as plantas daninhas não fossem controladas (Parker \& Murdoch, 1996). Segundo esses autores, seria necessário que as predições de perda de rendimento fossem avaliadas com precisão a partir de observações simples da comunidade de plantas daninhas, no início do crescimento da cultura, para permitir uma aplicação efetiva de herbicidas, caso necessário ou, ampliando a visão dos autores, para permitir uma aplicação efetiva de uma medida de controle.

O grau de perda de rendimento da cultura depende, entre outros fatores, da densidade das plantas daninhas, da distribuição dessas plantas na área, do tamanho das mesmas, determinado pela época relativa entre a emergência da cultura e das plantas daninhas, e de seus fluxos de emergência (Parker \& Murdoch, 1996).

A equação hiperbólica que relaciona as perdas de rendimento da cultura à densidade de uma espécie de planta daninha é o modelo de regressão mais utilizado para descrever os efeitos da 

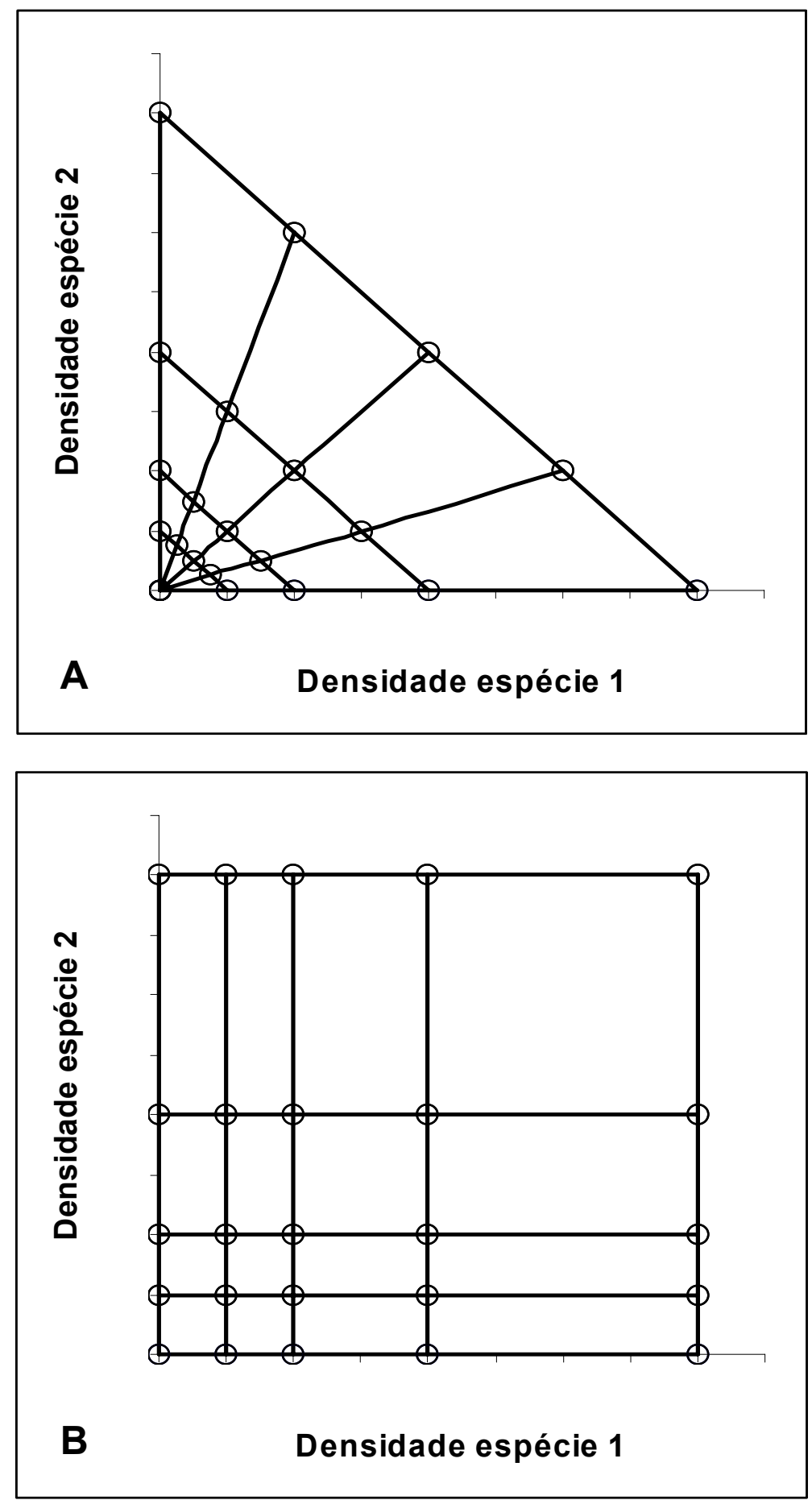

Figura 5 - Combinação de densidades em um delineamento em séries substitutivas (A) e em um aditivo completo (B). Adaptado de Cousens, 1991. 
competição em dado momento (Cousens ${ }^{4}$ e Spitters et al. ${ }^{5}$, citados por Kropff \& Lotz, 1992). Entretanto, a densidade de plantas daninhas nem sempre é uma medida precisa para predizer perdas uma vez que desconsidera os demais fatores mencionados no parágrafo anterior. Por essa razão e com o objetivo de melhorar a predição de perdas, alguns autores modificaram a equação hiperbólica, utilizando artificios matemáticos, substituindo a variável densidade por outras e estimando novos parâmetros.

Kropff \& Lotz (1992 e 1993) mencionaram quatro modelos de predição de perda de rendimento relativo da cultura $(P R R)$ ou seja, a perda de rendimento em relação ao que se obteria com a cultura mantida livre da presença da planta daninha. No primeiro, $P R R$ é função da densidade da planta daninha ( $N_{p d}$ - número de plantas por unidade de área) e tem como parâmetro, a perda de rendimento causada a cada adição de uma planta daninha por $\mathrm{m}^{2}$ (a) [eq.(11)]; no segundo, há um parâmetro adicional que descreve a perda máxima de rendimento relativo $(m)$ [eq. (12)]. No terceiro, $P R R$ é função da área foliar relativa da planta daninha $\left(F_{p d}\right)$, expressa pela razão entre o índice de área foliar da planta daninha e a soma dos índices de área foliar da cultura e da planta daninha, logo após a emergência da cultura e tem um coeficiente de dano relativo (q) [eq. (13)] que expressa a competitividade da planta daninha em relação à cultura (Lotz et al., 1996). O quarto modelo [eq. (14)] é uma versão ampliada da eq. (13), desenvolvido em analogia com a eq. (12).

4 Journal of Agricultural Science, v.105, p.513-521, 1985

${ }^{5}$ Ann. Appl. Biol., v.115, p.541-551, 1989. 


$$
\begin{aligned}
& P R R=\frac{a \times N_{p d}}{1+a \times N_{p d}} \\
& P R R=\frac{a \times N_{p d}}{1+\frac{a}{m} \times N_{p d}} \\
& P R R=\frac{q \times F_{p d}}{1+(q-1) \times F_{p d}} \\
& P R R=\frac{q \times F_{p d}}{1+\left(\frac{q}{m}-1\right) \times F_{p d}}
\end{aligned}
$$

Segundo os autores, as equações 11 e 12 ajustam bem os dados dos experimentos quando somente a densidade da planta daninha varia. Entretanto, demonstraram com exemplos que os parâmetros $a$ e $m$ variam de forma acentuada entre os experimentos, devido a efeitos de outros fatores sobre os processos de competição.

Simulando perdas de rendimento e utilizando um modelo ecofisiológico, Kropff (1988) demonstrou que o periodo entre a emergência da cultura e da plantas daninha foi um dos fatores mais importantes e responsável pela variação de resultados entre experimentos. O autor, também com o uso de simulações, variando tanto a densidade da planta daninha como o período entre a emergência da cultura e da planta daninha, demonstrou que há uma estreita 
relação entre essas variáveis e a área foliar relativa das plantas daninhas determinada logo após a emergência da cultura. Portanto, concluiu que as variáveis densidade e período relativo entre a emergência da cultura e planta daninha poderiam ser caracterizadas por uma única variável, a área foliar relativa das plantas daninhas. Assim, foi desenvolvido o modelo da eq. (13) (Kropff \& Spitters, 1991). Esse modelo, por ter sido matematicamente derivado da eq. (11) considera, indiretamente, a densidade da planta daninha. Além disso, tendo como variável a área foliar relativa da planta daninha, os autores afirmaram que o modelo também considera o período decorrido entre a emergência da cultura e da planta daninha, conferindo-lhe uma grande vantagem pois, dessa forma, os fluxos de emergência da planta daninha não precisam ser manuseados separadamente (Kropff \& Lotz, 1993). Portanto, o modelo pode ser usado em situações em que a planta daninha emerge em vários fluxos mas determinando sua área foliar relativa apenas uma vez, por exemplo, no momento de se decidir pela aplicação ou não um herbicida (Lotz et al., 1994).

Em alguns casos, a eq. (14) proporcionou uma descrição mais precisa do efeito da competição (Kropff \& Lotz, 1992 e Kropff et al., 1995). Lotz et al., (1992) citam que o parâmetro $m$ explica as diferenças entre as espécies quanto à morfologia, ciclo de vida e desenvolvimento, podendo ser necessária a sua utilização, quando a planta daninha apresenta crescimento prostrado ou floresce relativamente cedo.

O uso da variável $F_{p d}$, embora eficiente em predizer perdas de rendimento, envolve amostragens destrutivas e um trabalho moroso para determinar o índice de área foliar da cultura e da(s) planta(s) daninhas(s). Sugeriu-se então que $F_{p d}$, em termos práticos, poderia ser estimada pela cobertura foliar relativa das plantas daninhas (Kropff, 
1988), uma estimativa da área coberta pela projeção vertical das folhas das plantas daninhas como uma fração da área total coberta pelas folhas das plantas daninhas e da cultura. A cobertura foliar relativa das plantas daninhas será daqui em diante mencionada como cobertura relativa do solo pela(s) planta(s) daninha(s) $\left(S_{p d}\right)$.

A substituição de $F_{p d}$ por $S_{p d}$, pretendendo facilitar as observações de campo, tem esbarrado na morosidade das avaliações quando envolvem o uso de fotografias e grades ou na subjetividade das avaliações visuais. Lotz et al. (1994) alertaram que a experiência do avaliador e as características da espécie, como cor e tipo de crescimento, podem distorcer os dados de forma considerável. Ao contrário, Florez et al. (1999), consideram que, visualmente, o avaliador integra em sua mente a área total da unidade experimental contribuindo para reduzir erros de amostragem.

Lotz et al. (1994) avaliaram a área foliar relativa e a cobertura relativa do solo de Chenopodium album L., Polygonum persicaria L. e Stelllaria media (L.) Vill. na cultura de trigo (Triticum aestivum L.). A cobertura relativa do solo foi avaliada visualmente e com uma grade de 2,50 x 0,50 m constituída de subquadrados de 12,5 x $12,5 \mathrm{~mm}$. Os autores observaram a relação entre área foliar relativa e cobertura relativa avaliada com a grade, assim como a relação entre esta última e a cobertura relativa avaliada visualmente. No primeiro caso houve uma relação linear e que foi consistente nos estádios iniciais de crescimento das três espécies de plantas daninhas. A estimativa visual da cobertura relativa apresentou baixa correlação com a cobertura avaliada com a grade e, pelos resultados obtidos, consideraram que o treinamento dos avaliadores não contribuiria de forma considerável para melhorar a precisão de suas avaliações. Entretanto, os mesmos autores 
citam que Lutman6, a partir da comparação entre a avaliação visual e fotográfica da cobertura de aveia em feijão e linho, sugeriu que observadores treinados são capazes de avaliar visualmente a cobertura com um nível aceitável de precisão.

A cobertura relativa do solo estimada com o uso de fotografias, comparativamente à estimada pelo uso de uma grade, proporcionou melhor predição de perdas no rendimento (Parker \& Murdoch, 1996). A estimativa com o uso de fotos foi feita pela projeção da imagem em uma tela com 200 pontos igualmente espaçados e contando o número de pontos cobertos pela cultura (trigo) e pelas plantas das espécies utilizadas como planta daninha (mostarda branca Sinapsis alba e aveia - Avena sativa) e calculando a porcentagem de solo coberto pelas espécies. Essa estimativa foi comparada à obtida com o auxílio de uma grade de $1 \mathrm{~m}^{2}$ com 200 pontos, colocada no centro da parcela. Os autores observaram que utilizando a cobertura relativa do solo como variável, no modelo da eq. (13) não houve descrição adequada dos dados $\left(\mathrm{r}^{2}\right.$, para cobertura estimada a partir de fotos, variou entre 0,33 e 0,48). No entanto, argumentaram que há potencial para ser uma medida precisa de predição de perdas do rendimento das culturas, com o avanço das técnicas eletrônicas de reconhecimento da vegetação ou, como sugeriram Florez et al. (1999), pelo uso da tecnologia de imagem digitalizada, o que permitiria executar avaliações rápidas e precisas no campo.

Estimativas rápidas e de modo não destrutivo podem ser feitas com o uso de técnicas de assinaturas multiespectrais. Lotz et al. (1994) utilizando mostarda branca como planta daninha em trigo,

${ }_{6}^{6}$ Colloque International sur la Biologie des Mauvaises Herbes, 9, Dijon, Paris, 1992, p.337-345. 
demonstraram que, para situações em que a emergência da cultura é uniforme e se a planta daninha e a cultura não cobrem substancialmente uma à outra, a área foliar relativa das plantas daninhas pode ser estimada através dessa técnica, comparando-se a leitura da cultura infestada com a de parcelas livres de plantas daninhas. Essas condições podem ocorrer nos estádios iniciais de estabelecimento da cultura. Entretanto, nesses estádios, os autores lembram que deve-se assumir que o índice de área foliar das plantas daninhas $\left(I A F_{p d}\right)$ pode ser considerado de forma aditiva ao da cultura $\left(I A F_{c}\right)$.

Florez et al. (1999) observaram que das variáveis independentes utilizadas nos modelos hiperbólicos, a densidade foi a que pior descreveu os efeitos da competição, resultando em regressões com os maiores valores de quadrado médio de resíduo e os menores valores de coeficiente de determinação. Os mesmos autores obtiveram melhor predição quando utilizaram como variáveis o índice de área foliar relativa e cobertura relativa do solo pela planta daninha, sendo esta, avaliada visualmente. 


\section{COMPETITIVIDADE DA CULTURA DE FEIJÃO COM A PLANTA DANINHA CAPIM-MARMELADA (Brachiaria plantaginea (Link) Hitchc.]}

\section{Resumo}

A quantificação das interações competitivas entre plantas cultivadas e daninhas é essencial para a fundamentação das recomendações das estratégias de manejo das plantas daninhas na agricultura, porém as metodologias de quantificação não foram amplamente elucidadas e comparadas na literatura. Assim, os objetivos deste estudo foram de avaliar a competitividade da cultura de feijão (Phaseolus vulgaris L.) em relação à planta daninha capim-marmelada [Brachiaria plantaginea (Link) Hitchc.] e comparar dois métodos de análise de resultados de experimentos com tratamentos em delineamento substitutivo. Dois experimentos foram conduzidos em casa de vegetação, no período de dezembro de 1999 a fevereiro de 2000, na Universidade de São Paulo (USP), Escola Superior de Agricultura "Luiz de Queiroz" (ESALQ), Departamento de Produção Vegetal, no município de Piracicaba - SP. No primeiro experimento, avaliou-se a resposta de cada espécie à sua própria densidade, determinando-se o valor de densidade a partir do qual a produção de massa vegetal tornase independente do aumento da densidade de plantas. Os tratamentos foram as densidades ( 37 a 2381 plantas. $\mathrm{m}^{-2}$ ), em quatro repetições, e o delineamento experimental foi em blocos ao acaso. No segundo, a resposta de cada espécie devido à presença da outra, em diferentes 
densidades e proporções, obtida a partir de um experimento com tratamentos em três séries substitutivas, com 4 repetições, e delineamento experimental em blocos ao acaso. As densidades totais de cada série substitutiva foram de 625, 816 e 1111 plantas.m-2. Em cada série, as proporções entre plantas de feijão e de capim-marmelada foram de 100:0 (estande puro de feijão), 75:25, 50:50, 25:75 e 0:100\% (estande puro de capim-marmelada). A análise dos resultados foi feita com o método qualitativo e um método quantitativo. As informações gerais obtidas com os dois métodos foram semelhantes. Entretanto, as dúvidas na interpretação dos dados, devido ao uso do método qualitativo, foram esclarecidas com a interpretação quantitativa. Além disso, com o método quantitativo foi possivel separar e quantificar os efeitos da competição intra e interespecífica. Considerando o efeito da competição sobre a massa seca produzida pela cultura, uma planta de feijão competiu com outra da mesma espécie com a intensidade de 21,3 plantas de capimmarmelada e, considerando o efeito da competição sobre a massa seca produzida pela planta daninha, uma planta de capim-marmelada competiu com outra da mesma espécie com a intensidade de 0,68 planta de feijão. Há diferenciação parcial de nicho ecológico, isto é, as plantas competem pelos mesmos recursos do meio mas o feijão evita a presença do capim-marmelada. O feijão como espécie competidora é superior ao capim-marmelada.

\section{Summary}

The quantification of competitive interactions between weeds and crops is essential to support the recommendations of the weed management strategies in agriculture. However, the methodologies of quantification were not thoroughly elucidated and compared in the 
literature. Therefore, the goals of this study were to assess the competitive ability of bean (Phaseolus vulgaris L.) and alexandergrass [Brachiaria plantaginea (Link) Hitchc.], and to compare two approaches to analysis of replacement series experiment. Two experiments were carried out in a glasshouse from December 1999 to February 2000, at University of São Paulo (USP), Escola Superior de Agricultura "Luiz de Queiroz" (ESALQ), Department of Crop Production, in Piracicaba, São Paulo State, Brazil. In the first experiment, the response of each species to its own density was assessed. The density at which the biomass production becomes independent of density was determined. Four replicates of densities (37 to 2381 plants. $\mathrm{m}^{-2}$ ) were conducted at a randomized block design. In the second experiment the response of each species to the presence of each other at different densities and proportion between them was assessed. Replacement series at total densities of 625,816 and 1111 plants. $\mathrm{m}^{-2}$ were performed at the proportions of bean : alexandergrass 100:0 (pure stand of bean), 75:25, $50: 50,25: 75$ and 0:100\% (pure stand of alexandergrass), at four replicates in a randomized block design. Data analyzes were performed with the qualitative approach compared to a quantitative approach. General information resulted from these two approaches was similar. However, the doubtful interpretation from data by using the qualitative approach was clarified by quantitative interpretation. Besides, by using the quantitative approach to quantify and separate the competition effect into intra- and interespecific components were possible. The competition as measured by effects on bean biomass, one bean plant is, to another plant of the same species, competitively equivalent to 21,3 alexandergrass plants and, as measured by effects on alexandergrass biomass, one alexandergrass plant is, to another plant of the same species, equivalent to 0,68 plant of bean. There is partial niche 
differentiation. So, the species compete for the same resources however, bean plants avoid the alexandergrass presence. Bean, as a competitor species is superior to alexandergrass.

\subsection{Introdução}

Para avaliar a resposta das espécies vegetais às interações competitivas, é importante que no momento da coleta dos dados as plantas estejam utilizando, para o seu crescimento, todos os recursos disponiveis no meio. Portanto, quando experimentos com tratamentos em delineamento substitutivo são conduzidos, assume-se que a densidade total das plantas em convivência é tal que os fatores de crescimento estão sendo plenamente utilizados. Nessa situação, a produção de biomassa é constante, mesmo que haja incremento no número de plantas por unidade de área (Wit ${ }^{7}$, citado por Roush et al., 1989). Esse fenômeno é chamado de "lei da produção final constante".

Quando os resultados de um experimento substitutivo são utilizados para estudar a interação competitiva entre duas espécies vegetais, assume-se que as plantas das duas espécie capturam todos os recursos do ambiente e que, sendo assim, a produção de cada espécie pode ser comparada à sua produção em estande puro, quando as espécies em estande puro encontram-se em densidade mínima de produção final constante. Nestas condições, é possivel executar a análise convencional dos resultados de tratamentos em delineamento substitutivo, comparando a produção das espécies em mistura com a produção das mesmas em estande puro (Rejmánek et al., 1989; Harper, 1977).

7 Versl. Landbouwk. D. Onderz., v. 66, n. 8, p.1-82, 1960. 
Uma outra forma de análise de resultados obtidos com experimentos substitutivos é a regressão do recíproco da produção por planta, que proporciona coeficientes que expressam a competitividade relativa como determinantes do desempenho da planta na mistura, independentemente das densidades totais das plantas. Esses coeficientes podem assumir unidades biológicas simples como número de plantas e, assumindo que a relação é de fato linear, estarão livres de termos de confundimento de interação (Spitters, 1983; Joliffe et al., 1984).

A comparação entre a análise convencional e a técnica de regressão do recíproco da produção por planta fornece informações importantes na análise da competitividade entre cultura e planta daninha que servem para fundamentar as recomendações de manejo de plantas daninhas. Sendo a planta daninha capim-marmelada, importante infestante na cultura do feijão, foi desenvolvida a presente pesquisa, utilizando delineamento de tratamentos em séries substitutivas, em três densidades totais, com os objetivos de avaliar a competitividade da cultura de feijão em relação à planta daninha capimmarmelada e comparar o método qualitativo de análise dos resultados com o método quantitativo proposto por Spitters (1983).

\subsection{Material e Métodos}

Os experimentos foram conduzidos na Universidade de São Paulo (USP), Escola Superior de Agricultura "Luiz de Queiroz" (ESALQ), Departamento de Produção Vegetal, no município de Piracicaba - SP, latitude $22^{\circ} 42^{\prime} 30^{\prime \prime}$ sul, longitude $47^{\circ} 38^{\prime} 00^{\prime \prime}$ oeste, altitude de $560 \mathrm{~m} \mathrm{e}$ clima, segundo a classificação de Köppen, do tipo $\mathrm{CW}_{\mathrm{a}}$, isto é, mesotérmico, úmido, subtropical com inverno seco. De acordo com o Departamento de Ciências Exatas da USP/ESALQ, a temperatura média 
do mês mais quente está acima de $24^{\circ} \mathrm{C}$ e a do mês mais frio, abaixo de $17^{0} \mathrm{C}$, com precipitação pluvial média de $1200 \mathrm{~mm}$ ao ano.

Em casa de vegetação, foram conduzidos dois experimentos. No primeiro utilizou-se metodologia para determinar a densidade de plantas $\left(N\right.$ - plantas. $\left.\mathrm{m}^{-2}\right)$ a partir da qual a produção de massa da parte aérea por unidade de área $\left(Y-\mathrm{g}^{-2} \mathrm{~m}^{-2}\right)$ torna-se independente da densidade, de acordo com a "lei da produção final constante". A partir do resultado desse experimento instalou-se o segundo, com tratamentos em séries substitutivas para determinar a competitividade das duas espécies.

A metodologia geral utilizada é descrita a seguir e as variações metodológicas específicas de cada experimento são descritas nos tópicos que tratam de cada experimento.

A temperatura da casa de vegetação foi regulada para o máximo de $25^{\circ} \mathrm{C}$ e a irrigação realizada por aspersão, a cada duas horas, das sete as $17 \mathrm{~h}$, aplicando-se o total de $10 \mathrm{~mm}$ de água ao dia. Em dias nublados ou com chuva, a irrigação foi realizada das nove as $15 \mathrm{~h}$. A luminosidade foi controlada com uma cobertura de sombrite que era distendida de acordo com um sensor de luminosidade instalado no interior da casa de vegetação.

As sementes de feijão (Phaseolus vulgaris L.) e de capimmarmelada [Brachiaria plantaginea (Link) Hitchc.] foram adquiridas comercialmente. A variedade de feijão utilizada foi a Carioca, com sementes de peneira $11 / 14$, tratada com carboxin+thiran, apresentando germinação de $80-89 \%$ e pureza de $98-99,9 \%$. A semente de capimmarmelada era de lote que apresentava início de germinação no sexto 
dia após a semeadura e taxa de emergência de 25 plântulas para cada $0,58 \mathrm{~g}$ de semente.

Os vasos utilizados apresentavam $18,5 \mathrm{~cm}$ de diâmetro superior, $14,0 \mathrm{~cm}$ de diâmetro inferior e $15,0 \mathrm{~cm}$ de altura. Estes foram preenchidos com substrato (Quadro 1) constituído por material de solo, areia, esterco curtido e palha de arroz queimada, na proporção de, respectivamente, $3: 1: 1: 0,5$, tratado com brometo de metila para eliminar o banco de sementes.

\begin{tabular}{|c|c|c|c|c|c|c|c|c|c|c|}
\hline \multicolumn{11}{|c|}{ Análise química } \\
\hline $\mathrm{pH}$ & M.O. & $\mathrm{P}$ & $\mathrm{S}-\mathrm{SO}_{4}$ & $\mathrm{Al}$ & $\mathrm{Ca}$ & $\mathrm{Mg}$ & K & SB & $\mathrm{T}$ & \multirow{2}{*}{$\mathrm{V} \%$} \\
\hline $\mathrm{CaCl}_{2}$ & g.dm-3 & \multicolumn{2}{|c|}{$\mathrm{mg} \cdot \mathrm{dm}^{-3}$} & \multicolumn{6}{|c|}{ mmolc. $\mathrm{dm}^{-3}$} & \\
\hline 6,4 & 34 & 497 & 156 & 0 & 81 & 36 & 15,3 & 132,3 & 147,3 & 90 \\
\hline \multicolumn{11}{|c|}{ Análise física } \\
\hline \multicolumn{2}{|c|}{$\%$ Areia } & \multicolumn{3}{|c|}{$\%$ Silte } & \multicolumn{3}{|c|}{$\%$ Argila } & \multicolumn{3}{|c|}{ Classe de Textura } \\
\hline \multicolumn{2}{|c|}{72} & \multicolumn{3}{|c|}{6} & \multicolumn{3}{|c|}{22} & \multicolumn{3}{|c|}{ Média arenosa } \\
\hline
\end{tabular}

$\mathrm{SB}=$ soma de bases, $\mathrm{T}$ = capacidade de troca de cátions, $\mathrm{V} \%=(\mathrm{SB} / \mathrm{T}) .100$ Análises realizadas pelo Laboratório de Análise de Solo do Departamento de Solos e Nutrição de Plantas - USP/ESALQ.

Quadro1. Análise química e física do substrato.

Foram feitos dois desbastes, o primeiro para estabelecer densidades de plantas em valores próximo ao desejado, com o feijão no estádio de folhas cotiledonares e o capim-marmelada no de primeira folha verdadeira e, o segundo, dois dias após o primeiro, estabelecendo as densidades desejadas. 
Na colheita, o número de plantas de cada espécie, em cada vaso, foi anotado, as plantas foram cortadas rente à superfície do solo e a parte aérea colocada para secar em estufa com circulação forçada de ar, à $75^{\circ} \mathrm{C}$. Dois dias após, foi retirada para pesagem. O material da parte aérea seco em estufa será, daqui em diante, referido no texto como massa seca.

\subsubsection{Densidade na qual as espécies atingem a produção final constante}

Os tratamentos foram as densidades de plantas, em quatro repetições e o delineamento experimental foi o de blocos ao acaso. As densidades da cultura foram de $1,2,4,8,16,24,32$ e 64 plantas por vaso $^{8}$ e, as de capim-marmelada, de $1,2,4,8,16,32$ e 64 plantas por vaso.

Os vasos foram preenchidos com o substrato até $15 \mathrm{~cm}$ abaixo da borda superior. Enquanto as sementes de feijão foram distribuídas na superficie do substrato e cobertas com uma porção do mesmo, completando-se o volume do vaso, as da planta daninha foram misturadas à quantidade de substrato necessária para completar o volume de cada vaso. Para que as sementes da planta daninha fossem distribuídas nesse volume de substrato, a mistura foi colocada em sacos plásticos para agitação manual.

Para estabelecer a densidade desejada em cada tratamento, a semeadura (14/12/1999) foi realizada com uma quantidade de sementes acima do necessário e, posteriormente, o excesso de plântulas foi eliminado em dois desbastes (20 e 22/12/1999).

8 Os valores correspondem a 37, 74, 149, 297, 595, 892, 1190 e 2381 plantas.m-2 
A colheita da parte aérea e a contagem do estande final do feijoeiro foram feitas no dia 03/01/2000 e do capim-marmelada, no dia 04/01/2000. O feijoeiro estava no estádio V3 (Dourado Neto \& Fancelli, 1997) e o capim-marmelada, no estádio 14 (Zadoks et al., 1974).

Para determinar a densidade total mínima a ser utilizada no experimento com tratamentos em séries substitutivas, os dados foram analisados pelo método do recíproco da produção por planta (Spitters, 1983). Os dados de massa seca produzida por unidade de área $\left(Y-\mathrm{g} . \mathrm{m}^{-2}\right)$ e densidade $\left(N\right.$ - plantas. $\left.\mathrm{m}^{-2}\right)$ foram utilizados para calcular o recíproco da massa seca produzida por planta $(1 / w=N / Y)$. Utilizando $1 / w$ como variável dependente e $N$ como variável independente, fez-se uma análise de regressão linear. Os coeficientes obtidos foram utilizados para escrever a equação do recíproco da produção de massa seca por planta na forma da eq. (15) e da produção de massa seca, na forma da eq. (16):

$$
\begin{aligned}
& \frac{1}{w}=b o+b 1 \times N \\
& Y=\frac{N}{b o+b 1 \times N}
\end{aligned}
$$

$b_{0}$ representa o recíproco da massa virtual produzida por uma planta isolada; $b_{1}$ representa a taxa de aumento em $1 / w$ ou de decréscimo em $w$ devido a adição de cada planta à população e também é o recíproco da massa máxima produzida por unidade de área $\left(b_{1}=1 / Y_{\text {máx }}\right)$ quando a densidade $(N)$ tende ao infinito e $b_{1} / b_{0}$ expressa o aumento de $1 / w \mathrm{em}$ relação ao seu valor na ausência de competição e portanto mede o estresse da competição intraespecífica (Spitters, 1983). 
Uma vez ajustados os dados à equação da hipérbole (eq. 16), determinou-se, para cada espécie, o valor de densidade acima da qual haveria indícios de que a massa seca $(Y)$ seria semelhante à $Y_{\text {máx. }}$. (Anexos A e B - procedimento SAS para, respectivamente, dados de feijão e capim-marmelada). Foram calculadas, para cada densidade, a diferença entre os valores de $Y$ observados e o valor de $Y_{\text {máx. }}$ Considerouse como hipótese de nulidade $\left(H_{0}\right)$ que a média da diferença era igual a zero. Para testar $H_{0}$, verificou-se primeiro se os valores das diferenças apresentavam distribuição normal (Teste W). Apresentando distribuição normal, $(\operatorname{Pr}<\mathrm{W})>0,05$, a comparação foi feita com o teste-t, aceitando-se $H_{O}$ quando $(\operatorname{Pr}>|\mathrm{T}|)>0,05$.

\subsubsection{Determinação da competitividade da cultura de feijão com a planta daninha capim-marmelada}

Adotou-se delineamento de tratamentos em séries substitutivas com quatro repetições e delineamento experimental em blocos ao acaso. As densidades totais de cada série substitutiva foram de 625, 816 e 1111 plantas.m-2. Em cada série, as proporções entre plantas de feijão e plantas de capim-marmelada foram de 100:0 (estande puro de feijão), $75: 25$, 50:50, 25:75 e 0:100\% (estante puro de capimmarmelada). A proporção entre as densidades das duas espécies são representadas no diagrama de delineamento de tratamentos (Figura 6) de forma semelhante a Suehiro \& Ogawa (1980) e Cousens (1991). Para representar as densidades desejadas em vasos, manteve-se o número total de 16 plantas/vaso nos espaçamento de 4,0 x 4,0 cm $(625$ plantas. $\left.\mathrm{m}^{-2}\right), 3,5 \times 3,5 \mathrm{~m}\left(816\right.$ plantas. $\left.\mathrm{m}^{-2}\right)$ e 3,0 x 3,0 m (1111 plantas. $\mathrm{m}^{-2}$ ) (Anexo C). Esses espaçamentos foram obtidos com o auxílio de gabaritos de madeira com furos para a colocação das sementes, 
facilitando a distribuição das plantas das espécies nas proporções desejadas e em pontos equidistantes (Figura 7).

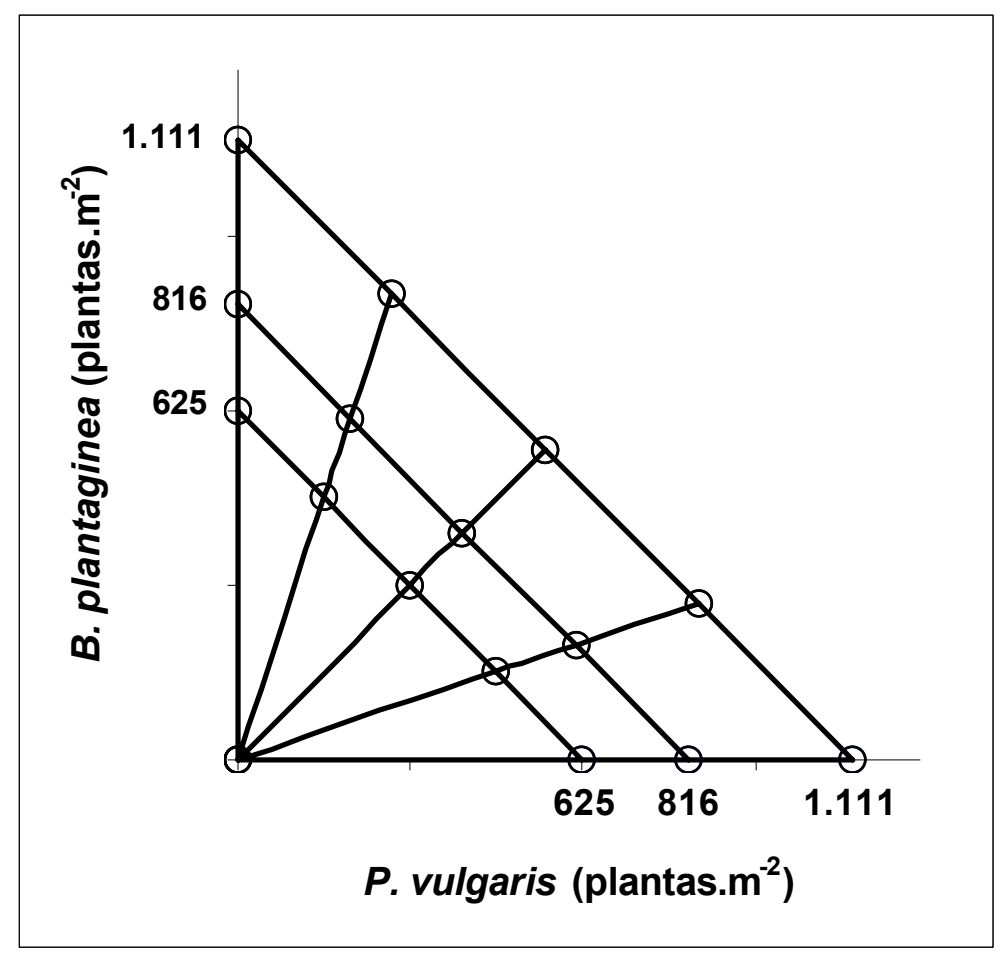

Figura 6 - Diagrama do delineamento de tratamentos indicando a proporção entre as densidades das duas espécies. Os círculos indicam os tratamentos utilizados, incluindo os estantes puros, nos eixos.

$\mathrm{Na}$ semeadura $(31 / 01 / 2000)$, foram colocadas duas sementes de feijão e uma quantidade aleatória de sementes de capimmarmelada, em cada ponto pré determinado (Figura 7). Foram realizados dois desbastes (05 e 07/02/2000) para estabelecer as densidades desejadas em cada tratamento. A contagem do número de plantas e a colheita da parte aérea das plantas das duas espécies foram feitas separadamente, no dia 21/02/2000, para determinar a massa 
seca. O feijoeiro estava no estádio V3 (Dourado Neto \& Fancelli, 1997) e, o capim-marmelada, no estádio 14 (Zadoks et al., 1974).

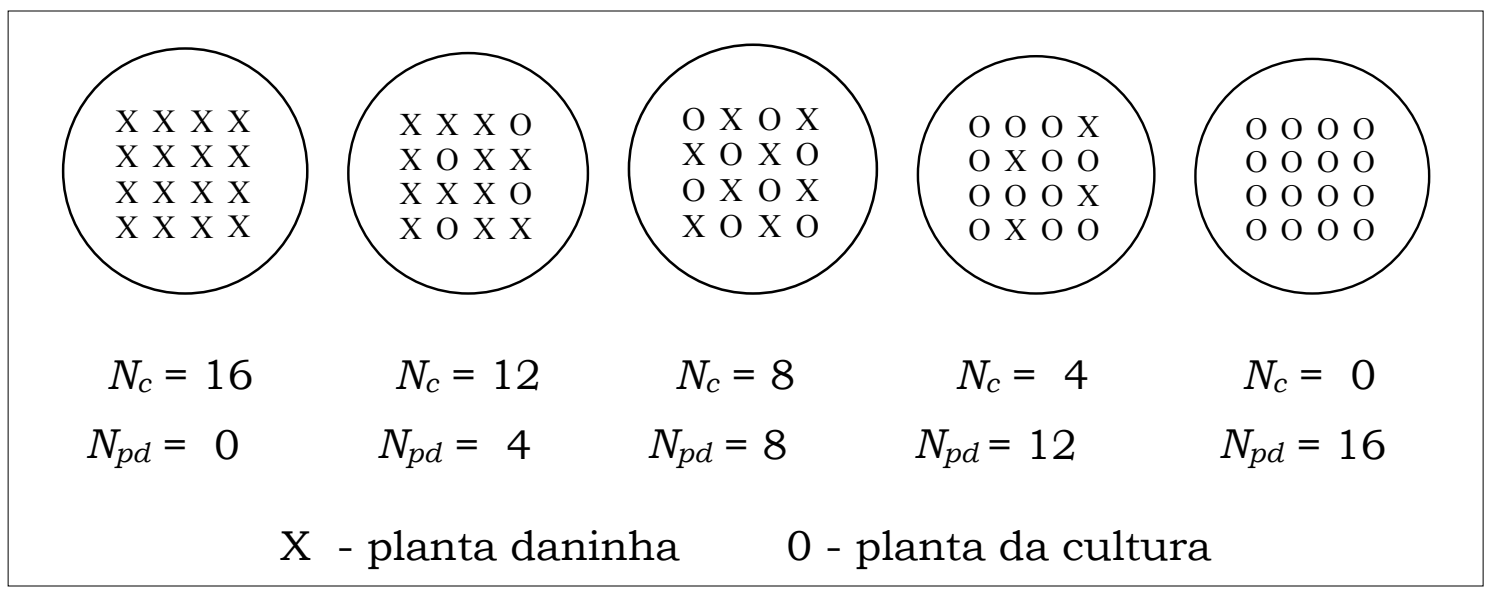

Figura 7 - Distribuição das plantas nos vasos para a densidade total de 625 plantas.m-2 ${ }^{2}$ (16 plantas/vaso ao espaçamento de 0,040 x 0,040 m). Para as densidades de 816 e 1111 plantas.m-2 ${ }^{2}$, manteve-se o mesmo esquema e reduziu-se o espaçamento para $0,035 \times 0,035$ e $0,030 \times 0,030 \mathrm{~m}$. $N$ é o número de plantas e os subscritos $c$ e $p d$ são, respectivamente, cultura e planta daninha.

Os resultados foram analisados de forma qualitativa, ou convencional (Harper, 1977), e por um método quantitativo (Spitters, 1983).

\subsubsection{Análise qualitativa da competitividade das espécies}

A análise qualitativa ou convencional dos dados foi feita pela interpretação visual da produção relativa obtida em função das proporções entre as densidades das espécies, para cada série substitutiva e para a média das três séries. Em cada proporção, a 
produção relativa $(Y r)$ de uma espécie foi calculada pela razão entre a quantidade de massa seca produzida por essa espécie $(Y x)$ e a quantidade de massa seca produzida pela mesma espécie no tratamento com 100\% de plantas da mesma espécie (Y) (Roush et al., 1989):

$$
Y r=\frac{Y x}{Y}
$$

As análises de regressão linear e quadrática foram feitas utilizando a média das quatro repetições da produção relativa como variável dependente e a proporção das densidades como variável independente (Anexo D - procedimento SAS). Para verificar se houve indícios de que a produção relativa observada era semelhante ao valor da competitividade equivalente ${ }^{9}$, foram calculadas, para cada proporção, a média da diferença entre os valores de produção relativa observados e o valor de competitividade equivalente. Considerou-se como hipótese de nulidade $\left(H_{0}\right)$ que a média da diferença era igual a zero. Para testar $H_{0}$, verificou-se primeiro se os valores das diferenças apresentavam distribuição normal (Teste $\mathrm{W})$. Apresentando distribuição normal $[(\operatorname{Pr}<\mathrm{W})>0,05]$, a comparação foi feita com o teste-t, aceitando-se $H_{O}$ quando $\operatorname{Pr}>|\mathrm{T}|$ ) $>0,05$ (Anexos $\mathrm{E}, \mathrm{F}$ e G, respectivamente para as séries substitutivas nas densidades totais de 625, 816 e 1111 plantas.m² e Anexo $\mathrm{H}$ para a média das três séries substitutivas).

\subsubsection{Análise quantitativa da competitividade das espécies}

Com os dados de massa seca produzida pela cultura $\left(Y_{\mathrm{c}}\right)$ e planta daninha $\left(Y_{p d}\right)$, e a densidade de plantas $\left(N_{\mathrm{c}}\right.$ e $\left.N_{p d}\right)$, calculou-se a

9 Para cada espécie, o valor da produção relativa (eixo Y) da linha de competitividade equivalente correspondente às proporções $0,25,50,75$ e 100\% (eixo X) era de, respectivamente, $0 ; 0,25 ; 0,50 ; 0,75$ e 1,00 . 
massa produzida por planta da cultura $\left(w_{\mathrm{c}}=Y_{\mathrm{c}} / N_{\mathrm{c}}\right)$ e da planta daninha $\left(w_{p d}=Y_{\mathrm{pd}} / N_{\mathrm{pd}}\right)$. Os dados do recíproco da produção por planta $\left(1 / w_{\mathrm{c}} \mathrm{e}\right.$ $\left.1 / w_{p d}\right)$ foram submetidos à análise de regressão linear múltipla, tendo $N_{c}$ e $N_{p d}$ como variáveis dependentes e, conforme Rejmánek et al. (1989), eliminando os três tratamentos em que a espécie que representava a variável dependente estava ausente (Anexos I e J - procedimento SAS para, respectivamente, dados de feijão e capim-marmelada). Os coeficientes obtidos foram utilizados para escrever o par de equações na forma proposta por Spitters (1983):

$$
\begin{gathered}
\frac{1}{w c, p d}=b c, o+b c, c \times N_{c}+b c, p d \times N_{p d} \\
\frac{1}{w p d, c}=b p d, o+b p d, p d \times N_{p d}+b p d, c \times N_{c}
\end{gathered}
$$

em que, o primeiro subscrito de cada termo refere-se à espécie cuja massa está sendo avaliada e o segundo subscrito identifica a espécie associada.

Os coeficientes de competição intraespecífica $\left(b_{c, c}\right.$ e $\left.b_{p d, p d}\right)$ e interespecífica $\left(b_{c, p d}\right.$ e $\left.b_{p d, c}\right)$ foram utilizados para calcular a competitividade relativa $(C R)$ do feijão e da planta daninha bem como o índice de diferenciação de nicho ecológico (IDN), conforme Spitters, (1983): 


$$
\begin{aligned}
& C R c=\frac{b c, c}{b c, p d} \\
& C R p d=\frac{b p d, p d}{b p d, c} \\
& I D N=C R_{c} \times C R p d
\end{aligned}
$$

\subsection{Resultados e Discussão}

\subsubsection{Densidade na qual as espécies atingem a produção final constante}

Os coeficientes obtidos através da regressão linear dos dados, tendo o recíproco da massa seca produzida por planta $(1 / w)$ como variável dependente e a densidade de plantas $(N)$ como variável independente (Quadro 2) foram utilizados para escrever as equações das retas na forma da eq. (15) (Figura 8.A - feijão e Figura 9.A - capimmarmelada). O valor da interseção da reta corresponde ao valor de $b_{o}$ e o da variável, ao de $b_{1}$ (Quadro 2).

Considerando o significado biológico dos coeficientes (Spitters, 1983), a produção teórica máxima da massa seca ( $Y_{\text {máx }}$ ) da parte aérea do feijão foi de 958,7728 g.m ${ }^{-2}\left(1 / b_{1}=1 / 0,001043=958,7728\right)$ (Figura 8.B) e do capim-marmelada, de 117,1641 g.m $\mathrm{m}^{-2}\left(1 / b_{1}=\right.$ $1 / 0,008535=117,1641$ ) (Figura 9.B). A cada acréscimo de uma planta 
de feijão à população, o recíproco da massa seca por planta $(1 / w)$ aumentou, ou a massa seca por planta $(w)$ foi reduzida, em 0,001043 g $\left(b_{1}\right)$. De forma análoga, a cada acréscimo de uma planta de capimmarmelada à população, o recíproco da produção por planta $(1 / w)$ aumentou, ou a produção por planta $(w)$ foi reduzida, em 0,008535 g.

\begin{tabular}{|c|c|c|c|c|}
\hline $\begin{array}{l}\text { Fonte de } \\
\text { variação }\end{array}$ & GL & QM & \multicolumn{2}{|c|}{$\mathrm{Pr}>\mathrm{Fa}$} \\
\hline \multicolumn{5}{|c|}{ Phaseolus vulgaris } \\
\hline Regressão & 1 & 19,18314 & \multicolumn{2}{|c|}{$1,52 \cdot 10^{-12}$} \\
\hline Resíduo & 30 & 0,144446 & \multicolumn{2}{|c|}{-} \\
\hline & Coeficiente $^{a}$ & Erro padrão & $\mathrm{t}^{\mathrm{b}}$ & $\mathrm{P}^{\mathrm{c}}$ \\
\hline Interseção & 1,466960 & 0,09247 & 15,86398 & $3,92 \cdot 10^{-16}$ \\
\hline Variável X & 0,001043 & $9,0.10^{-5}$ & 11,52409 & $1,52 \cdot 10^{-12}$ \\
\hline \multicolumn{5}{|c|}{ Brachiaria plantaginea } \\
\hline Regressão & 1 & 1273,115 & \multicolumn{2}{|c|}{$3,3 \cdot 10^{-20}$} \\
\hline Resíduo & 26 & 1,858565 & \multicolumn{2}{|c|}{-} \\
\hline \multirow{3}{*}{$\begin{array}{l}\text { Interseção } \\
\text { Variável X }\end{array}$} & Coeficiente & Erro padrão & $\mathrm{t}$ & $\mathrm{P}$ \\
\hline & 3,049351 & 0,338859 & 8,99889 & $1,82.10^{-9}$ \\
\hline & 0,008535 & 0,000326 & 26,17248 & $3,3 \cdot 10^{-20}$ \\
\hline
\end{tabular}

a. Probabilidade do valor de F ser significativo

b. Os valores de coeficiente para interseção e variável X correspondem, respectivamente aos valores de $b_{0}$ e $b_{1}$ da eq. (15).

c. Teste t para verificar se o coeficiente é igual a zero.

d. Probabilidade do coeficiente ser igual a zero.

Quadro 2 - Resumo da análise de regressão linear do recíproco da massa seca produzida por planta $\left(1 / w=\right.$ planta. $\left.\mathrm{g}^{-1}\right) \mathrm{em}$ função da densidade de plantas $\left(N=\right.$ plantas. $\left.\mathrm{m}^{-2}\right)$. 

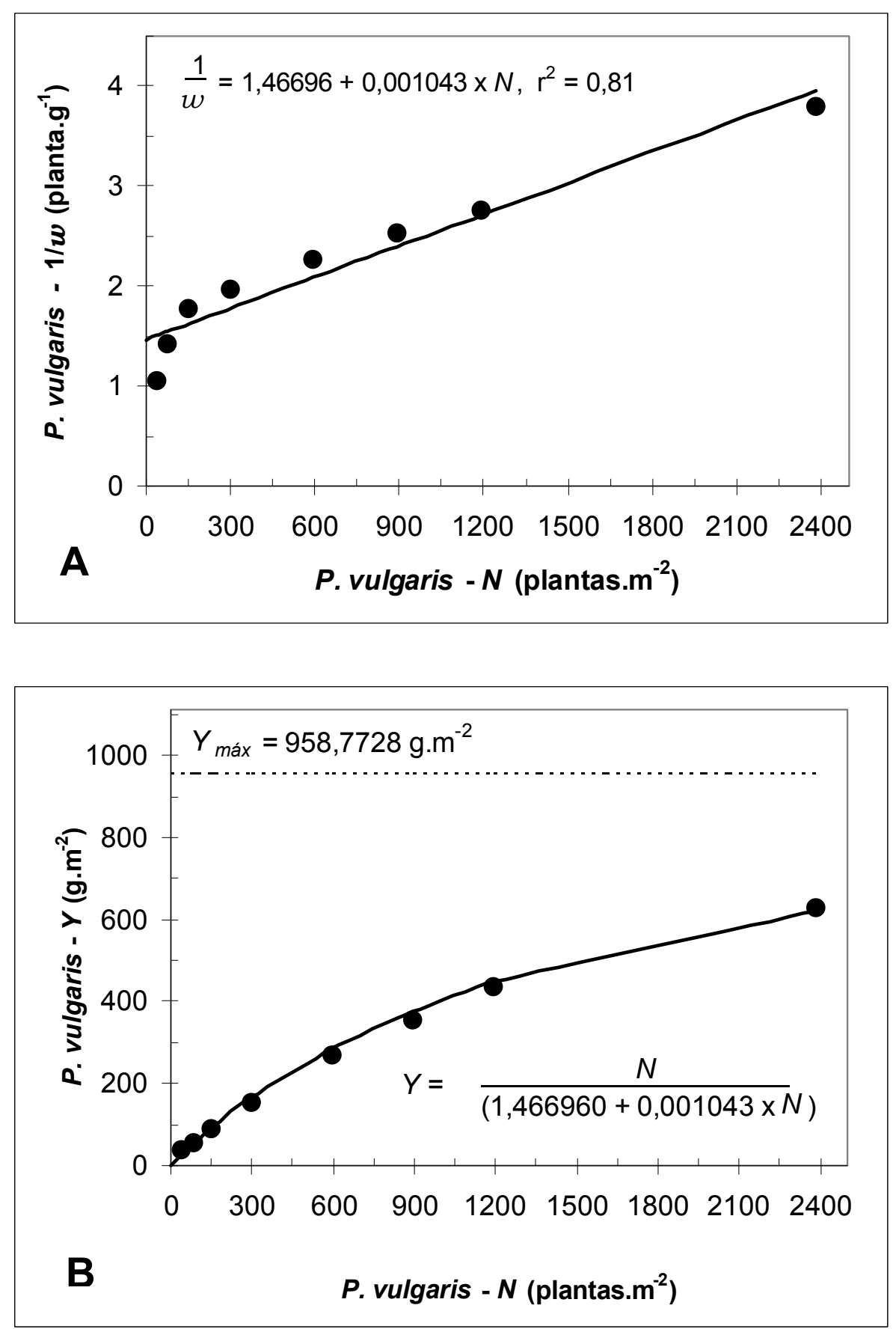

Figura 8 - (A) - Efeito da densidade de plantas de $P$. vulgaris $(N)$ sobre o recíproco da massa seca produzida por planta $(1 / w)$. (B) Efeito da densidade de plantas de $P$. vulgaris $(M)$ sobre a produção de massa seca por unidade de área (Y). 

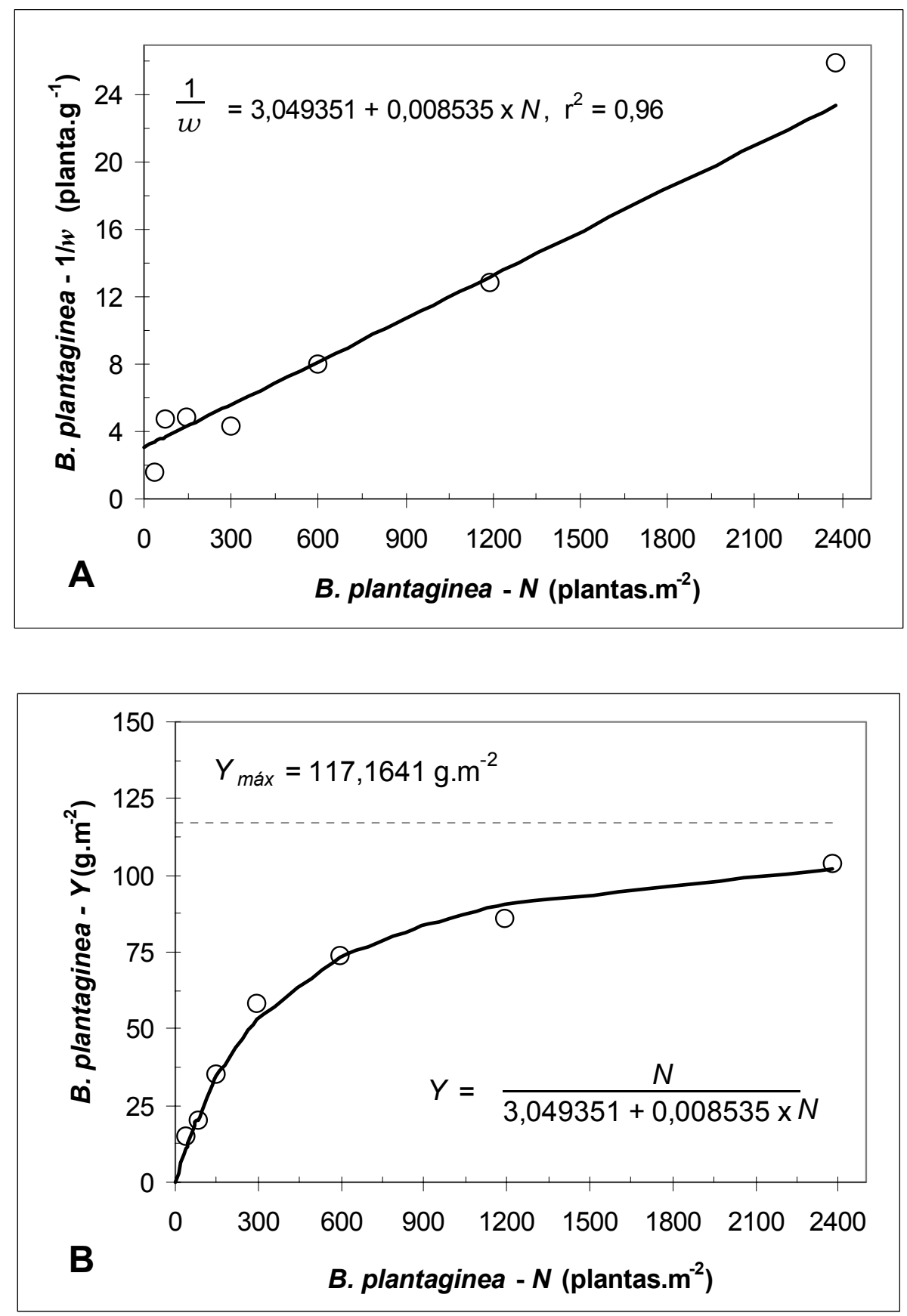

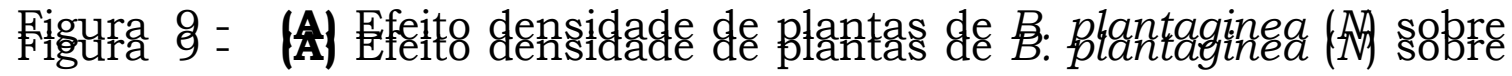
8 recíproco de massa seca produzida por planta ( 1 / wh): (B)

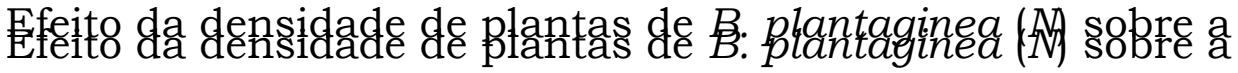

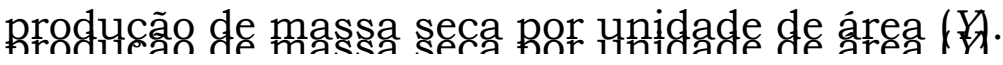


A redução na produção de massa seca por planta a cada acréscimo de uma planta na população foi menor para o feijão, indicando que essa espécie, em comparação ao capim-marmelada, apresentou menor competição intraespecífica. Esse fato foi confirmado pelos índices de competição intraespecífica de cada espécie, calculado pela proporção $b_{1} / b_{0}$. Tal proporção, segundo Spitters (1983), expressa o aumento em $1 / w$ em relação ao seu valor na ausência de competição e pode ser utilizada como medida de estresse da competição intraespecífica. Essa relação foi de $0,000711(0,001043 / 1,466960)$ para feijão e de 0,002798 $(0,008535 / 3,049351)$ para capim-marmelada. Sendo assim, era de se esperar que com o aumento na densidade $(N)$, a produção de massa seca por unidade de área $(Y)$ do feijão aproximar-se-ia de $Y_{\text {máx }}$ em densidade maior do que a de capim-marmelada. Para a cultura, o valor dessa densidade estaria acima de 2381 plantas. $\mathrm{m}^{-2}$, a maior densidade estudada (Figura 8.B) pois, até essa densidade, a média da diferença entre a massa seca produzida ( $Y$ ) e $Y_{\text {máx }}$ foi diferente de zero (Tabela 1), indicando ou que a cultura continuaria a apresentar aumento na produção de massa seca devido ao aumento no número de plantas por unidade de área ou que a colheita da parte aérea das plantas foi feita antes de haver total competição entre as plantas. Em trabalhos anteriormente realizados não houve menção de tal fato (Roush et al., 1989 e Christoffoleti \& Victoria Filho, 1996), contudo, enquanto a colheita da parte aérea de feijão e capimmarmelada foi realizada três semanas após a semeadura, Roush et al. (1989) colheram a parte aérea de trigo (Triticum aestivum L.) e azevém (Lolium multiflorum Lam.) após sete semanas de crescimento.

O valor da densidade acima do qual a planta daninha apresentaria produção semelhante à $Y_{\text {máx }}$ ocorreu a partir de 2381 plantas. $\mathrm{m}^{-2}$ pois a média da diferença entre a massa seca produzida $(Y)$ e a teórica máxima ( $\left.Y_{\operatorname{má}}\right)$ foi estatisticamente igual a zero (Tabela 2), indicando 
Tabela 1. Dados estatísticos de cada tratamento para a cultura de feijão, obtidos a partir da massa seca da parte aérea $\left(\mathrm{g} \cdot \mathrm{m}^{-2}\right), 21$ dias depois da semeadura. e A produção de massa seca teórica máxima ( $Y_{m a ́ x}$ ), calculada pela equação do recíproco da produção por planta, foi de 958,7728 g.m².

\begin{tabular}{|c|c|c|c|c|c|c|c|c|}
\hline \multirow{2}{*}{ Dados } & \multicolumn{8}{|c|}{ Densidade de feijão (plantas.m-2) } \\
\hline & 37 & 74 & 148 & 297 & 595 & 892 & 1190 & 2381 \\
\hline No. de observações & 4 & 4 & 4 & 4 & 4 & 4 & 4 & 4 \\
\hline Média (g.m-2) & 36,99 & 54,32 & 89,47 & 153,37 & 267,86 & 356,58 & 437,67 & 688,62 \\
\hline $\begin{array}{l}\text { Média da diferença em } \\
\text { relação a } Y_{\text {máx }}\left(\mathrm{g} \cdot \mathrm{m}^{-2}\right)\end{array}$ & $-921,77$ & $-904,46$ & $-869,30$ & $-805,41$ & $-690,92$ & $-602,19$ & $-521,09$ & $-332,19$ \\
\hline $\begin{array}{l}\text { Desvio padrão da } \\
\text { diferença em relação a } \\
Y_{\operatorname{máx}}\left(\mathrm{g} \cdot \mathrm{m}^{-2}\right)\end{array}$ & 9,16 & 11,51 & 26,13 & 21,06 & 48,17 & 44,30 & 56,08 & 26,69 \\
\hline $\mathrm{CV} \%$ & $-0,99$ & $-1,27$ & $-3,01$ & $-2,61$ & $-6,97$ & $-7,36$ & $-10,76$ & $-8,04$ \\
\hline $\begin{array}{l}\text { Teste W (Shapiro- } \\
\text { Wilks) }^{\mathrm{f}} \\
(\mathrm{Pr}<\mathrm{W})\end{array}$ & $\begin{array}{c}0,98 \\
(0,9311)\end{array}$ & $\begin{array}{c}0,82 \\
(0,1317)\end{array}$ & $\begin{array}{c}0,97 \\
(0,8253)\end{array}$ & $\begin{array}{c}0,90 \\
(0,4038)\end{array}$ & $\begin{array}{c}0,87 \\
(0,2941)\end{array}$ & $\begin{array}{c}0,8801 \\
(0,3345)\end{array}$ & $\begin{array}{c}0,90 \\
(0,4101)\end{array}$ & $\begin{array}{c}0,94 \\
(0,6373)\end{array}$ \\
\hline $\begin{array}{l}\text { Teste } \mathrm{tg} \\
(\operatorname{Pr}>|\mathrm{T}|)\end{array}$ & $\begin{array}{l}-202,17 \\
(0,0001)\end{array}$ & $\begin{array}{l}-157,20 \\
(0,0001)\end{array}$ & $\begin{array}{l}-66,53 \\
(0,0001)\end{array}$ & $\begin{array}{l}-76,48 \\
(0,0001)\end{array}$ & $\begin{array}{c}-28,68 \\
(0,0001)\end{array}$ & $\begin{array}{c}-27,18 \\
(0,0001)\end{array}$ & $\begin{array}{c}-18,58 \\
(0,0003)\end{array}$ & $\begin{array}{c}-24,89 \\
(0,0001)\end{array}$ \\
\hline
\end{tabular}

e. O feijão estava no estádio V3 (Dourado Neto \& Fancelli, 1997).

f. A distribuição dos dados da média da diferença em relação a $Y_{\text {máx }}$ foi normal quando $(\operatorname{Pr}<\mathrm{W})>0,05$.

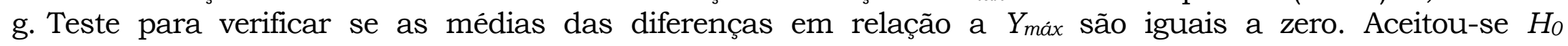
quando( $\operatorname{Pr}>\mid \mathrm{T})>0,05)$. 
Tabela 2. Dados estatísticos de cada tratamento para o capim-marmelada, obtidos a partir da massa seca da parte aérea $\left(\mathrm{g} \cdot \mathrm{m}^{-2}\right), 22$ dias depois da semeadura. ${ }^{\mathrm{h}}$ A produção de massa seca teórica máxima ( $Y_{\text {máx }}$, calculada pela equação do recíproco da produção por planta, foi de 117,1641 g.m².

\begin{tabular}{|c|c|c|c|c|c|c|c|}
\hline \multirow{2}{*}{ Dados } & \multicolumn{7}{|c|}{ Densidade de capim-marmelada ( $\mathrm{n}^{\mathrm{o}}$ de plantas. $\mathrm{m}^{-2}$ ) } \\
\hline & 37 & 74 & 148 & 297 & 595 & 1190 & 2381 \\
\hline No. de observações & 4 & 4 & 4 & 4 & 4 & 4 & 4 \\
\hline Média (g. m²) & 14,79 & 20,46 & 35,34 & 58,23 & 74,03 & 85,94 & 104,07 \\
\hline $\begin{array}{l}\text { Média da diferença em } \\
\text { relação a } Y_{\text {máx }}\left(\mathrm{g} \cdot \mathrm{m}^{-2}\right)\end{array}$ & $-102,38$ & $-96,70$ & $-81,82$ & $-58,94$ & $-43,13$ & $-31,23$ & $-13,09$ \\
\hline $\begin{array}{l}\text { Desvio padrão da } \\
\text { diferença em relação a } \\
Y_{\text {máx }}\left(\mathrm{g} \cdot \mathrm{m}^{-2}\right)\end{array}$ & 6,12 & 6,35 & 4,22 & 18,29 & 4,77 & 6,620 & 9,59 \\
\hline $\mathrm{CV} \%$ & $-5,98$ & $-6,57$ & $-5,16$ & $-31,03$ & $-11,07$ & $-21,20$ & $-73,28$ \\
\hline $\begin{array}{l}\text { Teste W (Shapiro- } \\
\text { Wilks) }{ }^{f} \\
(\operatorname{Pr}<W)\end{array}$ & $\begin{array}{c}0,93 \\
(0,5543)\end{array}$ & $\begin{array}{c}0,88 \\
0,3407)\end{array}$ & $\begin{array}{c}0,97 \\
(0,8372)\end{array}$ & $\begin{array}{c}0,87 \\
(0,2795)\end{array}$ & $\begin{array}{c}0,96 \\
(0,7622)\end{array}$ & $\begin{array}{c}0,96 \\
(0,7480)\end{array}$ & $\begin{array}{c}0,99 \\
(0,9423)\end{array}$ \\
\hline $\begin{array}{l}\text { Teste } \mathrm{t} g \\
(\operatorname{Pr}>|\mathrm{T}|)\end{array}$ & $\begin{array}{c}-33,44 \\
(0,0001)\end{array}$ & $\begin{array}{c}-30,46 \\
(0,0001)\end{array}$ & $\begin{array}{l}-38,78 \\
(0,0001\end{array}$ & $\begin{array}{c}-6,44 \\
(0,0076)\end{array}$ & $\begin{array}{l}-18,07 \\
(0,0004)\end{array}$ & $\begin{array}{c}-9,43 \\
(0,0025)\end{array}$ & $\begin{array}{c}-2,73 \\
(0,0720)\end{array}$ \\
\hline
\end{tabular}

h. O capim-marmelada estava no estádio 14 (Zadoks et al., 1974). 
que em densidades maiores, essa situação pode se manter ou, em outras palavras, que o acréscimo na produção de massa seca por unidade de área devido ao acréscimo de plantas à população será sempre próximo de zero.

A partir desses resultados foram estabelecidas as densidades totais do experimento com tratamentos em séries substitutivas. Assume-se que para a condução e análise de experimentos com tratamentos em delineamento com uma série substitutiva, a densidade total das espécies seja estabelecida acima do valor em que a produção de massa seca é independente da densidade de plantas, ou seja, o valor da densidade total deve estar além do ponto da produção final constante (Wit ${ }^{10}$, citado por Roush et al., 1989). Para atender a esse requisito, a densidade total de uma série substitutiva deveria ser maior que o maior valor de densidade encontrado para as duas espécies. Como não foi possivel determinar a densidade acima da qual a cultura atingiria a produção final constante, poder-se-ia utilizar o valor de densidade encontrado para a planta daninha, 2381 plantas. $\mathrm{m}^{-2}$. Nessa densidade, uma planta ocupa $4,1 \cdot 10^{-4} \mathrm{~m}^{2}$ ou $2,05 \times 2,05 \mathrm{~cm}$. Densidades maiores necessitariam espaçamentos menores. Entretanto, na prática, o menor espaçamento viável para a distribuição equidistante das plantas foi o de $3,0 \times 3,0 \mathrm{~cm}$. Com isso, decidiu-se desobedecer o requisito da "lei da produção final constante" e assumir que poderia haver prejuízo para a interpretação qualitativa dos resultados. Quanto ao delineamento de tratamentos com mais de uma série substitutiva, não há, na literatura, menção de que a densidade total de cada série deva atender à "lei da produção final constante". Assumiu-se, então que a interpretação quantitativa dos resultados não seria prejudicada $\mathrm{e}$ as densidades totais foram

10 Versl. Landbouwk. D. Onderz., v.66, n. 8, p. 1-82, 1960. 
estabelecidas em 625, 816 e 1111 plantas. $\mathrm{m}^{-2}$, utilizando-se os espaçamentos de, respectivamente, $4,0 \times 4,0 \mathrm{~cm}, 3,5 \times 3,5 \mathrm{~cm}$ e $3,0 \mathrm{x}$ $3,0 \mathrm{~cm}$.

\subsubsection{Competitividade da cultura de feijão com a planta daninha capim- marmelada}

\subsubsection{Análise qualitativa da competitividade das espécies}

De forma semelhante à Rejmánek et al. (1989) que trabalharam com tomate (Lycopersicon esculentum Mill.) e Echinochloa crus-galli var. frumentacea (Roxb.) W. F. Wight. e à Roush et al. (1989), com trigo (Triticum aestivum L.) e azevém (Lolium multiflorum Lam.), não se observou efeito da densidade total de plantas pois o padrão das curvas foi qualitativamente semelhante nas três densidades totais (Figuras 10 a 12 e Tabelas 3 a 5); desta forma, também foi feita uma análise com os resultados da média das três densidades (Figura 13 e Tabela 6). Os resumos das análises de regressão encontram-se nos Anexos L a O. A curva de produção relativa de feijão foi côncava nas densidades totais de 625 e 1111 plantas. $\mathrm{m}^{-2}$ e também na média das três densidades totais (Figuras 10, 12 e 13). Embora as médias das diferenças entre os valores de produção relativa observados e os valores correspondente à linha de competitividade equivalente, em cada proporção, tenham sido igual a zero $(\operatorname{Pr}>|\mathrm{T}|>0,05)$ (Tabelas 3, 5 e 6), o $\mathrm{CV}$ foi maior que $50 \%$, portanto as médias das diferenças podem ter sido diferentes de zero. Interpretou-se, então, que os valores de produção relativa de feijão observados foram superiores àqueles da linha de competitividade equivalente e, em consequencia, que para a cultura, a competição intraespecífica foi maior que a interespecífica, isto é, o efeito competitivo que houve entre as plantas de feijão foi maior que o efeito 
competitivo das plantas de capim-marmelada sobre as de feijão. Esse resultado deve ser considerado com reservas pois a densidade total de cada série substitutiva foi estabelecida abaixo da densidade em que a produção de massa seca de cada espécies seria independente de sua própria densidade, significando que o capim-marmelada pode não ter competido com o feijão e que a cultura estava numa densidade baixa o suficiente para que não houvesse competição intraespecífica e, assim, houvesse resposta ao aumento na densidade de plantas da própria espécie.

As curvas de produção relativa do capim-marmelada foram convexas nas três densidades totais e também na média das mesmas (Figuras 10 a 13). Exceto na densidade total de 816 plantas.m-2, na proporção de $25 \%$ de plantas de capim-marmelada (Tabela 4), a média da diferença entre os valores observados e o valor correspondente à linha de competitividade equivalente, em cada proporção, foi diferente de zero (Tabelas 3, 5, e 6), indicando que a competição interespecífica foi maior que a intraespecífica, com resultado desvantajoso para o capimmarmelada, ou seja, o efeito competitivo das plantas de feijão sobre as plantas de capim-marmelada foi maior que o efeito de competição entre as plantas de capim-marmelada.

Em resultados de alguns experimentos substitutivos, duas espécies tem demanda semelhante pelos recursos do ambiente mas diferem em suas respostas (Radosevich et al., 1997), uma espécie é mais agressiva que a outra e contribui, para a produção total, mais do que o esperado, enquanto a outra, contribui menos que o esperado. Sendo assim, uma curva é sempre côncava e a outra sempre convexa, indicando que a interação entre as espécies ocorre pelos mesmos 


\section{Densidade total de 625 plantas. $\mathrm{m}^{-2}$}

- P. vulgaris $\quad \mathrm{y}=-0,00008 \mathrm{x}^{2}+0,0175 \mathrm{x}+0,0145 \quad \mathrm{r}^{2}=0,9886$

B. plantaginea $\quad y=0,00013 x^{2}-0,0034 x+0,0231 \quad r^{2}=0,9814$

$-n_{-}-n_{-} \quad$ linha de competitividade equivalente

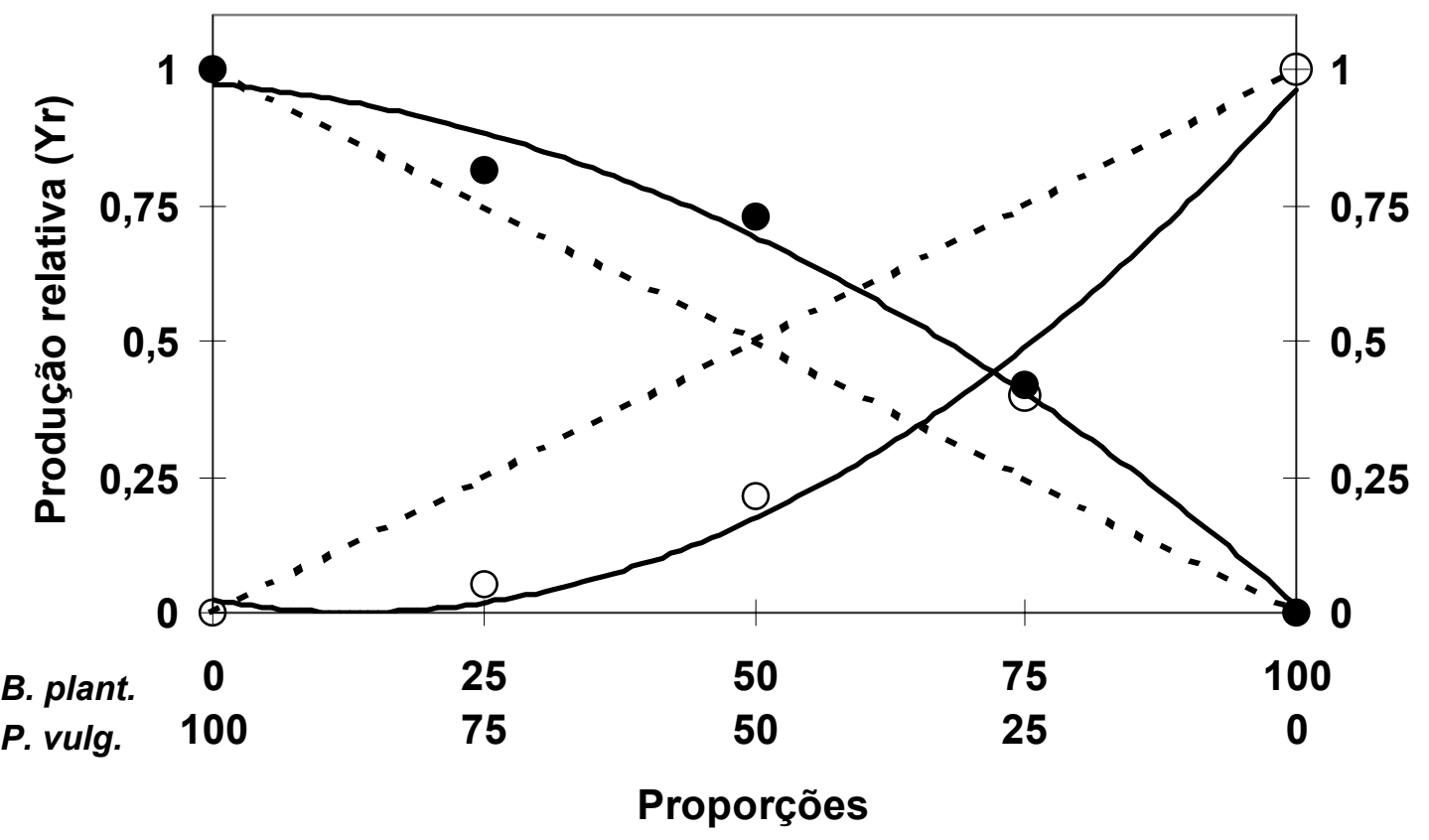

Figura 10 - Diagrama da série substitutiva na densidade total de 625 plantas. $\mathrm{m}^{-2}$ ilustrando a resposta da produção relativa de $P$. vulgaris e $B$. plantaginea à variação na proporção entre as espécies. As proporções são expressas como porcentagem da densidade total. 


\section{Densidade total de 816 plantas. $\mathrm{m}^{-2}$}

P. vulgaris

$$
y=0,00979 x+0,01039 r^{2}=0,9982
$$

B. plantaginea $y=0,00006 x^{2}+0,00439 x-0,01445 r^{2}=0,9821$

\section{$--_{----} \quad$ linha de competitividade equivalente}

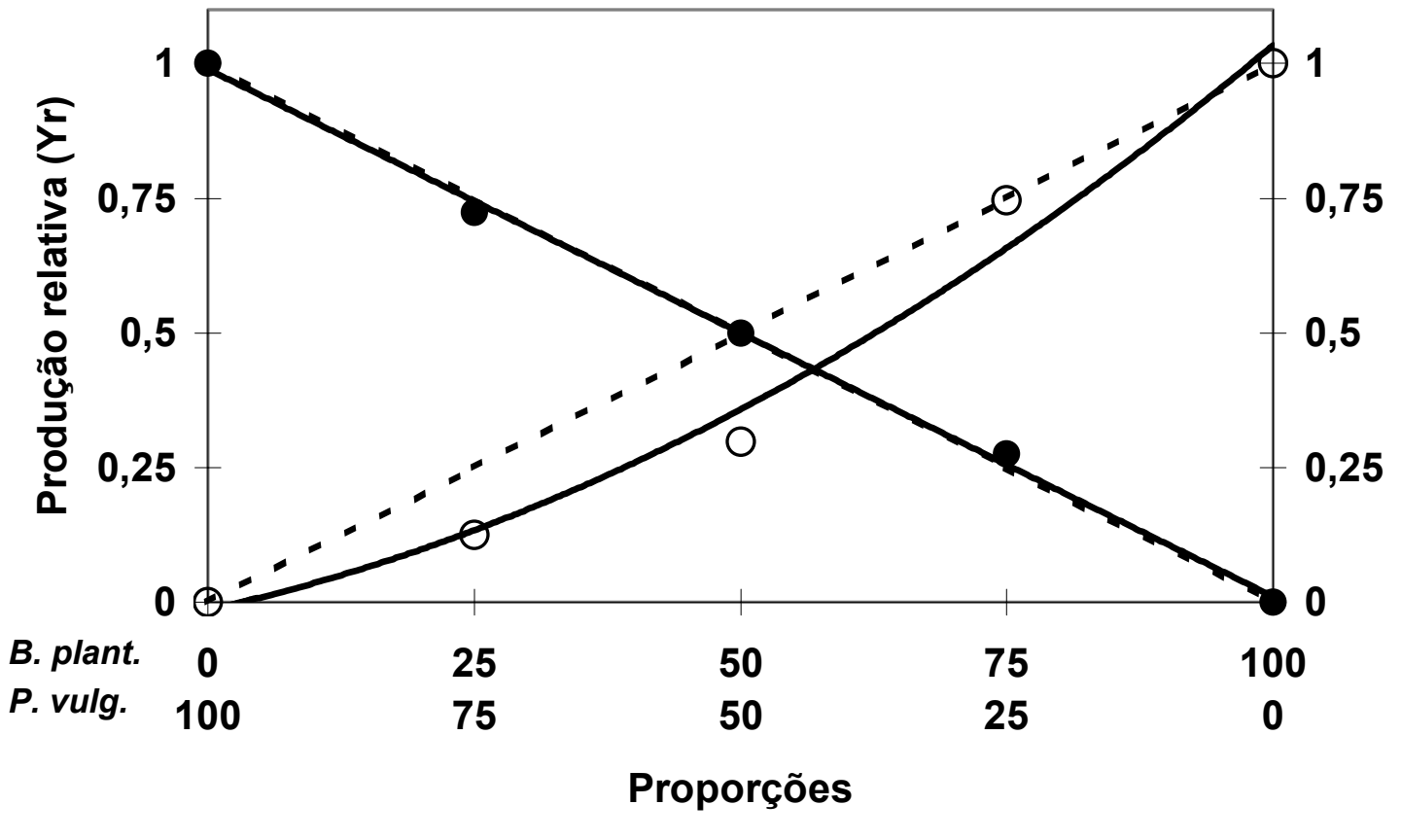

Figura 11 - Diagrama da série substitutiva na densidade total de 816 plantas. $\mathrm{m}^{-2}$ ilustrando a resposta da produção relativa de $P$. vulgaris e $B$. plantaginea à variação na proporção entre as espécies. As proporções são expressas como porcentagem da densidade total. 


\section{Densidade total de 1111 plantas. $\mathrm{m}^{-2}$}

-P. vulgaris $\quad \mathrm{y}=-0,00003 \mathrm{x}^{2}+0,01357 \mathrm{x}-0,00658 \mathrm{r}^{2}=0,9862$

B. plantaginea $y=0,00013 x^{2}-0,00392 x+0,03147 \quad r^{2}=0,9638$

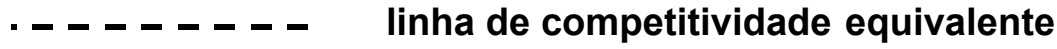

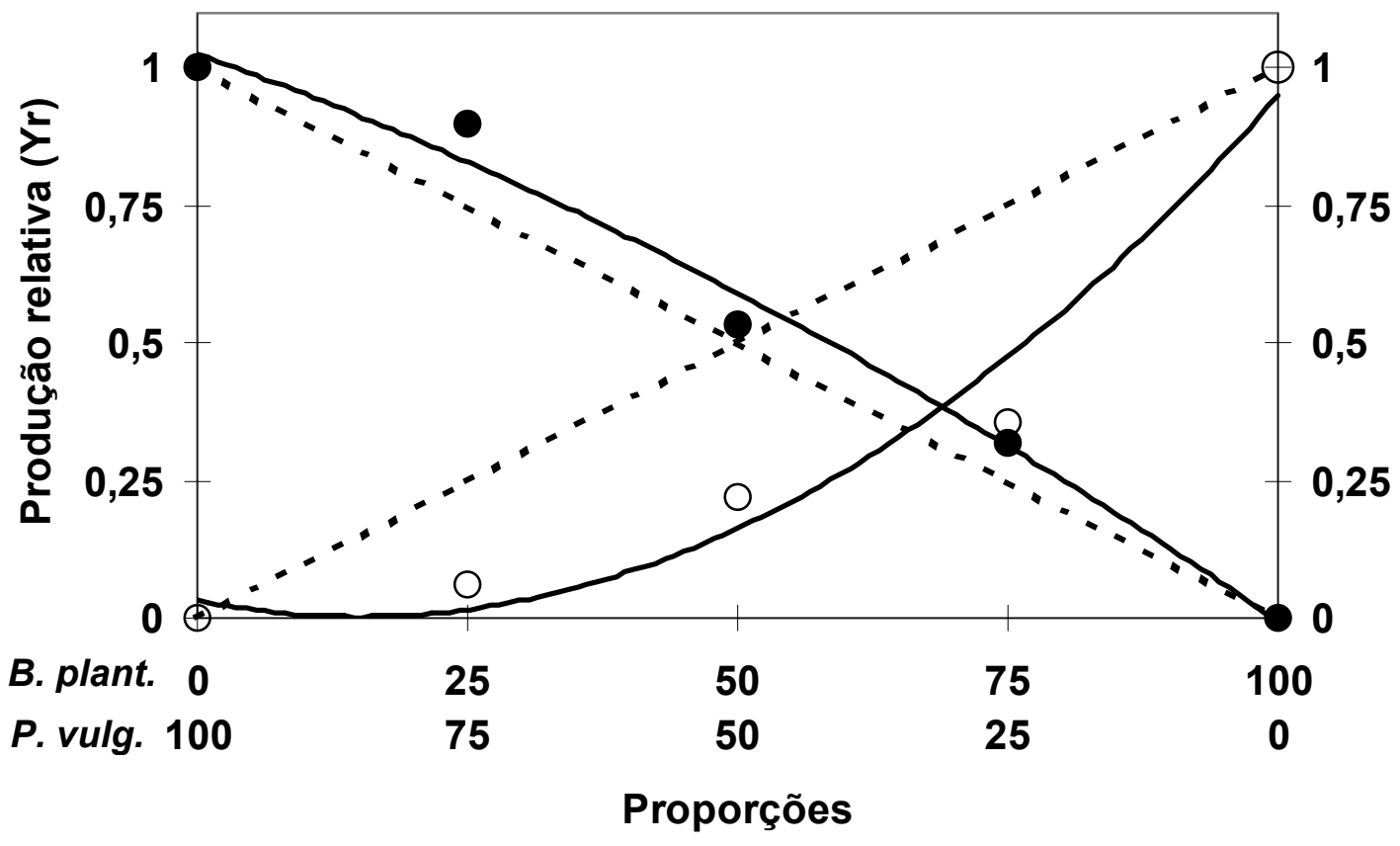

Figura 12 - Diagrama da série substitutiva na densidade total de 1111 plantas. $\mathrm{m}^{-2}$ ilustrando a resposta da produção relativa de $P$. vulgaris e $B$. plantaginea à variação na proporção entre as espécies. As proporções são expressas como porcentagem da densidade total. 


\section{Média das três séries substitutivas}

- P. vulgaris

$$
y=-0,00004 x^{2}+0,01363 x+0,00611 r^{2}=0,9995
$$

B. plantaginea $\quad y=0,00011 x^{2}-0,00097 x+0,01338 r^{2}=0,9958$

$\cdot-------\quad$ linha de competitividade equivalente

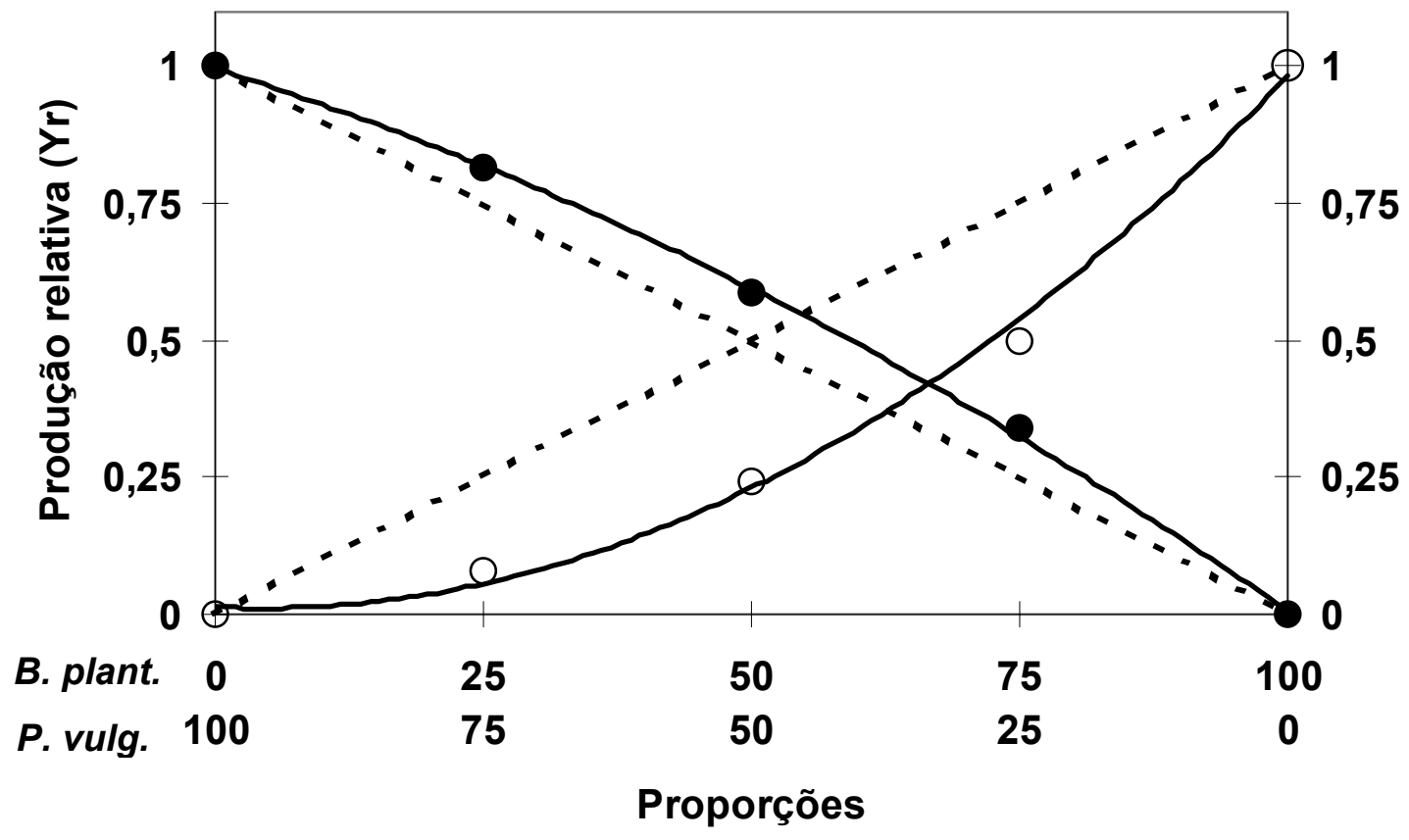

Figura 13 - Diagrama da média das três séries substitutivas, ilustrando a resposta da produção relativa de $P$. vulgaris e $B$. plantaginea à variação na proporção entre as espécies. As proporções são expressas como porcentagem da densidade total. 
Tabela 3. Dados estatísticos da diferença entre a produção relativa de massa seca da parte aérea e o valor da competitividade equivalente $(\mathrm{CE})$ em cada proporção. $\mathrm{O}$ valor de $\mathrm{CE}$ nas proporções de 75,50 e $25 \%$ foi de, respectivamente, 0,75 , 0,50 e 0,25. Resultado obtido aos 21 dias depois da semeadura ${ }^{\mathrm{e}} \mathrm{h}$, na densidade total de 625 plantas. $\mathrm{m}^{-2}$.

\begin{tabular}{|c|c|c|c|}
\hline \multirow{2}{*}{ Dados } & \multicolumn{3}{|c|}{ Proporção de plantas (\%) } \\
\hline & 75 & 50 & 25 \\
\hline \multicolumn{4}{|c|}{ Phaseolus vulgaris } \\
\hline No. de observações & 4 & 4 & 4 \\
\hline Média da produção relativa & 0,8189 & 0,7298 & 0,4197 \\
\hline Média da diferença em relação à $\mathrm{CE}$ & 0,0659 & 0,2298 & 0,1697 \\
\hline Desvio padrão da diferença em relação à $\mathrm{CE}$ & 0,1491 & 0,2067 & 0,1313 \\
\hline $\mathrm{CV} \%$ & 226,211 & 89,9883 & 77,3397 \\
\hline Teste W (Shapiro-Wilks) ${ }^{\mathrm{i}}$ & 0,9115 & 0,88413 & 0,9148 \\
\hline$(\operatorname{Pr}<\mathrm{W})$ & $(0,4808)$ & $(0,3519)$ & $(0,4970)$ \\
\hline Teste $\mathrm{t} \mathrm{j}$ & 0,8841 & 2,2251 & 2,5860 \\
\hline$(\operatorname{Pr}>|\mathrm{T}|)$ & $(0,4417)$ & $(0,1128)$ & $(0,0814)$ \\
\hline \multicolumn{4}{|c|}{ Brachiaria plantaginea } \\
\hline No. de observações & 4 & 4 & 4 \\
\hline Média da produção relativa & 0,4014 & 0,2141 & 0,0509 \\
\hline Média da diferença em relação à CE & $-0,3486$ & $-0,2859$ & $-0,1991$ \\
\hline Desvio padrão da diferença em relação à $\mathrm{CE}$ & 0,0392 & 0,0849 & 0,01435 \\
\hline $\mathrm{CV} \%$ & $-11,252$ & $-29,6812$ & $-7,2073$ \\
\hline Teste W (Shapiro-Wilks) ${ }^{\mathrm{i}}$ & 0,8539 & 0,7739 & 0,8345 \\
\hline$(\operatorname{Pr}<W)$ & $(0,2335)$ & $(0,0619)$ & $(0,1714)$ \\
\hline Teste $\mathrm{t} \mathrm{j}$ & $-17,774$ & $-6,7383$ & $-27,7496$ \\
\hline$(\operatorname{Pr}>|\mathrm{T}|)$ & $(0,0004)$ & $(0,0067)$ & $(0,0001)$ \\
\hline
\end{tabular}

i. A distribuição dos dados da média da diferença em relação a $\mathrm{CE}$ foi normal quando $(\operatorname{Pr}<\mathrm{W})>0,05$.

j. Teste para verificar se as médias das diferenças em relação a $\mathrm{CE}$ são iguais a zero. Aceitou-se $H_{0}$ quando $\left.(\operatorname{Pr}>\mid \mathrm{T})>0,05\right)$. 
Tabela 4. Dados estatísticos da diferença entre a produção relativa de massa seca da parte aérea e o valor da competitividade equivalente $(\mathrm{CE})$ em cada proporção. $\mathrm{O}$ valor de $\mathrm{CE}$ nas proporções de 75,50 e 25\% foi de, respectivamente, 0,75, 0,50 e 0,25. Resultado obtido aos 21 dias depois da semeadura e h, na densidade total de 816 plantas. $\mathrm{m}^{-2}$.

\begin{tabular}{|c|c|c|c|}
\hline \multirow{2}{*}{ Dados } & \multicolumn{3}{|c|}{ Proporção de plantas (\%) } \\
\hline & 75 & 50 & 25 \\
\hline \multicolumn{4}{|c|}{ Phaseolus vulgaris } \\
\hline $\mathrm{N}^{\circ}$ de observações & 4 & 4 & 4 \\
\hline Média da produção relativa & 0,7238 & 0,5002 & 0,2759 \\
\hline Média da diferença em relação à $\mathrm{CE}$ & $-0,0262$ & 0,0002 & 0,0259 \\
\hline Desvio padrão da diferença em relação à $\mathrm{CE}$ & 0,1123 & 0,0785 & 0,0562 \\
\hline $\mathrm{CV} \%$ & $-4,3.10^{2}$ & 42095,01 & 217,2549 \\
\hline Teste W (Shapiro-Wilks) ${ }^{\mathrm{i}}$ & 0,9275 & 0,6838 & 0,9219 \\
\hline$(\operatorname{Pr}<\mathrm{W})$ & $(0,5650)$ & $(0,0078)$ & $(0,5324)$ \\
\hline Teste $\mathrm{t}^{\mathrm{j}}$ & $-0,4656$ & 0,0047 & 0,9206 \\
\hline$(\operatorname{Pr}>|\mathrm{T}|)$ & $(0,6732)$ & $(0,9965)$ & $(0,4252)$ \\
\hline \multicolumn{4}{|c|}{ Brachiaria plantaginea } \\
\hline $\mathrm{N}^{\circ}$ de observações & 4 & 4 & 4 \\
\hline Média da produção relativa & 0,7466 & 0,2979 & 0,1245 \\
\hline Média da diferença em relação à $\mathrm{CE}$ & $-0,0034$ & $-0,2021$ & $-0,1254$ \\
\hline Desvio padrão da diferença em relação à $\mathrm{CE}$ & 0,1235 & 0,1375 & 0,0410 \\
\hline $\mathrm{CV} \%$ & $-3598,2$ & $-68,0446$ & $-32,6743$ \\
\hline Teste W (Shapiro-Wilks) ${ }^{\mathrm{i}}$ & 0,9408 & 0,9209 & 0,9145 \\
\hline$(\operatorname{Pr}<\mathrm{W})$ & $(0,6339)$ & $(0,5275)$ & $(0,4957)$ \\
\hline Teste $\mathrm{t}^{\mathrm{j}}$ & $-0,0556$ & $-2,9393$ & $-6,1201$ \\
\hline$(\operatorname{Pr}>|\mathrm{T}|)$ & $(0,9592)$ & $(0,0605)$ & $(0,0088)$ \\
\hline
\end{tabular}


Tabela 5. Dados estatísticos da diferença entre a produção relativa de massa seca da parte aérea e o valor da competitividade equivalente $(\mathrm{CE})$ em cada proporção. $\mathrm{O}$ valor de $\mathrm{CE}$ nas proporções de 75,50 e 25\% foi de, respectivamente, 0,75, 0,50 e 0,25. Resultado obtido aos 21 dias depois da semeadura $^{\mathrm{h}}$, na densidade total de 1111 plantas. $\mathrm{m}^{-2}$.

\begin{tabular}{|c|c|c|c|}
\hline \multirow{2}{*}{ Dados } & \multicolumn{3}{|c|}{ Proporção de plantas (\%) } \\
\hline & 75 & 50 & 25 \\
\hline \multicolumn{4}{|c|}{ Phaseolus vulgaris } \\
\hline No. de observações & 4 & 4 & 4 \\
\hline Média da produção relativa & 0,9007 & 0,5323 & 0,3189 \\
\hline Média da diferença em relação à $\mathrm{CE}$ & 0,1507 & 0,0323 & 0,0689 \\
\hline Desvio padrão da diferença em relação à $\mathrm{CE}$ & 0,2325 & 0,1139 & 0,1041 \\
\hline $\mathrm{CV} \%$ & 154,245 & 352,6177 & 151,0417 \\
\hline Teste W (Shapiro-Wilks) ${ }^{\mathrm{i}}$ & 0,8563 & 0,8076 & 0,8121 \\
\hline$(\operatorname{Pr}<\mathrm{W})$ & $(0,2417)$ & $(0,1124)$ & $(0,1212)$ \\
\hline Teste $\mathrm{t} \mathrm{j}$ & 1,2966 & 0,5672 & 1,3241 \\
\hline$(\operatorname{Pr}>|T|)$ & $(0,2855)$ & $(0,6103)$ & $(0,2773)$ \\
\hline \multicolumn{4}{|c|}{ Brachiaria plantaginea } \\
\hline No. de observações & 4 & 4 & 4 \\
\hline Média da produção relativa & 0,3538 & 0,2205 & 0,0591 \\
\hline Média da diferença em relação à $\mathrm{CE}$ & $-0,3962$ & $-0,2794$ & $-0,1909$ \\
\hline Desvio padrão da diferença em relação à $\mathrm{CE}$ & 0,0789 & 0,0825 & 0,0221 \\
\hline $\mathrm{CV} \%$ & $-19,935$ & $-29,5304$ & $-11,6042$ \\
\hline Teste W (Shapiro-Wilks) ${ }^{\mathrm{i}}$ & 0,9062 & 0,8367 & 0,8015 \\
\hline$(\operatorname{Pr}<\mathrm{W})$ & $(0,4550)$ & $(0,1801)$ & $(0,1013)$ \\
\hline Teste $\mathrm{t} \mathrm{j}$ & $-10,032$ & $-6,7727$ & $-17,2351$ \\
\hline$(\operatorname{Pr}>|T|)$ & $(0,0021)$ & $(0,0066)$ & $(0,0004)$ \\
\hline
\end{tabular}


Tabela 6. Dados estatísticos da diferença entre a produção relativa de massa seca da parte aérea o valor da competitividade equivalente $(\mathrm{CE})$ em cada proporção. $\mathrm{O}$ valor de $\mathrm{CE}$ nas proporções de 75,50 e 25\% foi de, respectivamente, 0,75, 0,50 e 0,25. Resultado obtido aos 21 dias depois da semeadura $\mathrm{e}$. Média das três densidades totais.

\begin{tabular}{|c|c|c|c|}
\hline \multirow{2}{*}{ Dados } & \multicolumn{3}{|c|}{ Proporção de plantas (\%) } \\
\hline & 75 & 50 & 25 \\
\hline \multicolumn{4}{|c|}{ Phaseolus vulgaris } \\
\hline $\mathrm{N}^{\circ}$ de observações & 4 & 4 & 4 \\
\hline Média da produção relativa & 0,8135 & 0,5874 & 0,3382 \\
\hline Média da diferença em relação à $\mathrm{CE}$ & 0,0635 & 0,0874 & 0,0882 \\
\hline Desvio padrão da diferença em relação à $\mathrm{CE}$ & 0,1260 & 0,0956 & 0,0446 \\
\hline $\mathrm{CV} \%$ & 198,524 & 109,3707 & 50,5385 \\
\hline Teste W (Shapiro-Wilks) ${ }^{\mathrm{i}}$ & 0,8737 & 0,9977 & 0,8530 \\
\hline$(\operatorname{Pr}<W)$ & $(0,3077)$ & $(0,9865)$ & $(0,2305)$ \\
\hline Teste $\mathrm{t} \mathrm{j}$ & 1,0074 & 1,8286 & 3,9574 \\
\hline$(\operatorname{Pr}>|\mathrm{T}|)$ & $(0,3879)$ & $(0,1649)$ & $(0,0288)$ \\
\hline \multicolumn{4}{|c|}{ Brachiaria plantaginea } \\
\hline $\mathrm{N}^{\circ}$ de observações & 4 & 4 & 4 \\
\hline Média da produção relativa & 0,5006 & 0,2442 & 0,0782 \\
\hline Média da diferença em relação à $\mathrm{CE}$ & $-0,2494$ & $-0,2558$ & $-0,1718$ \\
\hline Desvio padrão da diferença em relação à $\mathrm{CE}$ & 0,0437 & 0,0991 & 0,0199 \\
\hline $\mathrm{CV} \%$ & $-17,532$ & $-38,7289$ & $-11,6028$ \\
\hline Teste W (Shapiro-Wilks) ${ }^{\mathrm{i}}$ & 0,8464 & 0,8681 & 0,8985 \\
\hline$(\operatorname{Pr}<W)$ & $(0,2991)$ & $(0,2855)$ & $(0,4180)$ \\
\hline Teste $\mathrm{t} \mathrm{j}$ & $-11,408$ & $-5,1641$ & $-17,2372$ \\
\hline$(\operatorname{Pr}>|\mathrm{T}|)$ & $(0,0014)$ & $(0,0141)$ & $(0,0004)$ \\
\hline
\end{tabular}


recursos do ambiente mas que uma espécie captura recursos do meio de forma mais eficiente. Portanto, as plantas de feijão capturaram recursos do meio com maior eficiência que as plantas de capimmarmelada (Figuras 10 a 13) e, como espécie competidora, o feijão é superior ao capim-marmelada. Embora não se tenha avaliado a altura das plantas nem a área foliar das mesmas, como Rejmánek et al. (1989) o fizeram, observou-se que as plantas de feijão, além de emergirem antes das plantas de capim-marmelada, apresentaram crescimento mais rápido e, pela própria característica da planta, maior altura e área foliar, o que pode ter contribuído para o melhor desempenho competitivo da espécie.

\subsubsection{Análise quantitativa da competitividade das espécies}

A resposta das plantas de feijão e de capim-marmelada à sua própria densidade e à densidade da espécie competidora, expressa pelo recíproco de massa seca produzida por planta, é apresentada, respectivamente, nas Figuras 14 e 15 e o resumo das análises de regressão, na Quadro 3. O plano de regressão de cada figura representa os valores esperados derivados dos dados experimentais das três densidades totais.

O recíproco de massa seca produzida por planta de feijão $\left(1 / w_{c, p d}\right)$ aumentou com o aumento de densidade da própria espécie $\left(N_{c}\right)$ e da planta daninha $\left(N_{p d}\right)$ (Figura 14). Pela equação de regressão (eq. 18), conforme Spitters (1983), o coeficiente da densidade da cultura ( $b_{c, c}=$ 0,00064) quantifica a competição entre as plantas de feijão (competição intraespecífica) e o coeficiente da densidade da planta daninha ( $b_{c, p d}=$ 0,00003) quantifica o efeito das plantas de capim-marmelada sobre as de feijão (competição interespecífica). A competitividade da espécie cuja massa seca está sendo considerada, neste caso a cultura, em relação à outra espécie é definida pela razão entre os coeficientes $b_{c, c} / b_{c, p d}$. A adição de uma 


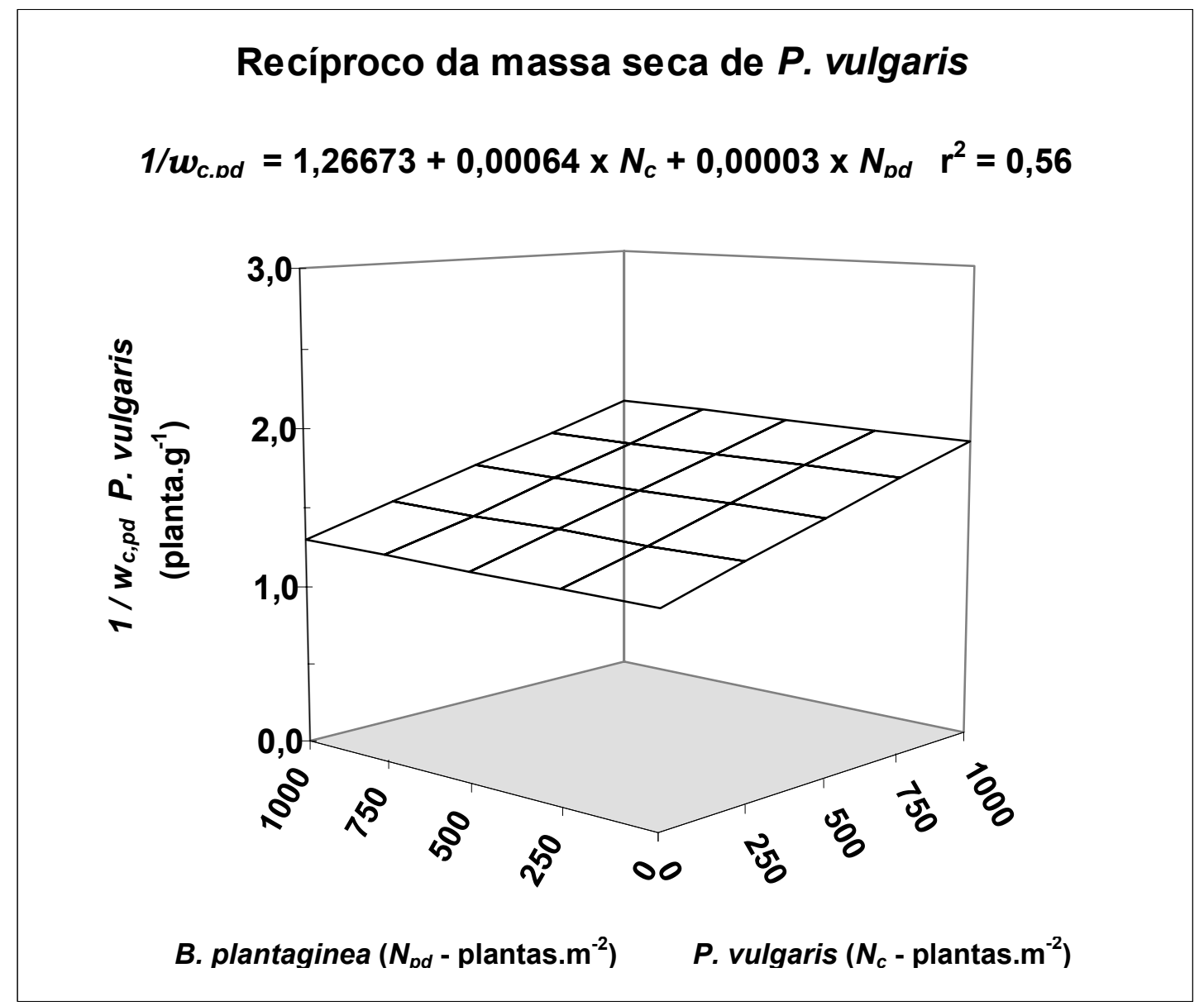

Figura 14 - Efeito simultâneo da densidade da planta daninha $\left(N_{p d}\right)$, capim marmelada (B. plantaginea), e da cultura $\left(N_{c}\right)$, feijão ( $P$. vulgaris), sobre o recíproco de produção de massa seca por planta de feijão $\left(1 / w_{c, p d)}\right.$ (eq. 18).

planta de feijão resulta no mesmo valor do recíproco da massa seca por planta da cultura $\left(1 / w_{c, p d}\right)$ que a adição de 21,3 plantas de capimmarmelada $(21,3=0,00064 / 0,00003)$. Em outras palavras, a adição de uma planta de feijão aumentou $1 / w_{c, p d}$, isto é, reduziu a produção por planta $\left(w_{c, p d}\right)$, na mesma intensidade que a adição de 21,3 plantas de capim-marmelada. Pode-se dizer que uma planta de feijão sentiu a 


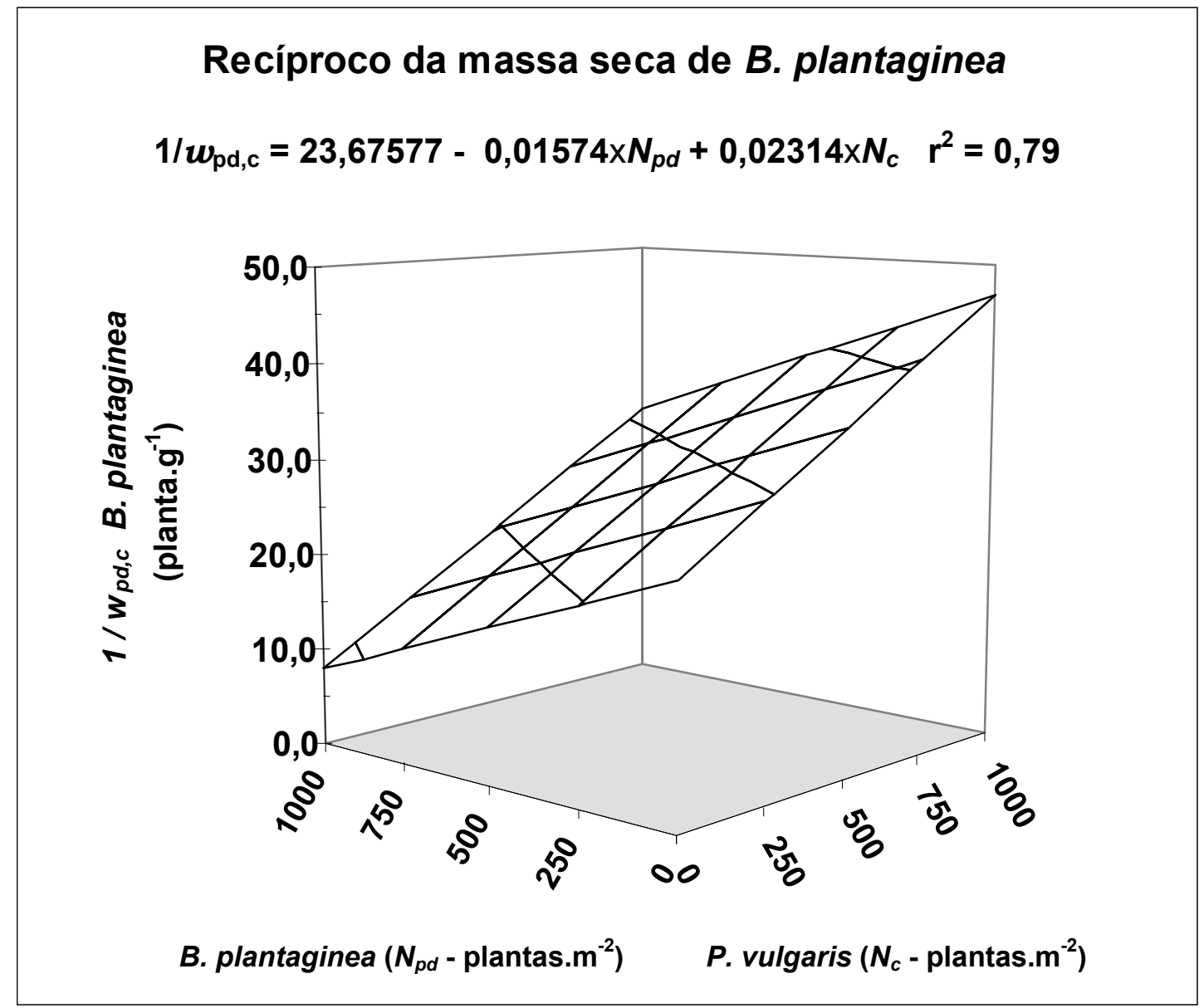

Figura 15 - Efeito simultâneo da densidade da planta daninha $\left(N_{p d}\right)$, capim marmelada (B. plantaginea), e da cultura $\left(N_{c}\right)$, feijão (P. vulgaris), sobre o recíproco de produção de massa seca por planta de capim marmelada (eq. 19).

presença de outra planta de feijão no mesmo grau que a presença de 21,3 plantas de capim-marmelada. Entretanto, a probabilidade do coeficiente de competição interespecífica $\left(b_{c, p d}\right)$ ser igual a zero foi de $91 \%$ (Quadro 3), indicando que há $91 \%$ de chance da planta daninha não ter interferido na produção de massa seca das plantas de feijão. 


\begin{tabular}{|c|c|c|c|c|}
\hline $\begin{array}{l}\text { Fonte de } \\
\text { variação }\end{array}$ & GL & $\mathrm{QM}$ & \multicolumn{2}{|c|}{$\operatorname{Pr}>F^{a}$} \\
\hline \multicolumn{5}{|c|}{ Phaseolus vulgaris } \\
\hline Regressão & 2 & 0,1700 & \multicolumn{2}{|c|}{0,0239} \\
\hline Resíduo & 9 & 0,0292 & \multicolumn{2}{|c|}{-} \\
\hline $\mathrm{CV}$ & 10,5856 & - & - & - \\
\hline \multirow[t]{2}{*}{$\mathrm{R}^{2}$} & 0,5639 & - & - & - \\
\hline & Coeficiente & Erro padrão & $t^{c}$ & $P d$ \\
\hline Interseção & 1,26673 & 0,21567 & 5,87326 & 0,00024 \\
\hline Variável $N_{c}$ & 0,00064 & 0,00026 & 2,45956 & 0,03618 \\
\hline Variável $N_{p d}$ & 0,00003 & 0,00028 & 0,11741 & 0,90910 \\
\hline \multicolumn{5}{|c|}{ Brachiaria plantaginea } \\
\hline Regressão & 2 & 541,4422 & \multicolumn{2}{|c|}{0,000837} \\
\hline Resíduo & 9 & 31,43026 & \multicolumn{2}{|c|}{ - } \\
\hline $\mathrm{CV}$ & 24,71 & - & - & - \\
\hline \multirow[t]{2}{*}{$\mathrm{R}^{2}$} & 0,7929 & - & - & - \\
\hline & Coeficiente & Erro padrão & $\mathrm{t}$ & $\mathrm{P}$ \\
\hline Interseção & 23,67577 & 7,07402 & 3,34686 & 0,00857 \\
\hline Variável $N_{c}$ & 0,02314 & 0,00909 & 2,54443 & 0,03148 \\
\hline Variável $N_{p d}$ & $-0,01574$ & 0,00847 & $-1,8583$ & 0,09592 \\
\hline
\end{tabular}

Quadro 3. Resumo da análise de regressão linear múltipla do recíproco da massa seca produzida por planta de feijão ( $P$. vulgaris) $\left(1 / w_{c, p d}\right)$ e de capim-marmelada (B. plantaginea) $\left(1 / w_{p d, c}\right)$ em função da densidade das duas espécies $\left(N_{c}\right.$ e $\left.N_{p d}\right)$. 
O reciproco de massa seca produzida por planta de capimmarmelada foi reduzido com o aumento na densidade da própria espécie e aumentou com o aumento na densidade de plantas de feijão (Figura 15). O sinal negativo do coeficiente $b_{p d, p d}$ indica que para cada acréscimo de uma planta de capim-marmelada à mistura de plantas, $1 / w_{p d}$ decresce, ou $w_{p d}$ aumenta, em 0,01574 g. Não se avaliou mas se observou que com o aumento na densidade das plantas dessa espécie, houve menor crescimento e atraso na emissão de novas folhas. É possivel que as plantas, recrutando menor quantidade de recursos do meio, cresceram menos mas acumularam maior quantidade de matéria seca. De forma análoga ao apresentado para o feijão, o coeficiente da densidade da planta daninha $\left(b_{p d, p d}=0,01574\right)$ quantifica a competição entre as plantas de capim-marmelada e o coeficiente da densidade da cultura $\left(b_{p d, c}=0,02314\right)$ quantifica o efeito da competição das plantas de feijão sobre as de capim-marmelada. Uma planta de capim-marmelada. Uma planta de capim-marmelada sentiu a presença de outra, da mesma espécie, no mesmo grau que a presença de 0,68 plantas de feijão $\left(b_{p d, p d} / b_{c, p d)}\right.$. A competitividade do feijoeiro em relação ao capim-marmelada tendo sido de 21,3 e a de capim-marmelada em relação ao feijoeiro, de 0,68, indica que as duas espécies sofreram menor grau de competição quando tiveram plantas de capim-marmelada como vizinhas.

Houve diferenciação de nicho ecológico uma vez que a relação entre a competitividade relativa das duas espécies (eq. 20, eq. 21 e eq. 22) foi de 14,48. Essa diferenciação de nicho, no entanto, foi parcial pois a competição intraespecífica do feijão foi maior que a competição exercida pelas plantas de capim-marmelada sobre as de feijão ao mesmo tempo que a competição exercida pelas plantas de feijão sobre as de capim-marmelada foi maior que a competição intraespecífica do capim-marmelada. Portanto, as espécies competiram 
pelos mesmos recursos mas as plantas de feijão evitaram a competição da planta daninha. Spitters (1983) observou diferenciação de nicho entre milho e amendoim e afirmou que a diferenciação de nicho é uma regra em mistura de culturas gramíneas com leguminosas. É provável que essa afirmação possa ser generalizara para a diferenciação de nicho entre a cultura de feijão e plantas daninhas gramíneas.

Realizando a análise qualitativa dos resultados, não se observou diferença na competitividade relativa das espécies devido à densidade das plantas mas com a análise quantitativa detectou-se efeito significativo da densidade das plantas. Roush et al. (1989) também observaram essa contradição de interpretação. Os autores sugeriram que o método qualitativo foi menos sensivel em detectar as possiveis influências da densidade sobre as interações competitivas e que essa diferença de sensibilidade pode ser devido à transformação dos dados. Enquanto no método qualitativo a análise é feita com a produção relativa, no método quantitativo, análise é feita com o recíproco da produção por planta.

Pelo método qualitativo, (a) quando se considera a produção relativa do feijão, o efeito de competição intraespecífica do feijão foi ou nulo ou maior que o efeito da competição das plantas de capimmarmelada sobre as plantas de feijão e, o efeito competitivo das plantas de capim-marmelada sobre as plantas de feijão foi ou nulo ou semelhante ao que ocorreu entre as plantas de feijão e (b) quando se considera a produção relativa do capim-marmelada, o efeito competitivo das plantas de feijão sobre as de capim-marmelada foi maior que o ocorrido entre as plantas de capim-marmelada de tal forma que a produção relativa do feijão foi ou superior ou semelhante à linha de competitividade equivalente e a de capim-marmelada, inferior à essa 
linha. Isto posto, a espécie feijão foi uma competidora mais forte que a espécie capim-marmelada. Pelo método quantitativo, (1) evidenciou-se que (a) houve competição entre as plantas de feijão, (b) capimmarmelada exerceu um efeito competitivo sobre o feijão com $91 \%$ de probabilidade de ser nulo, (2) confirmou-se que (a) houve competição entre as plantas de capim-marmelada, (b) o efeito da cultura sobre a planta daninha foi maior que o efeito competitivo entre as plantas de capim-marmelada e (3) observou-se diferenciação parcial de nicho ecológico uma vez que (a) para a cultura, a competição intraespecífica foi maior que a interespecífica, sendo a ultima desprezivel e (b) para a planta daninha, a competição interespecífica foi maior que a intraespecífica.

\subsection{Conclusões}

a. O feijão, como espécie competidora é superior ao capim-marmelada.

b. Há diferenciação parcial de nicho ecológico entre feijão e capimmarmelada, isto é, as espécies utilizam os mesmos recursos do meio mas o feijão evita a presença do capim-marmelada.

c. Há diferença entre os métodos de análise dos dados quanto à detectar o efeito da densidade de plantas.

d. O efeito da densidade das plantas na competitividade relativa das espécies é detectada com a análise quantitativa dos dados.

e. Há efeito da proporção entre plantas sobre as interações competitivas entre as espécies. 


\section{MODELOS EMPÍRICOS DE PREDIÇÃO DE PERDAS DE RENDIMENTO DA CULTURA DE FEIJÃO EM CONVIVÊNCIA COM Brachiaria plantaginea (Link) Hitchc.}

\section{Resumo}

A predição de perdas de rendimento de uma cultura devido à interferência de plantas daninhas é fundamental para o planejamento e seleção de estratégias de manejo das plantas daninhas na agricultura. Diversos modelos empíricos foram descritos na literatura porém, há necessidade de validá-los e determinar variáveis cuja avaliação, na prática, seja fácil e rápida, sem perder em precisão da predição de perdas de rendimento. Assim, os objetivos deste estudo foram os de comparar a eficiência de modelos empíricos em predizer perdas de rendimento da cultura de feijão (Phaseolus vulgaris L.) em função da densidade e do indice de área foliar relativa da planta daninha [Brachiaria plantaginea (Link) Hitchc.]; verificar se a cobertura relativa do solo pela planta daninha, avaliada visualmente, apresenta potencial como variável de substituição do índice de área foliar relativa da planta daninha; avaliar se as variáveis utilizadas nos modelos empíricos explicam as perdas de rendimento devido à época de emergência da planta daninha em relação à da cultura e propor uma metodologia para estimar os coeficientes dos modelos empíricos avaliados. Os experimentos foram conduzidos de outubro de 1999 a janeiro de 2000, na Universidade de São Paulo (USP), Escola Superior de Agricultura "Luiz de Queiroz" (ESALQ), em área 
experimental do Departamento de Produção Vegetal, em Piracicaba-SP, latitude $22^{\circ} 42^{\prime} 30^{\prime \prime}$ sul, longitude $47^{\circ} 38^{\prime}$ 00" oeste, altitude de $560 \mathrm{~m}$; clima $\mathrm{CW}_{\mathrm{a}}$ (mesotérmico, úmido, subtropical com inverno seco), segundo a classificação de Köppen; a temperatura média do mês mais quente está acima de $24^{\circ} \mathrm{C}$ e a do mês mais frio, abaixo de $17^{\circ} \mathrm{C}$, com precipitação pluvial média de $1200 \mathrm{~mm}$ ao ano. Determinou-se a perda de rendimento de grãos de feijão devido à densidade e à época de emergência do capimmarmelada, simulada por diferentes datas de semeadura. As perdas de rendimento observadas foram comparadas às perdas preditas com o uso de modelos empíricos. O delineamento experimental foi em blocos ao acaso e o de tratamentos, em parcelas subdivididas, com três repetições. O tratamento de parcelas foi a época de semeadura da planta daninha (oito dias antes, no dia, cinco e 10 dias depois da semeadura da cultura) e o de subparcelas, a densidade da planta daninha $(0,25,50,100$ e 200 plantas. $\mathrm{m}^{-2}$ ). As maiores perdas de rendimento da cultura ocorreram quando a planta daninha, foi semeada antes da cultura. Tais perdas decresceram com o atraso na época de semeadura da planta daninha. $O$ modelo cuja variável é a densidade da planta daninha não descreve a perda de rendimento da cultura causada pela época de semeadura da planta daninha mas aqueles cuja variável é o índice relativo da área foliar ou a cobertura relativa do solo pela planta daninha descrevem. A cobertura relativa do solo pela planta daninha, avaliada visualmente, é uma variável potencial para substituir o índice de área foliar relativa da planta daninha. Com o método completo, proposto para estimar os coeficientes dos modelos, obtém-se melhor predição de perdas de rendimento da cultura do que com o método simplificado. 


\section{Summary}

The prediction of crop yield losses due to weed infestation is fundamental for selecting weed management strategies. Several empirical models have been presented in the literature. However, it is necessary to validate them and choose variables, which can be evaluated in more practical way without reducing the precision of the crop yield loss prediction. Therefore, the goals of this study were to compare the performance of empirical models on predicting crop (Phaseolus vulgaris L.) yield loss based on weed [Brachiaria plantaginea (Link) Hitchc.] density and weed relative leaf area index; to test whether weed relative ground cover, visually estimated, has the potential as substitute variable for weed relative leaf area index; to assess whether those three variables can explain the crop yield loss due to the time of weed emergence relative to crop emergence and, to suggest a methodology to estimate the coefficients of the tested empirical models. The experiments were carried out from October 1999 to January 2000, at University of São Paulo (USP), Escola Superior de Agricultura "Luiz de Queiroz" (ESALQ), in an experimental area of the Department of Crop Production, Piracicaba, São Paulo State, Brazil, located at $22^{\circ} 42^{\prime} 30^{\prime \prime} \mathrm{S}, 47^{\circ} 38^{\prime} 00^{\prime \prime} \mathrm{W}, 560 \mathrm{~m}$ elevation; $\mathrm{CW}_{\mathrm{a}}$ climate, according with Köppen (mesotermic, humid, subtropical with dry winter); the mean temperature of the warmest month is higher than $24^{\circ} \mathrm{C}$ and of the coldest month, lower than $17^{\circ} \mathrm{C}$; mean annual rainfall is 1200 $\mathrm{mm}$. The crop yield loss due to weed density and weed emergence relative to the crop emergence, simulated by sowing the weed at different time, was assessed. The observed crop yield losses were compared to the crop yield losses predicted by using three empirical models. The experiment was set up as a randomized block design and treatment as a split plot design with dates of sowing the weed (eight days before, at the same day, five and 10 days after sowing the crop) as the main plots and the weed 
densities $\left(0,25,50,100\right.$ and 200 plants. $\left.\mathrm{m}^{-2}\right)$ as subplots. The highest bean yield loss was observed when the alexandergrass sowing was done before sowing the crop. Crop yield losses decreased with the weed sowing delay. The model which variable is the weed density does not predict de crop yield loss due the relative time of weed sowing however, those models which variable is the weed relative leaf area index or weed relative ground cover, visually estimated, do. The visually estimated weed relative ground cover is a potential variable to substitute for the weed relative leaf area index. The suggested advanced method for estimating the model coefficients predicts the crop yield loss better than the simple method.

\subsection{Introdução}

O Brasil destaca-se como o segundo maior produtor de feijão (Phaseolus vulgaris L.) do mundo, o primeiro do Mercosul e tem o Paraná como o estado maior produtor nacional (Berg, 1999). Na safra de 1999/2000, o Brasil plantou 4.178.000 ha de feijão, 1.500.000 ha dos quais, em plantio direto (Kissmann, 2000). Em 55\% do total da área plantada, o controle das plantas daninhas foi feito com herbicidas (Kissmann, 2000). A planta daninha capim-marmelada [Brachiaria plantaginea (Link) Hitchc] é uma das espécies mais frequentes em áreas cultivadas no Centro e Sul do Brasil (Lorenzi, 1999). No Paraná, em 253 lavouras das principais regiões produtoras de feijão, capim-marmelada foi a planta daninha mais frequente, tanto em culturas solteiras como nas consorciadas com milho (Kranz, 1993). O nível de dano que essa espécie causa na cultura de feijão foi estudado por vários pesquisadores (Blanco et al., 1969; Blanco, 1982; Lunkes, 1997) e, para exemplificar, pode-se citar que, quando capim-marmelada foi a espécie dominante (92\% do total de plantas daninhas), na ausência de controle durante todo o ciclo da cultura houve perdas de rendimento de grãos que variaram de 61 a 85\%, dependendo da variedade (Kramm et al., 1990). 
Devido à importância da cultura de feijão na agricultura brasileira e do grande potencial de ocorrência de capim-marmelada e das perdas consideráveis que essa planta daninha pode provocar no rendimento da cultura, é que o resultado das interações competitivas entre essas espécies foi escolhido como motivo da realização desta pesquisa.

Melhorar a eficácia dos herbicidas no controle das plantas daninhas é uma das principais preocupações na agricultura atual, visando não só minorar a quantidade utilizada de herbicidas para reduzir os custos de produção mas também para minimizar o impacto ambiental e a pressão de seleção para biotipos resistentes de plantas daninhas. É de conhecimento geral que com a implantação de um sistema de manejo integrado de plantas daninhas, todos esses objetivos podem ser alcançados. Um sistema de manejo integrado de plantas daninhas envolve planejamento, implantação e acompanhamento de estratégias de manejo dessas espécies (Christoffoleti \& Passini, 1999), podendo-se obter maior eficiência do sistema, com a integração de uma ferramenta de tomada de decisão. Tal ferramenta deve apresentar em sua constituição um modelo para predizer o resultado da interação competitiva entre a cultura e as plantas daninhas e deve ser caracterizado por variáveis de fácil avaliação no campo.

Vários modelos empíricos que relacionam as perdas de rendimento da cultura devido à presença da plantas daninhas, em que a população dessas espécies é descrita pela densidade (Cousens, 1985; Spitters, 1989, Jasieniuk, 2001), pelo indice de área foliar relativa (Kropff \& Spitters, 1991), pela cobertura relativa do solo (Lotz et al., 1992), pelo volume (Busller et al., 1995) e pela biomassa e biomassa relativa (Florez et al., 1999) estão descritos na literatura. Entre esses, apenas modelos que utilizam a densidade como variável foram incorporados em programas de computador para suporte à tomada de decisão, por exemplo, HERB (Wilkerson, et al, 1991) e WEEDCAM (Vangessel et al., 1995). Um modelo de predição de 
perdas de rendimento, para que possa ser associado a outros, para compor um programa de auxílio na tomada de decisão precisa ser avaliado em diversas condições edafoclimáticas. Recentemente, o modelo que tem sido estudado com dados de campo é o que utiliza o índice de área foliar relativa da planta daninha (Dieleman et al., 1995 e Knežević et al., 1995). Embora diversos modelos empíricos tenham sido descritos, há necessidade de validálos e determinar variáveis cuja avaliação, na prática, possa ser rápida e fácil, sem perder em precisão na predição de perdas de rendimento.

Considerando o que foi exposto, este trabalho foi realizado com os objetivos de comparar a eficiência de modelos empíricos em predizer perdas de rendimento da cultura de feijão (Phaseolus vulgaris L.) em função da densidade e índice de área foliar relativa da planta daninha [Brachiaria plantaginea (Link) Hitchc.]; verificar se a cobertura relativa do solo pela planta daninha, avaliada visualmente, apresenta potencial como variável de substituição do índice de área foliar relativa da planta daninha, avaliar se as variáveis utilizadas nos modelos empíricos explicam as perdas de rendimento devido às épocas de emergência da planta daninha em relação à emergência das plantas da cultura e propor uma metodologia para estimar os coeficientes dos modelos empíricos avaliados.

\subsection{Material e Métodos}

Os experimentos foram conduzidos na Universidade de São Paulo (USP), Escola Superior de Agricultura "Luiz de Queiroz" (ESALQ), em área experimental do Departamento de Produção Vegetal, em PiracicabaSP, latitude $22^{\circ} 42^{\prime} 30^{\prime \prime}$ sul, longitude $47^{\circ} 38^{\prime} 00^{\prime \prime}$ oeste, altitude de $560 \mathrm{~m}$ e clima, segundo a classificação de Köppen, do tipo $\mathrm{CW}_{\mathrm{a}}$, isto é, mesotérmico, úmido, subtropical com inverno seco. De acordo com o Departamento de Ciências Exatas da USP/ESALQ, a temperatura média do 
mês mais quente está acima de $24^{\circ} \mathrm{C}$ e a do mês mais frio, abaixo de $17^{\circ} \mathrm{C}$, com precipitação pluvial média de $1200 \mathrm{~mm}$ ao ano.

Determinou-se a perda de rendimento de grãos de feijão devido a convivência com o capim-marmelada, em várias densidades, simulando-se épocas relativas entre a emergência da planta daninha e a cultura através de diferentes épocas de semeadura da planta daninha em relação à data de semeadura da cultura. Os valores de perda de rendimento observados foram comparados a valores de perda preditos com o uso de modelos empíricos, os quais foram avaliados quanto à eficiência em predizer perdas.

\subsection{1 Área experimental}

As amostras de solo, da área onde foi instalado o experimento, foram coletadas em 8 pontos, na profundidade de 0 a $20 \mathrm{~cm}$. Essas amostras foram misturadas e homogeneizadas para comporem uma única amostra. As análises química e física do solo encontram-se no Quadro 4.

\begin{tabular}{|c|c|c|c|c|c|c|c|c|c|c|c|}
\hline \multicolumn{12}{|c|}{ Análise química } \\
\hline \multirow{2}{*}{$\begin{array}{c}\mathrm{pH} \\
\mathrm{CaCl}_{2}\end{array}$} & & $\mathrm{P}$ & $\mathrm{S}-\mathrm{SO}_{4}$ & $\mathrm{Al}$ & $\mathrm{H}+\mathrm{Al}$ & $\mathrm{Ca}$ & $\mathrm{Mg}$ & $\mathrm{K}$ & $\Sigma$ Bases & Total & \multirow{2}{*}{$\mathrm{V} \%$} \\
\hline & g. $\mathrm{dm}^{-3}$ & \multicolumn{2}{|c|}{$\mathrm{mg} \cdot \mathrm{dm}^{-3}$} & \multicolumn{7}{|c|}{ mmolc. $\mathrm{dm}^{-3}$} & \\
\hline 5,2 & 30 & 245 & 25 & 0 & 42 & 76 & 25 & 4,8 & 105,8 & 147,8 & 72 \\
\hline \multicolumn{12}{|c|}{ Análise física } \\
\hline \multicolumn{3}{|c|}{$\%$ Areia } & \multicolumn{3}{|c|}{$\%$ Silte } & \multicolumn{3}{|c|}{$\%$ Argila } & \multicolumn{3}{|c|}{ Classe de Textura } \\
\hline & 37 & & \multicolumn{3}{|c|}{16} & \multicolumn{3}{|c|}{47} & \multicolumn{3}{|c|}{ argilosa } \\
\hline
\end{tabular}

$\mathrm{SB}=$ soma de bases, $\mathrm{T}=$ capacidade de troca de cátions, $\mathrm{V} \%=(\mathrm{SB} / \mathrm{T}) .100$

Análises realizadas pelo Laboratório de Análise de Solo do Departamento de Solos e Nutrição de Plantas - USP/ESALQ.

Quadro 4 - Análise química e física do solo da área onde foi instalado o experimento de campo. 


\subsubsection{Delineamento estatístico}

O experimento foi delineado em blocos ao acaso e os tratamentos, em parcelas subdivididas, com três repetições. O tratamento de parcelas foi a época de semeadura da planta daninha e o de subparcelas, a densidade da mesma. As épocas de semeadura foram: oito dias antes da semeadura da cultura (8 das), no dia da semeadura da cultura (dia 0) e 5 e 10 dias depois da semeadura da cultura (respectivamente, 5 e $10 \mathrm{dds}$ ). As densidades da planta daninha foram de 0, 25, 50, 100 e 200 plantas. - $^{-2}$ (Tabela 7). As subparcelas mediam 1,20 $\mathrm{m}$ de largura $\mathrm{x} 1,50 \mathrm{~m}$ de comprimento, com 3 linhas de feijão no espaçamento de 0,40 m. A área útil foi de $1,00 \mathrm{~m} \times 0,40 \mathrm{~m}$.

Tabela 7. Tratamentos instalados em área experimental da USP/ESALQ Departamento de Produção Vegetal, Piracicaba - SP, 1999/2000.

\section{Parcela}

Época de semeadura do capimmarmelada em relação à data de semeadura da cultura de feijão
Subparcela

Densidade do capim-marmelada

(plantas.m-2)
8 das
0
25
dia 0
50
5 dds
100
$10 \mathrm{dds}$
200

das - dias antes da semeadura do feijão; dia 0 - no mesmo dia da semeadura do feijão e, dds - dias depois da semeadura do feijão. 


\subsubsection{Preparo da área, instalação e condução do experimento}

Para reduzir a comunidade natural de plantas daninhas, em que a população de tiririca (Cyperus rotundus L.) era dominante, a área foi pulverizada com duas aplicações de glyphosate na dosagem de 540 g.ha-1, com um intervalo de 15 dias entre elas. No dia 08/10/99, um mês após a primeira pulverização, o terreno foi preparado com encanteiradora, formando dois canteiros de 1,20 x 85,0 m. Esses canteiros, em 19/10/99, foram cobertos com plástico e tratados com brometo de metila na dosagem de $50 \mathrm{~cm}^{3}$ do gás.m-2 de canteiro, considerando a profundidade de $3,0 \mathrm{~cm}$. Cinco dias antes desse tratamento, para forçar a germinação das sementes das plantas daninhas e facilitar a ação do produto, a área foi irrigada com $12 \mathrm{~mm}$ de água, durante uma hora. Três dias após a aplicação do gás $(22 / 10)$, o plástico foi retirado.

A semente da cultura de feijão, adquirida comercialmente, era da variedade Carioca, peneira 11/14, tratada com carboxin+thiran, com germinação de $80-89 \%$ e pureza de $98-99,9 \%$. A semeadura foi feita manualmente, em 03/11/99, sem adubação, no espaçamento de 0,40 m, à profundidade de $0,03 \mathrm{~m}$ e densidade de 20 sementes por metro linear. Quatorze dias após a semeadura (8 dias após a emergência) o desbaste foi realizado deixando-se 10 plantas por metro linear, permitindo uma densidade de 25 plantas. $\mathrm{m}^{-2}$. A cultura encontrava-se no estádio V2 (Dourado Neto \& Fancelli, 1997).

A semente de capim-marmelada, adquirida comercialmente,

era de lote que apresentava início de germinação no sexto dia após a semeadura e taxa de emergência de 25 plântulas para cada $0,58 \mathrm{~g}$ de semente. O capim-marmelada foi semeado, conforme o tratamento (Tabela 7), nos dias 26/10 (8 das), 03/11 (dia 0), 08/11 (5 dds) e 12/11/99 (10 dds). A semeadura foi feita à lanço, em mistura com uma porção de solo 
retirada de cada subparcela. Esse material de solo foi colocado em saco plástico com capacidade de 50 L e deixado ao lado da subparcela, protegido da água da chuva e de irrigação, até a data da semeadura do tratamento. Na época da semeadura, adicionou-se à essa porção de solo, o triplo da quantidade necessária de semente da planta daninha para estabelecer as densidades desejadas de plantas. A seguir, os sacos plásticos foram agitados para distribuição uniforme das sementes na massa de solo. Esse material de solo, contendo sementes, foi então distribuído o mais uniformemente possivel na superficie do canteiro. Em cada época de semeadura, após essa operação, os canteiros foram irrigados para facilitar a germinação e garantir a sobrevivência das plântulas, pois as sementes estavam inseridas superficialmente no solo. Os dados de irrigação e precipitação pluvial são apresentados no Anexo P.

Para estabelecer o capim-marmelada na densidade desejada em cada tratamento de subparcela, fez-se a contagem de plantas na área toda da subparcela e, em seguida eliminou-se o excesso de plantas. Ao eliminar o excesso, procurou-se deixar a distribuição das plantas na área o mais uniforme possível. Para conseguir tal distribuição, a subparcela foi dividida em três seções transversais (Figura 16). Uma seção continha duas entre linhas e duas laterais que, em área, correspondiam à área uma entre linha, portanto, em área, uma seção era equivalente à área de três entrelinhas. O valor do excesso de plantas foi então dividido para as três seções transversais $(1 / 3)$ e novamente divido para três entrelinhas $(1 / 3 \div$ $3=1 / 9)$. De cada área de entre linha retirou-se $1 / 9$ do valor do excesso e, de cada lateral, metade desse valor.

O desbaste, nos tratamentos semeados oito dias antes da cultura e no mesmo dia da cultura, foi realizada 13 dias após a semeadura do feijão. Nos tratamentos em que o capim-marmelada foi 
semeado cinco e dez dias após a semeadura da cultura, o desbaste da planta daninha foi realizado 20 dias após a semeadura do feijão. Durante a condução do experimento, as demais plantas daninhas que eventualmente emergiram na área foram eliminadas manualmente.

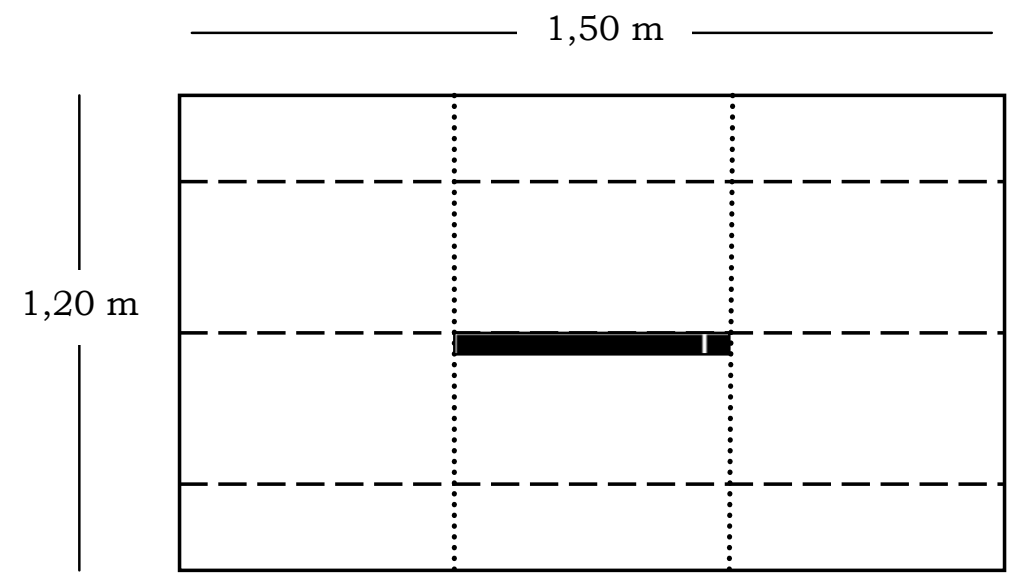

Figura 16 - Esquema de divisão da subparcela para facilitar o desbaste.

A ocorrência de chuvas impossibilitou o controle eficiente de doenças, tendo sido necessário antecipar a colheita do feijão, o que foi realizado quando a cultura encontrava-se no estádio de formação e enchimento dos grãos. A operação (13 a 16/01/2000) foi feita manualmente, colhendo-se um bloco ao dia, arrancando-se as plantas da linha central de cada subparcela. As vagens foram separadas e colocadas para secar em casa de vegetação. Após secas, os grãos foram separados para pesagem. 
A seqüência de atividades realizadas na condução do experimento é apresentada no Anexo Q.

\subsubsection{Avaliações e cálculos}

Foram avaliadas a área foliar média de uma planta de cada espécie e a porcentagem de solo coberto pelas plantas da cultura e da planta daninha e o rendimento de feijão em grãos. Exceto a última que foi feita à colheita, as outras foram realizadas, respectivamente, 21 e 23 dias após a semeadura do feijão, o que corresponde, na mesma ordem, a 15 e 17 dias após a emergência da cultura. Nessa época, as plantas de feijão estavam no estádio V3 (Dourado Neto \& Fancelli, 1997) e as de capimmarmelada, no estádio 12 ao 22 (Zadocks, et al., 1974).

A área foliar média de uma planta de cada espécie foi determinada a partir de duas plantas, colhidas na bordadura lateral das subparcelas, utilizando os folíolos das plantas de feijão sem o pecíolo e a lâmina das folhas da planta daninha sem a bainha. Para medir a área foliar foi utilizado um medidor de área foliar automático LICOR LI-300. Em cada tratamento, os valores de área foliar média de uma planta da cultura $\left(A F_{c}\right)$ e de uma da planta daninha $\left(A F_{p d}\right)$ foram utilizados para o cálculo dos valores de índice de área foliar $(I A F)$ de cada espécie:

$$
\begin{aligned}
& I A F_{c}=N_{c} \times A F_{c} \\
& I A F_{p d}=N_{p d} \times A F_{p d}
\end{aligned}
$$

O IAF é resultado da interação entre densidade de plantas $(N)$ e área foliar média de uma planta $(A F)$, ambas no momento da avaliação. Estes índices foram utilizados no cálculo da área foliar relativa da planta daninha $\left(F_{p d}\right)$ : 


$$
F_{p d}=\frac{I A F_{p d}}{I A F_{p d}+I A F_{c}}
$$

O índice de área foliar relativa da planta daninha $\left(F_{p d}\right)$, no momento da avaliação, é uma relação entre o índice de área foliar da planta daninha $\left(I A F_{p d}\right)$ e o índice de área foliar total proporcionado pela planta daninha e cultura.

A porcentagem de solo coberto pela parte aérea das plantas foi estimada visualmente por um único avaliador. Para cada tratamento de subparcela, estimou-se a porcentagem do total da área coberta pelas plantas da cultura $\left(C_{c}\right)$ e da planta daninha $\left(C_{p d}\right)$. Esses valores foram utilizados para calcular a cobertura relativa do solo pela planta daninha, $S_{p d}$, conforme Lotz et al. (1994):

$$
S_{p d}=\frac{C_{p d}}{C_{c}+C_{p d}}
$$

A partir do rendimento de feijão, em grãos $\left(\mathrm{kg} \cdot \mathrm{ha}^{-1}\right)$, calculouse a perda de rendimento relativo $(P R R)$ :

$$
P R R=\frac{R 0-R}{R 0}
$$

$R_{O}$ é o rendimento da cultura no tratamento mantido na ausência da planta daninha $\left(N_{p d}=0\right)$ e $R$, o rendimento da cultura quando na presença da planta daninha. 


\subsubsection{Modelos empíricos utilizados}

A perda estimada de rendimento relativo $(P R R)$ foi calculada com o uso de três modelos empíricos. Os valores de densidade da planta daninha $\left(N_{p d}\right)$ estabelecidos em cada tratamento foram utilizados no modelo sugerido por Spitters et al. (1989), cujo desenvolvimento matemático é melhor compreendido pela descrição apresentada por Kropff $\& \operatorname{Lotz}(1993)$ :

$$
P R R=\frac{a \times N_{p d}}{1+a \times N_{p d}}
$$

em que, a descreve a perda de rendimento causada pela adição da primeira planta daninha por $\mathrm{m}^{2}$. Uma vez que o índice de área foliar relativo da planta daninha reflete as diferenças de densidade da planta daninha e da época de sua emergência em relação à das plantas da cultura (Kropff \& Spitters, 1991), a perda de rendimento também foi predita com o uso do modelo proposto por esses autores:

$$
P R R=\frac{q \times F_{p d}}{1+(q-1) \times F_{p d}}
$$

$q$ é o coeficiente de dano relativo que considera o efeito de ambos, densidade e época relativa de emergência da planta daninha (Kropff \& Lotz, 1991). O uso da variável $F_{p d}$ envolve amostragens destrutivas e determinação trabalhosa da área foliar das plantas das espécies envolvidas. Lotz et al. (1992) demonstraram ser possível substituir $F_{p d}$ pela porcentagem de cobertura relativa do solo pela planta daninha $\left(S_{p d}\right)$ : 


$$
P R R=\frac{q \times S_{p d}}{1+(q-1) \times S_{p d}}
$$

sendo este, o terceiro modelo utilizado para predizer as perdas de rendimento.

\subsubsection{Estimativa dos coeficientes dos modelos empíricos}

Os coeficientes $a$ [eq. (28)] e $q$ [eq. (29) e eq. (30)] foram estimados, a partir dos dados observados no campo, com um método denominado "simplificado" e outro, "completo". Com o método simplificado (i) os modelos foram linearizados, utilizando-se o artifício de anamorfose; em seguida, (ii) obteve-se a equação da soma de quadrado de erros, (iii) fez-se a derivada de primeira ordem dessa equação em razão do coeficiente da equação linear (iv) igualou-se a derivada de primeira ordem a zero e (v) isolou-se o coeficiente para determinar o valor do mesmo que torna a soma de quadrado dos erros nula. A partir desse valor, estimou-se o coeficiente do modelo na forma de hipérbole (eq. 28, eq. 29 e eq. 30). Com o "método completo", o valor do coeficiente do modelo que torna a soma de quadrados nula foi calculado com o método de iterativo de NewtonRaphson, tomando-se como valor inicial do coeficiente do modelo, o valor obtido com o "método simplificado". Para os dois métodos, o ajuste dos dados ao modelo linearizado ou à hipérbole foi realizado com o programa Table Curve 2D Windows v2.03 (Jandel Scientific, AISN Software, 19891994).

Para os três modelos e os dois métodos de estimativa dos coeficientes, a média de rendimento de cada tratamento $\left(\overline{R_{i}}\right)$ foi calculada: 


$$
\bar{R} i=\frac{\sum_{i=1}^{n} R i}{N R}
$$

i a $n$ são os números dos tratamentos e $N R$, o número de repetições e, a perda relativa de rendimento observada em cada tratamento $\left(P R R_{i}\right)$ foi calculada rescrevendo-se a eq. (27) na forma:

$$
P R R i=\frac{\bar{R} 0-\bar{R} i}{\bar{R} 0}
$$

$R_{0}$ é a média de 12 valores de rendimento do tratamento mantido na ausência da planta daninha (quatro épocas de semeadura e três repetições).

\subsection{Modelo de densidade da planta daninha}

\subsection{Método simplificado}

O modelo da hipérbole da eq. (28) foi linearizado:

$$
\frac{1}{P R R}=\frac{1}{a} \times \frac{1}{N_{p d}}+1
$$

e escrito na forma:

$$
Y=A \times X+1
$$


Para cada valor observado $\left(Y_{i}\right)$ existe um desvio ou erro $(\varepsilon)$ em relação ao valor estimado $\left(\hat{Y}_{i}\right)$ :

$$
\begin{aligned}
& \varepsilon=Y_{i}-\hat{Y}_{i}, \text { ou } \\
& \varepsilon=Y_{i}-\left(A \times X_{i}+l\right)
\end{aligned}
$$

e a soma de quadrados dos erros:

$$
S Q E=\sum[Y i-(A \times X i+1)]^{2}
$$

O valor de $A$ que minimiza os erros foi determinado igualando a zero a primeira derivada da equação da $S Q E$ [eq. (36)] em razão de $A$ :

$$
\partial S Q E / \partial A=0
$$

e isolando o valor de $A$ :

$$
A=\frac{\sum_{i}^{n}\left(Y_{i} \times X_{i}\right)-\sum_{i}^{n} X_{i}}{\sum_{i}^{n}\left(X_{i}\right)^{2}}
$$

Da eq. (33) e eq. (34) nota-se que $Y=1 / P R R$ e $X=1 / N_{p d}$, portanto:

$$
A=\frac{\sum_{i}^{n}\left(\frac{1}{P R R i} \times \frac{1}{N_{p d i}}\right)-\sum_{i}^{n}\left(\frac{1}{N_{p d i}}\right)}{\sum_{i}^{n}\left(\frac{1}{N_{p d i}}\right)^{2}}
$$


$P R R_{i}$ são os valores obtidos com a eq. (32) e $N_{p d i}$, os valores de densidade da planta daninha estabelecidos em cada tratamento. Obtido o valor de $A$, calculou-se o valor de $a$, pois, da eq. (33) e eq. (34), $1 / a=A$, ou seja, $a=$ $1 / A$, que é o coeficiente do modelo da hipérbole de predição da perda relativa de rendimento em função da densidade da planta daninha [eq. (28)]. A descrição detalhada do procedimento com os dados originais é apresentada no Anexo R.

\subsection{Método completo}

Sendo a perda relativa de rendimento estimada pela eq. (28) rescrita na forma:

$$
P \hat{R} R i=\frac{a \times N_{p d i}}{1+a \times N_{p d i}}
$$

a equação da soma de quadrados dos erros entre valores observados $\left[P R R_{i}\right.$, eq. (32)] e estimados [eq. (40)] será:

$$
S Q E=\sum_{i=l}^{n}\left(P R R i-\frac{a \times N_{p d i}}{1+a \times N_{p d i}}\right)^{2}
$$

Para determinar o valor de a que minimiza a $S Q E$, utilizou-se o método iterativo de Newton-Raphson:

$$
a(k+1)=a_{k}-\frac{f\left(a_{k}\right)}{f^{\prime}\left(a_{k}\right)}
$$


$a_{(k+1)}$ é o valor de a que minimiza a $S Q E$ [eq. (41)]; $a_{k}$, o valor inicial atribuído à $a ; f\left(a_{k}\right)$, a derivada de primeira ordem da equação da $S Q E$ [eq. (41)] em razão de $a$ e, $f^{\prime}\left(a_{k}\right)$, a derivada primeira de $f\left(a_{k}\right)$ :

$$
\begin{aligned}
& f(a k)=\sum_{i=1}^{n}\left[\left(P R R_{i}-\frac{a_{k} \times N_{p d i}}{1+a_{k} \times N_{p d i}}\right) \times \frac{N_{p d i}}{\left(1+a k \times N_{p d i}\right)^{2}}\right] \\
& f^{\prime}\left(a_{k}\right)=-\frac{1}{2} \times \sum_{i=1}^{n} \frac{\left(N_{p d i}\right)^{2} \times\left[2+P R R i+a k N_{p d i}\left(P R R_{i}-1\right)\right]}{\left(1+a k \times N_{p d i}\right)^{4}}
\end{aligned}
$$

O valor $a_{k}$ atribuído como valor inicial de $a$ para as iterações foi o valor de a obtido com o "método simplificado". A descrição do procedimento com os dados originais é apresentada no Anexo S.

\subsection{Modelo de índice de área foliar relativa da planta daninha}

\subsection{Método simplificado}

Linearizando o modelo da hipérbole da eq. (29) obtém-se:

$$
\frac{1}{P R R}=\frac{1}{q} \times \frac{1}{F_{p d}}+\frac{1}{q} \times(q-1)
$$

Fazendo $1 / \mathrm{PRR}=\mathrm{Y}, 1 / \mathrm{q}=\mathrm{A}$ e, $1 / \mathrm{F}_{\mathrm{pd}}=\mathrm{X}$, a equação anterior pode ser escrita na forma:

$$
Y=A \times(X-1)+1
$$

Para cada valor observado $\left(Y_{i}\right)$ existe um desvio ou erro $(\varepsilon)$ em relação ao valor estimado $\left(\hat{Y}_{i}\right)$ : 


$$
\begin{aligned}
& \varepsilon=Y_{i}-\hat{Y}_{i} \text { ou } \\
& \varepsilon=Y_{i}-\left[A\left(X_{i}-1\right)+1\right]
\end{aligned}
$$

Então, a soma de quadrados dos erros será:

$$
S Q E=\Sigma\left\{Y_{i}-\left[\left(A \times\left(X_{i}-1\right)+1\right]\right\}^{2}\right.
$$

O valor de $A$ que minimiza o erro foi determinado igualando a zero a primeira derivada da equação da $S Q E$ [eq. (48)] em razão de $A$ :

$$
\partial S Q E / \partial A=0
$$

e isolando o valor de $A$ :

$$
A=\frac{\sum_{i}^{n}\left(Y_{i} \times X_{i}\right)-\sum_{i}^{n} Y_{i}-\sum_{i}^{n}\left(X_{i}-1\right)}{\sum_{i}^{n}\left(X_{i}\right)^{2}+2 X_{i}-1}
$$

podendo-se escrever:

$$
A=\frac{\sum_{i}^{n}\left(\frac{1}{P R R i} \cdot \frac{1}{F_{p d i}}\right)-\sum_{i}^{n}\left(\frac{1}{P R R i}\right)-\sum_{i}^{n}\left(\frac{1}{F_{p d i}}-1\right)}{\sum_{i}^{n}\left[\left(\frac{1}{F_{p d i}}\right)^{2}+\frac{2}{F_{p d i}}-1\right]}
$$

$P R R_{i}$ são os valores obtidos com a eq. (32) e $F_{p d i}$, os valores de $F_{p d}$ de cada tratamento $i$, calculado com a eq. (25). Obtido o valor de $A$, calculou-se o valor de $q$, pois, das eq. (45) e eq. (46), $1 / q=A$, ou seja, $q=1 / A$, que é o 
coeficiente de dano relativo do modelo da hipérbole de predição da perda relativa de rendimento em função do índice de área foliar relativa da planta daninha [eq. (29)]. A descrição do procedimento com os dados originais é apresentada no Anexo T.

\subsection{Método completo}

A perda relativa de rendimento sendo estimada pela eq. (29) rescrita na forma:

$$
P \hat{R} R_{i}=\frac{q \times F_{p d i}}{1+(q-1) \times F_{p d i}}
$$

a soma de quadrado dos erros entre valores observados [PRR , eq. (32)] e estimados [eq. (52)] será:

$$
S Q E=\sum_{i=l}^{n}\left(P R R i-\frac{q \times F_{p d i}}{1+(q-1) \times F_{p d i}}\right)^{2}
$$

Para determinar o valor de $q$ que minimiza a $S Q E$, utilizou-se o método iterativo de Newton-Raphson:

$$
q(k+1)=q_{k}-\frac{f(q k)}{f^{\prime}(q k)}
$$

$q_{(k+1)}$ é o valor de $q$ que minimiza a $S Q E$ [eq. (53)]; $\mathrm{q}_{k}$, o valor inicial atribuído à q; $f\left(q_{k}\right)$, a derivada primeira da equação da $S Q E$ (eq. 53) em razão de $q$ e $f^{\prime}\left(q_{k}\right)$, a derivada primeira de $f\left(q_{k}\right)$ : 


$$
\begin{aligned}
f(q k)= & \sum_{i=1}^{n} P R R i\left\{\frac{F_{p d i}{ }^{2}-F_{p d i}}{\left[1+(q k-1) \times F_{p d i}\right]^{2}}\right\}-q k \sum_{i=1}^{n} \frac{F_{p d i}{ }^{3}-F_{p d i}{ }^{2}}{\left.1+(q k-1) \times F_{p d i}\right]^{3}} \\
f^{\prime}(q k)= & \sum_{i=1}^{n} P R R i\left\{\frac{-2 \times\left(F_{p d i}{ }^{2}-F_{p d i}\right)\left[1+(q k-1) F_{p d i}\right] \times F_{p d i}}{\left[1+(q k-1) \times F_{p d i}\right]^{4}}\right\}+ \\
& (-1) \sum_{i=1}^{n} \frac{F_{p d i}{ }^{3}+F_{p d i}{ }^{2}}{\left[1+(q k-1) \times F_{p d i}\right]}+ \\
& (-q k) \sum \frac{-3 \times\left(F_{p d i}+F_{p d i}{ }^{2}\right)\left[1+(q-1) F_{p d i}\right]^{2} F_{p d i}}{\left[1+(q k-1) \times F_{p d i}\right]^{6}}
\end{aligned}
$$

O valor $q_{k}$ atribuído como valor inicial para as iterações foi o valor de $q$ obtido com o "método simplificado". A descrição do procedimento com os dados originais é apresentada no Anexo U.

\subsection{Modelo de cobertura relativa do solo pela planta daninha}

\subsection{Método simplificado}

O modelo da hipérbole que utiliza a cobertura relativa do solo pela planta daninha [eq. (30)] foi linearizado:

$$
\frac{1}{P R R}=\frac{1}{q} \times \frac{1}{S_{p d}}+\frac{1}{q} \times(q-1)
$$

Fazendo $1 / \mathrm{PRR}=\mathrm{Y}, 1 / \mathrm{q}=\mathrm{A}$ e, $1 / \mathrm{S}_{\mathrm{pd}}=\mathrm{X}$, a equação anterior pode ser escrita na forma da eq. (46). Calculando o erro conforme a eq. (47) e o valor de $A$ que minimiza o erro com as equações eq. (48) e eq. (50), pode-se substituir $F_{p d i}$ da eq. (51) por $S_{p d i}$ : 


$$
A=\frac{\sum_{i}^{n}\left(\frac{1}{P R R i} \times \frac{1}{S_{p d i}}\right)-\sum_{i}^{n}\left(\frac{1}{P R R_{i}}\right)-\sum_{i}^{n}\left(\frac{1}{S_{p d i}}-1\right)}{\sum_{i}^{n}\left[\left(\frac{1}{S_{p d i}}\right)^{2}+\frac{2}{S_{p d i}}-1\right]}
$$

$P R R_{i}$ são os valores obtidos com a eq. (32) e $S_{p d i}$, os valores de $\mathrm{S}_{p d}$ de cada tratamento $i$, calculado com a eq. (26). Obtido o valor de $A$, calculou-se o valor de $q$, pois, da eq. (45) e eq. (46), $1 / q=A$, ou seja, $q=1 / A$. Neste caso, $q$ é o coeficiente de dano relativo do modelo da hipérbole de predição da perda relativa de rendimento em função da cobertura relativa do solo pela planta daninha [eq. (30)]. A descrição do procedimento com os dados originais é apresentada no Anexo V.

\subsection{Método completo}

A perda relativa de rendimento sendo estimada pela eq. (30), rescrita na forma:

$$
P \hat{R} R i=\frac{q \times S p d i}{1+(q-1) \times S_{p d i}}
$$

a soma de quadrado dos erros entre valores observados [PRR estimados [eq. (59)] será:

$$
S Q E=\sum_{i=l}^{n}\left(P R R i-\frac{q \times S_{p d i}}{1+(q-1) \times S_{p d i}}\right)^{2}
$$

Para determinar o valor de $q$ que minimiza a $S Q E$, utilizou-se o método iterativo de Newton-Raphson [eq. (54)], sendo $q_{(k+1)}$, o valor de $q$ que 
minimiza a $S Q E$ [eq. (60)]; $\mathrm{q}_{k}$, o valor inicial atribuído à $q ; f\left(q_{k}\right)$ a derivada primeira da equação da $S Q E$ [eq. (60)] em razão de $q$ e $f^{\prime}\left(q_{k}\right)$, a derivada primeira de $f\left(q_{k}\right)$ :

$$
\begin{aligned}
f(q)= & \sum_{i=1}^{n}\left\{P R R i\left[\frac{S_{p d i}{ }^{2}-S_{p d i}}{\left[1+(q-1) \times S_{p d i}\right]^{2}}\right]\right\}-q \sum_{i=1}^{n} \frac{S_{p d i}{ }^{3}-S_{p d i}{ }^{2}}{\left.1+(q-1) \times S_{p d i}\right]^{3}} \\
f^{\prime}(q k)= & \sum_{i=1}^{n} P R R i\left\{\frac{-2 \times\left(S_{p d i}{ }^{2}-S_{p d i}\right)\left[1+(q k-1) S_{p d i}\right] \times S_{p d i}}{\left[1+(q k-1) \times S_{p d i}\right]^{4}}\right\}+ \\
& (-1) \sum_{i=1}^{n} \frac{S_{p d i}{ }^{3}+S_{p d i}{ }^{2}}{\left[1+(q k-1) \times S_{p d i}\right]}+ \\
& (-q k) \sum \frac{-3 \times\left(S_{p d i}+S_{p d i}{ }^{2}\right)\left[1+(q-1) S_{p d i}\right]^{2} S_{p d i}}{\left[1+(q k-1) \times S_{p d i}\right]^{6}}
\end{aligned}
$$

O valor $q_{k}$ atribuído como valor inicial para as iterações foi o valor de $q$ obtido com o "método simplificado". A descrição do procedimento com os dados originais é apresentada no Anexo X.

De forma semelhante a Dieleman et al. (1995), o teste de ajuste, subdividindo a soma de quadrados do resíduo em erro de ajuste e erro experimental puro, foi realizado apenas para o modelo de densidade (eq. 28) pois para o ajuste dos dados à esse modelo haviam quatro valores de perda relativa de rendimento da cultura $(P R R)$ para cada densidade da planta daninha estabelecida $\left(N_{p d}\right)$. Para a mesma densidade, cada um dos quatro valores de perda era resultado da média de três repetições de cada época de semeadura da planta daninha. Entretanto, para os modelos de indice de área foliar relativa da planta daninha $\left(F_{p d}\right)$ e cobertura relativa 
do solo pela planta daninha $\left(S_{p d}\right)$, havia apenas um valor de $P R R$, média de três repetições, para cada valor de $F_{p d}$ ou $S_{p d}$.

Para os três modelos, o ajuste dos dados, tanto pelo método simplificado quanto pelo completo, foi comparado pelo quadrado médio do resíduo $(Q M R)$ e pelo coeficiente de determinação $\left(\mathrm{r}^{2}\right)$. Quanto menor o $Q M R$ e maior o $\mathrm{r}^{2}$, melhor o ajuste dos dados.

\subsection{Resultados e Discussão}

\subsubsection{Métodos de ajuste dos dados}

Melhor ajuste dos dados foi observado com o método completo. Com esse método, para os três modelos, os valores de quadrado médio de resíduo (QMR) foram menores e os valores dos coeficientes de determinação $\left(\mathrm{r}^{2}\right)$ foram maiores que os obtidos com o método simplificado (Tabela 8). O resumo das análises de regressão de cada modelo é apresentado no Anexo $Z$.

Tabela 8. Quadrados médios dos resíduos (QMR) das regressões e coeficientes de determinação $\left(\mathrm{r}^{2}\right)$ de cada modelo.

\begin{tabular}{ccccccc}
\hline $\begin{array}{c}\text { Variável do } \\
\text { modelo }\end{array}$ & \multicolumn{2}{c}{ Método simplificado } & & \multicolumn{2}{c}{ Método completo } \\
\cline { 2 - 3 } \cline { 5 - 6 } \cline { 5 - 6 } & QMR & $\mathrm{r}^{2}$ & & QMR & $\mathrm{r}^{2}$ \\
\hline$N_{p d}$ [eq. (28)] & $11,9213 n s$ & 0,04 & & $0,0736 n s$ & 0,03 \\
$F_{p d}$ [eq. (29)] & $2,7402 * *$ & 0,78 & & $0,0140 * *$ & 0,82 \\
$S_{p d}$ [eq. (30)] & $3,1709 * *$ & 0,75 & & $0,0083 * *$ & 0,89 \\
\hline
\end{tabular}

$n s$ - não significativo pelo teste $\mathrm{F}$; ${ }^{*}$ - significativo pelo teste $\mathrm{F}(\mathrm{P}>0,01) ; N$ é a densidade; $F$, a área foliar relativa; $S$, a cobertura relativa do solo e o subscrito $p d$, planta daninha. 
O modelo de densidade não ajustou os dados (Tabela 8). Os valores de QMR e de $\mathrm{r}^{2}$ obtidos com os modelos de índice de área foliar relativa e de cobertura relativa do solo foram numericamente semelhantes (Tabela 8).

\subsubsection{Modelos empíricos}

\subsubsection{Modelo de densidade da planta daninha}

Com o modelo de densidade não foi possivel predizer as perdas de rendimento devido às diferentes épocas de semeadura (emergência) da planta daninha (Figura 17, Anexo Z). Entretanto, houve redução de perda relativa de rendimento de feijão com o atraso da semeadura (emergência) do capim-marmelada e aumento com o aumento da densidade de capim-marmelada (Figura 17.B e C). As maiores perdas ocorreram quando a planta daninha foi semeada oito dias antes da cultura e emergiram antes ou junto com ela e, as menores perdas, quando a planta daninha foi semeada 10 dias após a semeadura da cultura. Para essa última época de semeadura, as plantas de capim-marmelada foram sombreadas pelo fechamento da cultura antes que pudessem causar perdas no rendimento de grãos. Dieleman et al. (1995), ao descreverem o impacto das plantas de caruru (Amaranthus spp) sobre o rendimento da cultura de soja (Glycine max), observaram que a época relativa de emergência foi mais importante que a densidade. De maneira semelhante,

pode-se afirmar que para o feijão, o efeito da época relativa de emergência de capim-marmelada foi mais importante que o de sua densidade na redução de rendimento da cultura. 

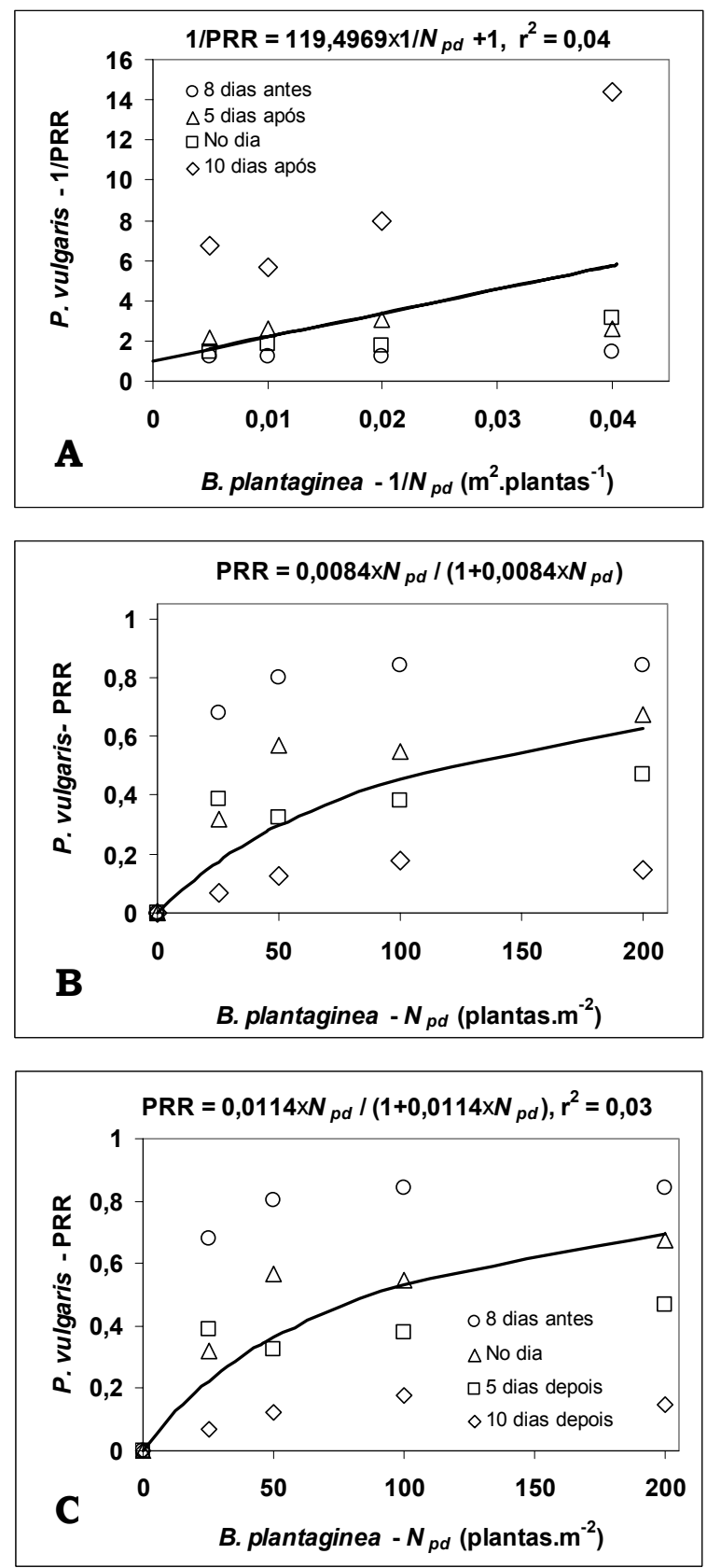

Figura 17 - (A e B) Método simplificado. (A) Linearização do modelo de densidade. O coeficiente angular da reta representa o valor inverso do coeficiente da hipérbole apresentada em (B). (C) Método completo. Os simbolos (valores observados) representam a média de três repetições e a linha (valores preditos), o ajuste dos dados ao modelo. 


\subsubsection{Modelo de índice de área foliar relativa da planta daninha}

O indice de área foliar relativa da planta daninha $\left(F_{p d}\right)$, avaliado 21 dias após a semeadura da cultura ${ }^{11}$, explicou as perdas de rendimento da mesma devido ao efeito combinado da densidade e época relativa de semeadura (emergência) do capim-marmelada (Figuras 18.B e C). Os valores de perda devido o aumento em $F_{p d}$, das quatro épocas de semeadura (emergência), ficaram distribuídos ao longo da curva de valores estimados pela regressão. Resultados semelhantes foram observados quando se avaliou o $F_{p d}$ de plantas de Ambrosia artemisiifolia que emergiram em duas épocas na cultura de feijão (Chikoye \& Swanton, 1995) e quando se avaliou o $F_{p d}$ de plantas de Amaranthus spp que emergiram em duas épocas na cultura de soja (Dieleman et al., 1995) e na cultura de milho (Knežević et al., 1995). Kropff \& Spitters (1991) derivaram o modelo de índice de área foliar relativa [eq. (29)] a partir do modelo de densidade [eq. (28)] e demonstraram que o modelo da eq. (29) predizia perdas devido à densidade e à época relativa de emergência da planta daninha, o que pode ser comprovado nos trabalhos de Dieleman et al. (1995) e Knežević et al. (1995). Quanto mais tarde foi realizada a semeadura da planta daninha, os valores de $F_{p d}$ do capim-marmelada foram menores e as perdas de rendimento do feijão também.

O valor estimado do coeficiente de dano relativo $(q)$ foi de 25,0627, obtido com o método simplificado (Figura 18.B) e de 6,2693, obtido com o método completo. Sendo $q>1$, a planta daninha foi um competidor mais forte que a cultura (Kropff e Spitters, 1991).

1115 dias após a emergência da cultura. 


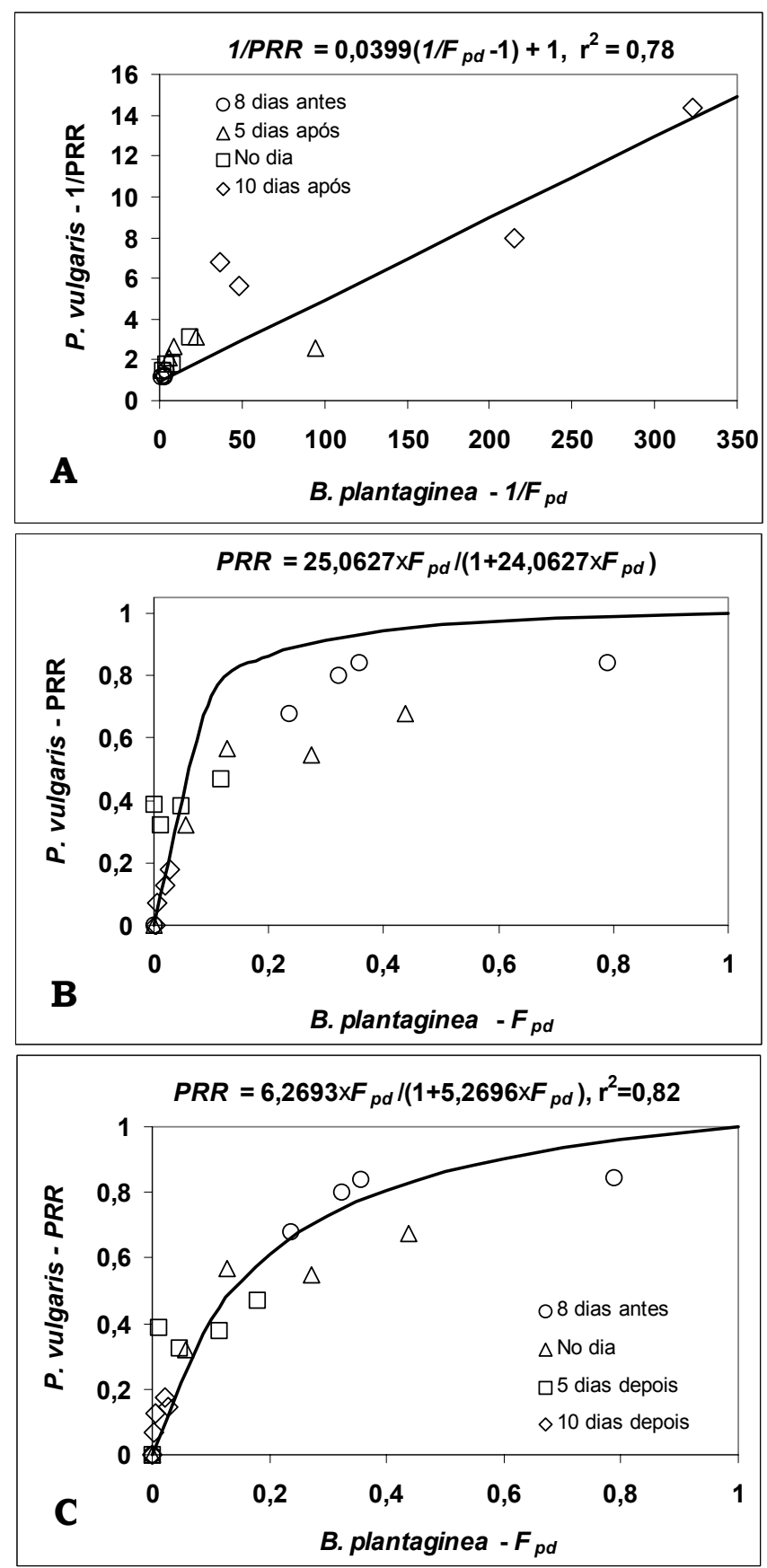

Figura 18 - (A e B) Método simplificado. (A) Linearização do modelo de indice relativo da área foliar. O coeficiente angular da reta representa o valor inverso do coeficiente da hipérbole apresentada em (B). (C) Método completo. Os simbolos (valores observados) representam a média de três repetições e a linha (valores preditos), o ajuste dos dados ao modelo. 


\subsubsection{Modelo de cobertura relativa do solo pela planta daninha}

A cobertura relativa do solo pela planta daninha $\left(S_{p d}\right)$ foi sugerida por vários autores como uma variável alternativa ao índice de área foliar relativa (Kropff \& Spitters, 1991; Lotz et al., 1992; Lotz et al., 1994; Florez et al., 1999 e Ngouajio et al., 1999). O ajuste dos dados obtido com modelo que utiliza $S_{p d}$ como variável [eq. (30]), Figura 19.B e C] foi semelhante ao obtido com o modelo que utiliza $F_{p d}$ como variável [eq. (29), Figura 18.B e C], o que é confirmado com os valores de QMR e $\mathrm{r}^{2}$ (Tabela 8) e com os valores do coeficiente de dano relativo (q) (Figuras 18 e 19 e Anexo Z). Lotz et al. (1992) consideraram que o modelo que utiliza $S_{p d}$ como variável ajustou bem os dados de perdas de rendimento da cultura de beterraba em competição com Chenopodium album L., explicando o efeito de plântulas dessa espécie que emergiram 1, 5 e 12 dias após a emergência da cultura $\left(\mathrm{r}^{2}=0,89\right)$. Florez et al. (1999) observaram que quando as plantas daninhas emergiram 15 dias após a emergência da

cultura de arroz, o ajuste dos dados obtido com o modelo que utiliza $S_{p d}$ como variável $\left(\mathrm{QMR}=72\right.$ e $\left.\mathrm{r}^{2}=0,90\right)$ foi semelhante ao obtido com o modelo que utiliza $F_{p d}$ como variável $\left(\mathrm{QMR}=90\right.$ e $\left.\mathrm{r}^{2}=0,86\right)$. A avaliação visual de $S_{p d}$ realizada por quatro individuos, separadamente, foi comparada à uma avaliação realizada com fotografias (Lutman et al., 1996). Os valores de perda de rendimento da cultura (Vicia faba) estimados com os valores das avaliações visuais de $S_{p d}$ foram semelhantes entre os quatro avaliadores $\left(\mathrm{r}^{2}\right.$ variou entre 0,78 e 0,83$)$ e semelhante aos obtidos com a avaliação por meio de fotos $\left(\mathrm{r}^{2}=0,87\right)$. Os autores observaram uma relação linear entre os dois tipos de avaliação, sendo o coeficiente angular da reta próximo da unidade. Isto indica que os valores de $S_{p d}$ estimados visualmente foram praticamente os mesmos valores encontrados com o método fotográfico. Lotz et al. (1994) observaram uma relação linear entre $F_{p d}$ e $S_{p d}$ avaliada visualmente com o auxílio de uma 

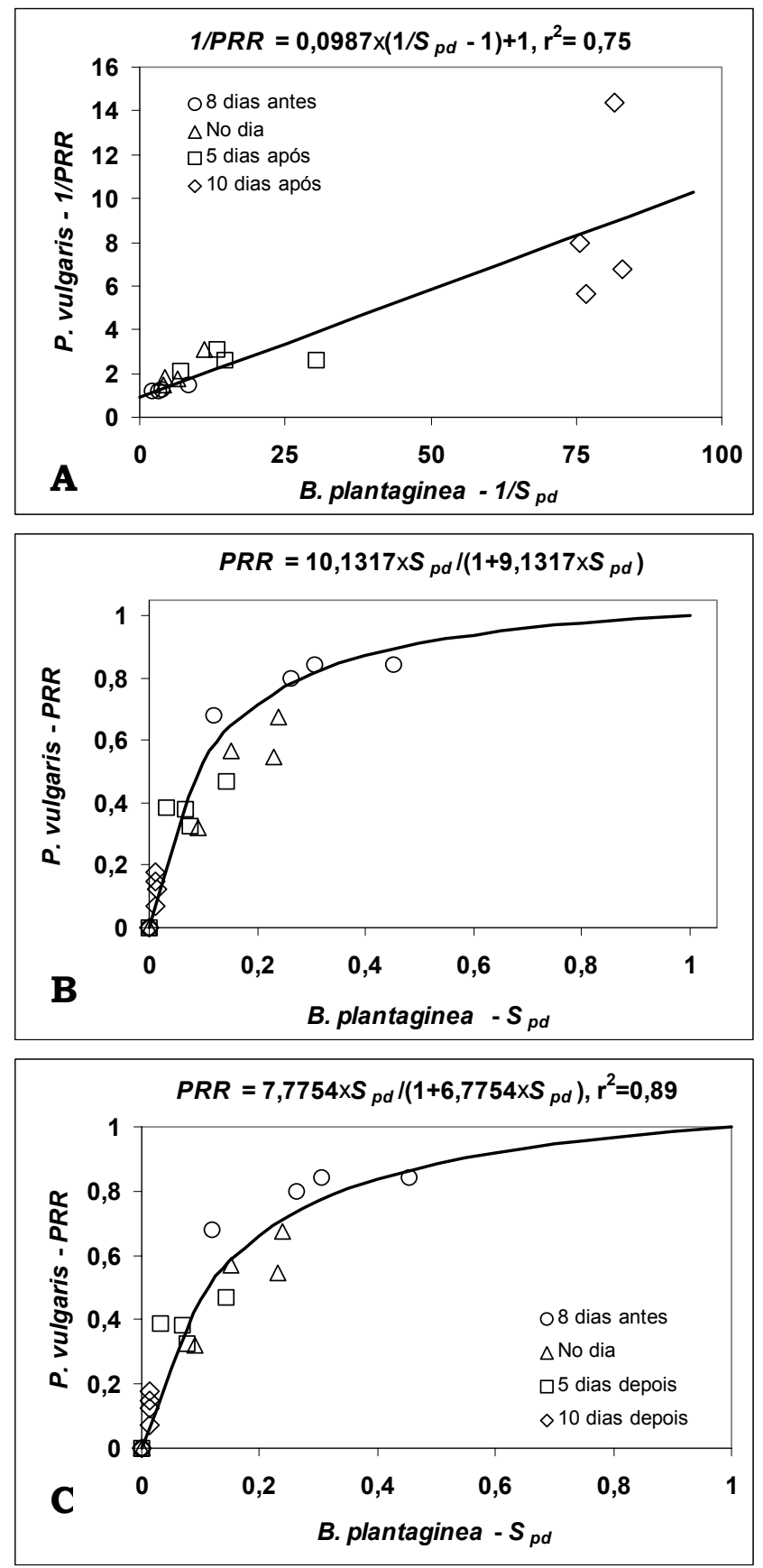

Figura 19 - (A e B) Método simplificado. (A) Linearização do modelo de cobertura relativa do solo. O coeficiente angular da reta representa o valor inverso do coeficiente da hipérbole apresentada em (B). (C) Método completo. Os simbolos (valores observados) representam a média de três repetições e a linha (valores preditos), o ajuste dos dados ao modelo. 
grade. Essa relação linear foi observada até três a quatro semanas após a emergência da cultura de trigo, para três espécies de plantas daninhas que apresentam formas distintas de crescimento: Chenopodium album, crescimento ereto, Stellaria media, crescimento prostrado e Polygonum persicaria, crescimento do tipo intermediário.

Considerando os três modelos, Florez et al. (1999) observaram resultados semelhantes para a cultura do arroz em competição com um conjunto de espécies de plantas daninhas. Isto é, o efeito das diferentes épocas de emergência da planta daninha não foi explicado com o modelo que tem a densidade como variável mas o foi com o modelo que tem como variável, o índice de área foliar relativa da planta daninha ou a cobertura relativa do solo pela planta daninha. Deve-se mencionar que os autores utilizaram, nos modelos, um parâmetro adicional que expressa a perda relativa máxima ${ }^{12}(\mathrm{~m})$ de rendimento, valor que corresponde à assíntota da hipérbole e que, a cobertura relativa do solo pela planta daninha não foi calculada pela razão entre as estimativas visuais de cobertura do solo pela planta daninha e de cobertura total de plantas mas estimada visualmente de uma só vez.

Analisando os resultados obtidos e comparando-os ao encontrado na literatura é possivel afirmar que é possivel substituir a variável $F_{p d}$ por $S_{p d}$, sendo esta avaliada visualmente. A vantagem da utilização de uma variável cuja avaliação possa ser realizada de forma rápida no campo e sem sofisticação seria a possibilidade de predição de perdas de rendimento da cultura por maior número de usuários.

$12 \mathrm{PRR}=\mathrm{a} \cdot \mathrm{Npd} /[1+(\mathrm{a} / \mathrm{m}) \cdot \mathrm{Npd} ; \mathrm{PRR}=\mathrm{q} \cdot \mathrm{Fpd} /\{1+[(\mathrm{q} / \mathrm{m})-1] \cdot \mathrm{Fpd}\}$ e $P R R=\mathrm{q} \cdot \mathrm{Spd} /\{1+[(\mathrm{q} / \mathrm{m})-1] \cdot \mathrm{Spd}\}$ 


\subsection{Conclusões}

a. Com o método completo, proposto para estimar os coeficientes dos modelos, obtém-se melhor predição de perdas de rendimento da cultura do que com o método simplificado.

b. O modelo cuja variável é a densidade da planta daninha não descreve a perda de rendimento da cultura causada pela época de semeadura da planta daninha mas aqueles cuja variável é o índice relativo da área foliar da planta daninha ou a cobertura relativa do solo pela planta daninha descrevem.

c. O efeito da época de emergência do capim-marmelada relativa à da cultura, sobre a perda de rendimento da cultura de feijão, é mais importante que o efeito da densidade do capim-marmelada.

d. A cobertura relativa do solo pela planta daninha, avaliada visualmente, é uma variável potencial para substituir o índice de área foliar relativa da planta daninha. 


\section{Conclusões}

Em casa de vegetação:

a. O feijão, como espécie competidora, é superior ao capim-marmelada

b. Há diferenciação parcial de nicho ecológico entre feijão e capimmarmelada, isto é, as espécies utilizam os mesmos recursos do meio mas o feijão evita a presença do capim-marmelada.

c. Há diferença entre o método qualitativo e quantitativo de análise de resultados de experimentos substitutivos, quanto à detectar o efeito da densidade de plantas.

d. Em experimentos com delineamento substitutivo, o efeito da densidade das plantas na competitividade relativa das espécies é detectada com a análise quantitativa dos dados.

Em campo:

a. Com o método completo, proposto para estimar os coeficientes dos modelos, obtém-se melhor predição de perdas de rendimento da cultura do que com o método simplificado.

b. O modelo cuja variável é a densidade da planta daninha não descreve a perda de rendimento da cultura causada pela época de semeadura da planta daninha mas aqueles cuja variável é o índice relativo da área foliar da planta daninha ou a cobertura relativa do solo pela planta daninha descrevem. 
c. O efeito da época de emergência do capim-marmelada relativa à da cultura, sobre a perda de rendimento da cultura de feijão, é mais importante que o efeito da densidade do capim-marmelada.

d. A cobertura relativa do solo pela planta daninha, avaliada visualmente, é uma variável potencial para substituir o índice de área foliar relativa da planta daninha. 
ANEXOS 
Anexo A - Produção final constante da cultura de feijão. Procedimento SAS para (i) análise da distribuição dos dados das médias da diferença entre a massa seca $(Y)$ e $Y_{\text {máx }}$ e (ii) determinar a densidade de plantas partir da qual a média da diferença torna-se igual a zero.

options ps=60;

Notas

data msf;

$\mathrm{msf}=$ massa seca feijão $\left(\mathrm{g} \cdot \mathrm{m}^{-2}\right)$

input d37 d74 d148 d297

Massa seca de feijão em cada densidade d

d595 d892 d1190 d2381;

$\mathrm{Ymax}=958.7728$

Produção máxima teórica

dif37 = d37 - Ymax;

$\operatorname{dif74}=\mathrm{d} 74$ - Ymax;

$\operatorname{dif} 148=\mathrm{d} 148-\mathrm{Ymax}$;

$\operatorname{dif} 297$ = d297 - Ymax;

dif595 = d595 - Ymax;

Diferença entre massa seca $(Y)$ e

dif892 = d892 - Ymax;

$\operatorname{dif} 1190=\mathrm{d} 1190-$ Ymax;

$\operatorname{dif} 2381=\mathrm{d} 2381$ - Ymax;

$Y_{\text {máx, }}$ em cada densidade (d)

cards;

massa seca de feijão (g.m-2)

$25.669642 .4107 \quad 102.6785135 .7886336 .3095392 .1131431 .5476656 .9900$

47.910764 .3601118 .3035154 .3898223 .2142348 .2142360 .8631628 .3482

$38.690463 .9881 \quad 77.3809140 .6250255 .5803297 .2470484 .3750629 .0900$

$35.714246 .5029 \quad 59.5238 \quad 182.6636256 .3244388 .7648473 .9583591 .8900$ ;

proc print data $=\mathrm{msf}$

proc univariate data $=\mathrm{msf}$ normal plot;

var dif37 -- dif2381;

run; 
Anexo B - Produção final constante de capim-marmelada. Procedimento SAS para (i) análise da distribuição dos dados das médias das diferenças entre a massa seca $(Y)$ e $Y_{\operatorname{máx}}$ e (ii) determinar a densidade de plantas partir da qual a média da diferença torna-se igual a zero.

options ps $=60$;

Notas

data $\mathrm{mscm}$; input d37 d74 d $148 \mathrm{~d} 297$ d595 d1190 d2381;

$\mathrm{Ymax}=117.1641$

dif37 = d37 - Ymax;

$\operatorname{dif74}=\mathrm{d} 74-$ Ymax;

$\operatorname{dif} 148=\mathrm{d} 148-$ Ymax;

dif297 = d297 - Ymax;

dif595 = d595 - Ymax;

$\operatorname{dif} 1190=\mathrm{d} 1190-\mathrm{Ymax} ;$

$\operatorname{dif} 2381=\mathrm{d} 2381$ - Ymax;

cards;

$\begin{array}{lllllll}9.3006 & 28.6458 & 35.7143 & 59.8958 & 79.2411 & 77.0089 & 102.679\end{array}$

$\begin{array}{lllllll}15.6250 & 22.3214 & 40.9226 & 72.9167 & 75.1488 & 88.5417 & 106.7708\end{array}$

$\begin{array}{lllllll}11.1607 & 15.2529 & 33.8542 & 31.9940 & 67.7083 & 85.5655 & 114.9554\end{array}$

$\begin{array}{lllllll}23.0655 & 15.6250 & 30.8779 & 68.0804 & 74.0327 & 92.6339 & 91.8898\end{array}$ $\mathrm{mscm}=$ massa seca capim-marmelada $\left(\mathrm{g} \cdot \mathrm{m}^{-2}\right)$

Massa seca de capim-marmelada em cada densidade $\mathrm{d}$ Produção teórica máxima (g.m²)

Diferença entre massa seca $(Y)$ e $Y_{\text {máx }}$, em cada densidade (d)

massa seca de capim-marmelada(g.m-2) ;

proc print data $=\mathrm{mscm}$;

proc univariate data $=\mathrm{mscm}$ normal plot;

var dif37 -- dif2381;

run; 
ANEXO C - Cálculo de espaçamento para as diferentes densidades totais de plantas, no experimento em séries substitutivas.

625 plantas

1 planta irá ocupar

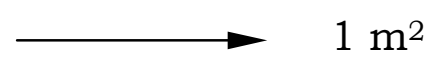

$0,0016 \mathrm{~m}^{2}$

ao espaçamento $X \times X=0,0016 \mathrm{~m}^{2} \Rightarrow X=\sqrt{ } 0,0016=0,040 \mathrm{~m}=4,0 \mathrm{~cm}$ então, o espaçamento foi estabelecido em 4,0 x 4,0 cm

Da mesma forma, a densidade total de 816 plantas.m-2 corresponde a 1 planta em $0,001225 \mathrm{~m}^{2}$ e o espaçamento entre plantas foi estabelecido em $3,5 \times 3,5 \mathrm{~cm}$ e, a densidade total de 1.111 plantas.m-2, corresponde a 1 planta em $0,00090 \mathrm{~m}^{2}$ e o espaçamento entre plantas foi estabelecido em 3,0 x 3,0 cm. 
ANEXO D - Análise qualitativa da competitividade entre feijão e capimmarmelada. Procedimento SAS de regressão linear e quadrática para cada espécie, em cada densidade total. ${ }^{13}$

data nome;

input niveis YR625F YR625B YR816F YR816B YR1111F $\quad$ YR1111B YRMF YRMB;

cards;

$\begin{array}{lllllllll}100 & 1 & 1 & 1 & 1 & 1 & 1 & 1 & 1 \\ 75 & 0.8159 & 0.4014 & 0.7238 & 0.7466 & 0.9007 & 0.3538 & 0.8135 & 0.5006 \\ 50 & 0.7298 & 0.2141 & 0.5002 & 0.2979 & 0.5323 & 0.2205 & 0.5874 & 0.2442 \\ 25 & 0.4197 & 0.0509 & 0.2759 & 0.1245 & 0.3189 & 0.0591 & 0.6727 & 0.0782 \\ 0 & 0 & 0 & 0 & 0 & 0 & 0 & 0 & 0\end{array}$

proc print; run;*impressão dos dados;

proc plot ;* gráfico de dispersão;

plot YR625F*niveis

YR625B*niveis

YR816F*niveis

YR816B*niveis

YR1111F*niveis

YR1111B*niveis

YRMF*niveis

YRMB*niveis

Notas
YR - produção relativa
625, 816 e 1111 - densidades totais
em no plantas.m-2
F - feijão
B - capim-marmelada

run;

proc reg; * regressão linear;

model YR625F -- YRMB = niveis $/ r$;

run;

proc glm ; *regressão quadrática;

model YR625F -- YRMB = niveis niveis*niveis /p;

run;

13 Os dados utilizados na análise foram digitados com 6 casas após a vírgula. 
ANEXO E - Análise qualitativa da séries substitutiva na densidade total de 625 plantas. $\mathrm{m}^{-2}$. Produção relativa $(Y r)$ de feijão e capimmarmelada em função das proporções $(75,50$ e $25 \%)$. Procedimento SAS para (i) analisar a distribuição dos dados das médias da diferença entre $Y r$ e a produção equivalente $(0,75 ; 0,50$ e 0,25$)$ e (ii) verificar se a média da diferença é igual a zero.

options ps=60;

Notas

data YRd625; input YrF75 YrF50 YrF25

YrB75 YrB50 YrB25;

Prop75 = 0.75;

Prop50 = 0.50;

Prop25 = 0.25;

difF75 = YrF75 - 0.75;

$\operatorname{difF} 50=$ YrF50 - 0.50;

$\operatorname{difF} 25=\mathrm{YrF} 25-0.25$

$\operatorname{difB75}=$ YrB75 -0.75 ;

$\operatorname{difB50}=$ YrB50 -0.50

$\operatorname{difB} 25=\mathrm{YrB} 25-0.25$

cards;

$\begin{array}{llll}0.834831 & 0.886516 & 0.404494\end{array}$

$\begin{array}{llll}0.687216 & 0.495920 & 0.293744\end{array}$

$\begin{array}{llll}1.018779 & 0.920187 & 0.377151 & 0 .\end{array}$

0.722891

0.616648

0.603504
Produção relativa na densidade de 625 plantas. $\mathrm{m}^{-2}$ Produção relativa em cada proporção F - Feijão, B - capim-marmelada

Proporção e competitividade equivalente

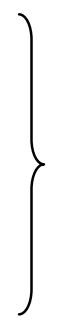

Diferença entre a produção relativa de massa seca e o valor correspondente à competitividade equivalente.

Produção relativa em cada proporção

;

proc print data $=$ YRd625;

proc univariate data $=$ YRd625 normal plot;

var difF75 -- difB25;

run; 
ANEXO F. Análise qualitativa da séries substitutiva na densidade total de 816 plantas. $\mathrm{m}^{-2}$. Produção relativa $(Y r)$ de feijão e capimmarmelada em função das proporções $(75,50$ e $25 \%)$. Procedimento SAS para (i) analisar a distribuição dos dados das médias da diferença entre $Y r$ e a produção equivalente $(0,75 ; 0,50$ e 0,25$)$ e (ii) verificar se a média da diferença é igual a zero.

options ps $=60$;

data YRd816; ; input YrF75 YrF50 YrF25

YrB75 YrB50 YrB25;

Prop75 = 0.75;

Prop50 = 0.50;

Prop25 = 0.25;

difF75 = YrF75 - 0.75;

$\operatorname{difF} 50=$ YrF50 - 0.50;

difF25 = YrF25 - 0.25;

$\operatorname{difB75}=$ YrB75 -0.75 ;

$\operatorname{difB50}=$ YrB50 - 0.50;

$\operatorname{difB} 25=$ YrB25 - 0.25;

cards;

0.825056

0.534988

0.711956

0.545652

0.787549

0.537549

0.570811

0.382556 ;

proc print data $=\mathrm{YRd} 816$;

proc univariate data $=$ YRd816 normal plot;

var difF75 -- difB25;

run;

$$
\}
$$

0.314130

\section{Notas}

Produção relativa na densidade de 816 plantas. $\mathrm{m}^{-2}$

Produção relativa em cada proporção F - feijão e B - capim-marmelada

Proporção e competitividade equivalente

Diferença entre a produção relativa de massa seca e o valor correspondente à competitividade equivalente.

Produção relativa

0.145833

0.084745

$0.802083 \quad 0.343750$

0.203389

0.096153

0.576923

0.173076

0.171428 
ANEXO G - Análise qualitativa da séries substitutiva na densidade total de 1111 plantas.m ${ }^{-2}$. Produção relativa $(Y r)$ de feijão e capim-marmelada em função das proporções $(75,50$ e $25 \%$ ). Procedimento SAS para (i) analisar a distribuição dos dados das médias da diferença entre $\mathrm{Yr}$ e a produção equivalente $(0,75 ; 0,50$ e 0,25$)$ e (ii) verificar se a média da diferença é igual a zero.

options ps=60;

Notas

data YRd1111; input YrF75 YrF50 YrF25

YrB75 YrB50 YrB25;

Prop75 = 0.75;

Prop50 = 0.50;

Prop25 = 0.25;

difF75 = YrF75 - 0.75;

$\operatorname{difF} 50=$ YrF50 - 0.50;

difF25 = YrF25 - 0.25;

$\operatorname{difB75}=$ YrB75 - 0.75;

$\operatorname{difB50}=$ YrB50 - 0.50;

$\operatorname{difB} 25=\mathrm{YrB} 25-0.25$;

cards;
0.707920
0.446369
0.166666
0.708506
0.624481
0.376556
0.260273
0.168949
0.091463
1.176548
0.636363
0.338603
0.317073
0.131707
0.045662
1.009845
0.421940
0.393811
0.411111
0.288888
0.043902
0.055555 ; proc print data $=$ YRd 1111 ;
proc univariate data=YRd1111 normal plot;
var difF75 -- difB25;
run;

0.426829

0.292682

proporção 
ANEXO H - Análise qualitativa da séries substitutiva (Média das três densidades totais). Produção relativa (Yr) de feijão e capim-marmelada em função das proporções $(75,50$ e 25\%). Procedimento SAS para (i) analisar a distribuição dos dados das médias da diferença entre $\mathrm{Yr}$ e a produção equivalente $(0,75 ; 0,50$ e 0,25$)$ e (ii) verificar se a média da diferença é igual a zero.

options ps=60;

Notas

data YRdM; input YrF75 YrF50 YrF25

YrB75 YrB50 YrB25;

Prop75 = 0.75;

Prop50 = 0.50;

Prop25 = 0.25;

$\operatorname{difF} 75=$ YrF75 - 0.75;

$\operatorname{difF} 50=$ YrF50 - 0.50;

$\operatorname{difF} 25=$ YrF25 - 0.25;

$\operatorname{difB75}=$ YrB75 -0.75 ;

$\operatorname{difB} 50=$ YrB50 -0.50

$\operatorname{difB} 25=\mathrm{YrB} 25-0.25$

cards;

$\begin{array}{llll}0.789269 & 0.622625 & 0.300620\end{array}$

Produção relativa - média das três densidades totais

0.702559

0.555351

0.328143

0.994292

0.698034

0.321259

0.767849

0.473715

0.402675

Produção relativa em cada proporção

Proporção e competitividade equivalente ;

proc print data $=$ YRdM;

proc univariate data $=$ YRdM normal plot;

var difF75 -- difB25;

run; 
Anexo I - Análise quantitativa pelo método do recíproco da produção por planta. Dados de feijão. Procedimento SAS da análise de regressão múltipla eliminando os tratamentos em que não haviam plantas de feijão.

options nodate;

Notas

data invmsf;

input nc npd invf;

cards;

$\begin{array}{lcl}625 & 0 & 1.876179719 \\ 468.75 & 156.25 & 1.714921818 \\ 312.5 & 312.5 & 1.314491979 \\ 156.25 & 468.75 & 1.182845716 \\ 816 & 0 & 1.626929938 \\ 612 & 204 & 1.698681319 \\ 408 & 408 & 1.583028222 \\ 204 & 612 & 1.49556013 \\ 1111 & 0 & 2.042036769 \\ 833.25 & 277.75 & 1.542662549 \\ 555.5 & 555.5 & 1.782657022 \\ 277.75 & 833.25 & 1.516779514\end{array}$

proc reg;

model onvf $=\mathrm{nc} \mathrm{npd} / \mathrm{p} \mathrm{r}$;

output out=novo $\mathrm{r}=$ res $\mathrm{p}=$ pre student $=\mathrm{stu}$;

run; 
Anexo J - Análise quantitativa pelo método do recíproco da produção por planta. Dados de capim-marmelada. Procedimento SAS da análise de regressão múltipla eliminando os tratamentos em que não haviam plantas de capim-marmelada.

options nodate;

\section{Notas}

data invmscm;

input nc npd invem; cards;

$\begin{array}{lllr}468.75 & 156.25 & 41.03535354 & \text { capim-marmelada } \\ 312.5 & 312.5 & 21.10261005 & \mathrm{nc}=\text { densidade da } \\ 156.25 & 468.75 & 15.01331241 & \text { cultura } \\ 0 & 625 & 8.04815891 & \mathrm{npd}=\text { densidade } \\ 612 & 204 & 35.47619048 & \text { da planta daninha } \\ 408 & 408 & 31.56565657 & \\ 204 & 612 & 17.60651114 & \\ \quad 0 & 816 & 17.11693674 & \\ 833.25 & 277.75 & 37.77777778 & \\ 555.5 & 555.5 & 20.82563333 & \\ 277.75 & 833.25 & 18.21831085 & \\ \quad & \end{array}$

invmscm = inverso da produção de massa seca/planta de capim-marmelada dade da 5.01331241 8.04815891 35.47619048 31.56565657 17.60651114 17.11693674 37.77777778 555.5 555.5 18.21831085

proc reg;

model ymed $=\mathrm{nc} \mathrm{nw} / \mathrm{p}$ r; run; 
ANEXO L - Resumo das análises de regressão da produção relativa de massa seca das espécies em função da proporção entre plantas. Série substitutiva na densidade total de 625 plantas. $\mathrm{m}^{-2}$. (n)

\begin{tabular}{|c|c|c|c|c|c|c|}
\hline Fonte & \multicolumn{3}{|c|}{ Modelo linear } & \multicolumn{3}{|c|}{ Modelo quadrático } \\
\hline \multicolumn{7}{|c|}{ Phaseolus vulgaris } \\
\hline & GL & QM & $\operatorname{Pr}>F^{a}$ & GL & $\mathrm{QM}$ & $\operatorname{Pr}>\mathrm{F}$ \\
\hline Modelo & 1 & 0,57418 & 0,0076 & 2 & 0,304355 & 0,0114 \\
\hline Erro & 3 & 0,01385 & & 2 & 0,003514 & \\
\hline $\mathrm{CV} \%$ & \multicolumn{3}{|c|}{19,84} & \multicolumn{3}{|c|}{9,995353} \\
\hline $\mathrm{R}^{2}$ & \multicolumn{3}{|c|}{0,9325} & \multicolumn{3}{|c|}{0,988585} \\
\hline & Coeficiente & Erro & Prob $>|\mathrm{T}|^{\mathrm{d}}$ & Coeficiente & Erro & Prob $>|T|$ \\
\hline Inters. & 0,113853 & 0,091169 & 0,3003 & 0,014526 & 0,055791 & 0,8189 \\
\hline Var. $\mathrm{X}$ & 0,009585 & 0,001488 & 0,0076 & 0,017531 & 0,002643 & 0,0220 \\
\hline Var. $X^{2}$ & - & - & - & $-0,00008$ & 0,00003 & 0,0885 \\
\hline \multicolumn{7}{|c|}{ Brachiaria plantaginea } \\
\hline & GL & QM & $\operatorname{Pr}>\mathrm{F}$ & GL & $\mathrm{QM}$ & $\operatorname{Pr}>\mathrm{F}$ \\
\hline Modelo & 1 & 0,55248 & 0,0273 & 2 & 0,320999 & 0,0186 \\
\hline Erro & 3 & 0,03390 & & 2 & 0,006082 & \\
\hline $\mathrm{CV} \%$ & \multicolumn{3}{|c|}{55,23973} & \multicolumn{3}{|c|}{23,40007} \\
\hline $\mathrm{R}^{2}$ & \multicolumn{3}{|c|}{0,8446} & \multicolumn{3}{|c|}{0,981404} \\
\hline & Coeficiente & Erro & Probs $>|\mathrm{T}|$ & Coeficiente & Erro & Prob>iTi \\
\hline Inters. & $-0,136811$ & 0,142608 & 0,4082 & 0,023118 & 0,073397 & 0,7826 \\
\hline Var. X & 0,009402 & 0,002329 & 0,0273 & $-0,00339$ & 0,003478 & 0,4322 \\
\hline Var. $X^{2}$ & - & - & - & 0,000128 & 0,000033 & 0,0317 \\
\hline
\end{tabular}

1. 16 planta por vaso ao espaçamento de $4,0 \times 4,0 \mathrm{~cm}$. 
ANEXO M - Resumo das análises de regressão da produção relativa de massa seca das espécies em função da proporção entre plantas. Série substitutiva na densidade total de 816 plantas. $\mathrm{m}^{-2}$. (o)

\begin{tabular}{|c|c|c|c|c|c|c|}
\hline Fonte & \multicolumn{3}{|c|}{ Modelo linear } & \multicolumn{3}{|c|}{ Modelo quadrático } \\
\hline \multicolumn{7}{|c|}{ Phaseolus vulgaris } \\
\hline & GL & QM & $\operatorname{Pr}>F^{a}$ & GL & QM & $\operatorname{Pr}>F$ \\
\hline Modelo & 1 & 0,59925 & 0,0001 & 2 & 0,299623 & 0,0018 \\
\hline Erro & 3 & 0,00036 & & 2 & 0,000541 & \\
\hline $\mathrm{CV} \%$ & \multicolumn{3}{|c|}{3,80122} & \multicolumn{3}{|c|}{4,655522} \\
\hline $\mathrm{R}^{2}$ & \multicolumn{3}{|c|}{0,9982} & \multicolumn{3}{|c|}{0,998195} \\
\hline & Coeficiente & Erro & Prob> $|\mathrm{T}| \mathrm{d}$ & Coeficiente & Erro & Prob $>|\mathrm{T}|$ \\
\hline Inters. & 0,010393 & 0,014721 & 0,5311 & 0,010378 & 0,021906 & 0,6824 \\
\hline Var. $\mathrm{X}$ & 0,009792 & 0,000240 & 0,0001 & 0,009793 & 0,001038 & 0,0110 \\
\hline Var. $\mathrm{X}^{2}$ & - & - & - & $-1,2.10^{-8}$ & $1,0.10^{-5}$ & 0,991 \\
\hline \multicolumn{7}{|c|}{ Brachiaria plantaginea } \\
\hline & GL & QM & $\operatorname{Pr}>F$ & GL & $\mathrm{QM}$ & $\operatorname{Pr}>F$ \\
\hline Modelo & 1 & 0,68750 & 0,0043 & 2 & 0,353900 & 0,0179 \\
\hline Erro & 3 & 0,01106 & & 2 & 0,006448 & \\
\hline $\mathrm{CV} \%$ & \multicolumn{3}{|c|}{24,24767} & \multicolumn{3}{|c|}{18,51027} \\
\hline $\mathrm{R}^{2}$ & \multicolumn{3}{|c|}{0,9539} & \multicolumn{3}{|c|}{0,982107} \\
\hline & Coeficiente & Erro & Prob $>|\mathrm{T}|$ & Coeficiente & Erro & Prob $>|\mathrm{T}|$ \\
\hline Inters. & $-0,090602$ & 0,081477 & 0,3472 & $-0,01445$ & 0,075571 & 0,8660 \\
\hline Var. X & 0,010488 & 0,001331 & 0,0043 & 0,004396 & 0,003581 & 0,3445 \\
\hline Var. $X^{2}$ & - & - & - & 0,000061 & 0,000034 & 0,2180 \\
\hline
\end{tabular}

m. 16 plantas por vaso ao espaçamento de $3,5 \times 3,5 \mathrm{~cm}$. 
ANEXO N - Resumo das análises de regressão da produção relativa de massa seca das espécies em função da proporção entre plantas. Série substitutiva na densidade total de 1111 plantas. $\mathrm{m}^{-2}$. (p)

\begin{tabular}{|c|c|c|c|c|c|c|}
\hline Fonte & \multicolumn{3}{|c|}{ Modelo linear } & \multicolumn{3}{|c|}{ Modelo quadrático } \\
\hline \multicolumn{7}{|c|}{ Phaseolus vulgaris } \\
\hline & GL & QM & $\operatorname{Pr}>\mathrm{F}$ a & GL & QM & $\operatorname{Pr}>\mathrm{F}$ \\
\hline Modelo & 1 & 0,66657 & 0,0014 & 2 & 0,336168 & 0,0138 \\
\hline Erro & 3 & 0,00505 & & 2 & 0,004687 & \\
\hline CV\% & & 12,90869 & & & 12,43906 & \\
\hline $\mathrm{R}^{2}$ & & 0,9778 & & & 0,976249 & \\
\hline & Coeficiente & Erro & Prob $>|\mathrm{T}|^{\mathrm{d}}$ & Coeficiente & Erro & Prob $>|\mathrm{T}|$ \\
\hline Inters. & 0,034021 & 0,055033 & 0,5802 & $-0,00658$ & 0,064431 & 0,9280 \\
\hline Var. X & 0,010327 & 0,000898 & 0,0014 & 0,013575 & 0,003053 & 0,0470 \\
\hline Var. $\mathrm{X}^{2}$ & - & - & - & $-0,00003$ & 0,000029 & 0,3828 \\
\hline \multicolumn{7}{|c|}{ Brachiaria plantaginea } \\
\hline & GL & QM & $\operatorname{Pr}>\mathrm{F}$ & GL & $\mathrm{QM}$ & $\operatorname{Pr}>F$ \\
\hline Modelo & 1 & 0,52655 & 0,0349 & 2 & 0,310174 & 0,0362 \\
\hline Erro & 3 & 0,03903 & & 2 & 0,011652 & \\
\hline $\mathrm{CV} \%$ & & 60,4730 & & & 33,0406 & \\
\hline $\mathrm{R}^{2}$ & & 0,8181 & & & 0,963794 & \\
\hline & Coeficiente & Erro & Prob $>|\mathrm{T}|$ & Coeficiente & Erro & Prob $>|\mathrm{T}|$ \\
\hline Inters. & $-0,132231$ & 0,153035 & 0,4511 & 0,031472 & 0,101589 & 0,7860 \\
\hline Var. X & 0,009179 & 0,002499 & 0,0349 & $-0,00392$ & 0,004814 & 0,5012 \\
\hline Var. $\mathrm{X}^{2}$ & - & - & - & 0,000131 & 0,000046 & 0,1050 \\
\hline
\end{tabular}

p. 16 plantas por vaso ao espaçamento de $3,0 \times 3,0 \mathrm{~cm}$. 
ANEXO O - Resumo das análises de regressão da produção relativa de massa seca das espécies em função da proporção entre plantas. Média das três densidades totais.

\begin{tabular}{|c|c|c|c|c|c|c|}
\hline Fonte & \multicolumn{3}{|c|}{ Modelo linear } & \multicolumn{3}{|c|}{ Modelo quadrático } \\
\hline \multicolumn{7}{|c|}{ Phaseolus vulgaris } \\
\hline & GL & $\mathrm{QM}$ & $\operatorname{Pr}>F^{a}$ & GL & QM & $\operatorname{Pr}>\mathrm{F}$ \\
\hline Modelo & 1 & 0,61272 & 0,0006 & 2 & 0,310168 & 0,0005 \\
\hline Erro & 3 & 0,00265 & & 2 & 0,000169 & \\
\hline $\mathrm{CV} \%$ & \multicolumn{3}{|c|}{9,40027} & \multicolumn{3}{|c|}{2,379777} \\
\hline $\mathrm{R}^{2}$ & \multicolumn{3}{|c|}{0,9872} & \multicolumn{3}{|c|}{0,999452} \\
\hline & Coeficiente & Erro & Prob $>|\mathrm{T}|^{\mathrm{d}}$ & Coeficiente & Erro & Prob> $|\mathrm{T}|$ \\
\hline Inters. & 0,052756 & 0,039889 & 0,2778 & 0,006109 & 0,012269 & 0,6679 \\
\hline Var. X & 0,009901 & 0,000651 & 0,0006 & 0,013633 & 0,000581 & 0,0018 \\
\hline Var. $\mathrm{X}^{2}$ & - & - & - & $-3,7.10^{-5}$ & 0,000005 & 0,0216 \\
\hline \multicolumn{7}{|c|}{ Brachiaria plantaginea } \\
\hline & GL & QM & $\operatorname{Pr}>\mathrm{F}$ & GL & QM & $\operatorname{Pr}>\mathrm{F}$ \\
\hline Modelo & 1 & 0,58680 & 0,0138 & 2 & 0,324478 & 0,0042 \\
\hline Erro & 3 & 0,02163 & & 2 & 0,001365 & \\
\hline $\mathrm{CV} \%$ & \multicolumn{3}{|c|}{40,33641} & \multicolumn{3}{|c|}{10,13260} \\
\hline $\mathrm{R}^{2}$ & \multicolumn{3}{|c|}{0,9004} & \multicolumn{3}{|c|}{0,995811} \\
\hline & Coeficiente & Erro & Prob> $|\mathrm{T}|$ & Coeficiente & Erro & Prob $>|\mathrm{T}|$ \\
\hline Inters. & $-0,119881$ & 0,113916 & 0,3699 & 0,013381 & 0,034768 & 0,7374 \\
\hline Var. $\mathrm{X}$ & 0,009690 & 0,001860 & 0,0138 & $-0,00097$ & 0,001647 & 0,6152 \\
\hline Var. $X^{2}$ & - & - & - & 0,000106 & 0,000016 & 0,0213 \\
\hline
\end{tabular}


Anexo P. Irrigação e precipitação pluvial (mm) (1999/2000). ${ }^{14}$

\begin{tabular}{|ccc|ccc|ccc|}
\hline $\begin{array}{c}\text { Data } \\
(1999)\end{array}$ & $\begin{array}{c}\text { Irriga- } \\
\text { ção }\end{array}$ & $\begin{array}{c}\text { Preci- } \\
\text { pitação }\end{array}$ & $\begin{array}{c}\text { Data } \\
(1999)\end{array}$ & $\begin{array}{c}\text { Irriga- } \\
\text { ção }\end{array}$ & $\begin{array}{c}\text { Preci- } \\
\text { pitação }\end{array}$ & $\begin{array}{c}\text { Data } \\
(1999 / \\
2000)\end{array}$ & $\begin{array}{c}\text { Irriga } \\
\text { ção }\end{array}$ & $\begin{array}{c}\text { Preci- } \\
\text { pitação }\end{array}$ \\
\hline $07 / 10$ & - & 11,0 & $19 / 11$ & 6 & - & $20 / 12$ & 12 & \\
$16 / 10$ & - & 1,1 & $20 / 11$ & - & 6,3 & $22 / 12$ & - & 45,5 \\
$17 / 10$ & - & 10,4 & $22 / 11$ & - & 0,9 & $24 / 12$ & - & 12,7 \\
$22 / 10$ & - & 3,4 & $23 / 11$ & - & 6,6 & $25 / 12$ & - & 0,8 \\
$26 / 10$ & 6 & - & $24 / 11$ & - & 0,7 & $27 / 12$ & - & 28,2 \\
$27 / 10$ & - & 2,6 & $25 / 11$ & 3 & 5,0 & $30 / 12$ & 12 & - \\
$29 / 10$ & 6 & - & $26 / 11$ & - & 6,4 & $31 / 12$ & - & 7,9 \\
$31 / 10$ & 6 & - & $27 / 11$ & 6 & - & $01 / 01$ & - & 21,90 \\
$03 / 11$ & 12 & - & $28 / 11$ & 6 & - & $02 / 01$ & - & 31,10 \\
$04 / 11$ & 6 & 4,4 & $30 / 11$ & 6 & - & $03 / 01$ & - & 6,60 \\
$05 / 11$ & - & 4,6 & $01 / 12$ & 6 & - & $04 / 01$ & - & 3,00 \\
$07 / 11$ & 6 & - & $03 / 12$ & 6 & 13 & $05 / 01$ & - & 0,90 \\
$08 / 11$ & 6 & 0,2 & $04 / 12$ & - & 7,3 & $06 / 01$ & - & 6,20 \\
$09 / 11$ & 6 & 1,2 & $06 / 12$ & - & 10,5 & $07 / 01$ & - & 71,60 \\
$10 / 11$ & - & 0,5 & $07 / 12$ & - & 48,2 & $11 / 01$ & - & 21,60 \\
$11 / 11$ & - & 2,6 & $08 / 12$ & - & 8,9 & $12 / 01$ & - & 0,20 \\
$12 / 11$ & - & 12,7 & $10 / 12$ & - & 39,6 & $13 / 01$ & - & 4,90 \\
$16 / 11$ & 18 & - & $13 / 12$ & - & 44,7 & $14 / 01$ & - & 10,40 \\
$17 / 11$ & 3 & - & $14 / 12$ & - & 2,3 & $15 / 01$ & - & 0,70 \\
$18 / 11$ & 6 & - & $17 / 12$ & 3 & - & $16 / 01$ & - & 4,80 \\
\hline
\end{tabular}

14 Base de Dados do Posto Agrometeorológico do Departamento de Ciências Exatas ESALQ-USP-Piracicaba-SP (http://www.ciagri.usp.br/ emdabreu/ROB99.TXT e (http://www.ciagri.usp.br/ emdabreu/DCE2000.TXT) 
Anexo Q. Principais atividades desenvolvidas.

\begin{tabular}{|c|c|}
\hline Data & Atividades \\
\hline $16 / 09 / 99$ & Pulverização de glyphosate (540 g.ha-1) \\
\hline $01 / 10 / 99$ & Pulverização de glyphosate (540 g.ha-1) \\
\hline $08 / 10 / 99$ & Preparo do solo com encanteiradora \\
\hline $14 / 10 / 99$ & $\begin{array}{l}\text { Irrigação dos canteiros para forçar a germinação de sementes de } \\
\text { plantas daninhas }\end{array}$ \\
\hline $19 / 10 / 99$ & $\begin{array}{l}\text { Aplicação de brometo de metila na dosagem de } 50 \mathrm{~cm}^{3} \text { do gás. } \mathrm{m}^{-2} \\
\text { de canteiro com } 0,030 \mathrm{~m} \text { de profundidade. }\end{array}$ \\
\hline $22 / 10 / 99$ & Retirada do plástico para liberação do gás \\
\hline 26/10/99 & Semeadura da B. plantaginea, 8 das do feijão; irrigação \\
\hline $03 / 11 / 99$ & Semeadura do feijão e de $B$. plantaginea, dia 0 ; irrigação \\
\hline $08 / 11 / 99$ & Semeadura B. plantaginea, 5 das do feijão; irrigação \\
\hline $12 / 11 / 99$ & Semeadura B. plantaginea, 10 das do feijão; irrigação \\
\hline $16 / 11 / 99$ & $\begin{array}{l}\text { Avaliação de densidade e desbaste de } B \text {. plantaginea nos } \\
\text { tratamentos } 8 \text { das e dia } 0 \text {. }\end{array}$ \\
\hline $17 / 11 / 99$ & $\begin{array}{l}\text { Desbaste do feijão para } 10 \text { plantas. } m^{-1} \text { linear; irrigação; } \\
\text { pulverização com Nuvacron para controle de cigarrinha }\end{array}$ \\
\hline $19 / 11 / 99$ & Adubação de cobertura ( $40 \mathrm{~kg} \cdot \mathrm{ha}^{-1}$ de N) com Sulfato de amônio \\
\hline $23 / 11 / 99$ & $\begin{array}{l}\text { Avaliação de densidade e desbaste de } B \text {. plantaginea nos } \\
\text { tratamentos } 5 \text { e } 10 \text { das. }\end{array}$ \\
\hline 24/11/99 & Avaliação da área foliar \\
\hline $26 / 11 / 99$ & Avaliação de cobertura foliar pela cultura e planta daninha. \\
\hline $30 / 11 / 99$ & Pulverização de monocrotophos para controle de pulgão. \\
\hline $16 / 12 / 99$ & $\begin{array}{l}\text { Pulverização de mancozeb }+ \text { oxicloreto de cobre para controle de } \\
\text { mancha angular, ferrugem e preventivo para antracnose }\end{array}$ \\
\hline $07 / 01 / 00$ & $\begin{array}{l}\text { Pulverização de Amistar }+ \text { benomyl }+ \text { monocrotophos }+ \\
\text { adjuvante, para controlar antracnose, ferrugem, mancha } \\
\text { angular, pulgão e ácaro. }\end{array}$ \\
\hline $11 / 01 / 00$ & Pulverização de monocrotophos para controle de ácaros. \\
\hline $\begin{array}{c}13 \mathrm{a} \\
16 / 01 / 00\end{array}$ & Colheita do feijão \\
\hline
\end{tabular}


Anexo R. Dados utilizados no cálculo do coeficiente $a$ do modelo de densidade [eq. (28)]. "Método simplificado". ${ }^{15}$

\begin{tabular}{cccccccc}
\hline $\mathrm{N}^{\circ}$ Trat & Época ${ }^{16}$ & $N_{p d i}$ & $P R R_{i}$ & $1 / P R R_{i}$ & $1 / N_{p d i}$ & $\begin{array}{c}1 / P R R_{i} \\
\mathrm{x} \\
1 / N_{p d i}\end{array}$ & $\left(1 / N_{p d i}\right)^{2}$ \\
\hline 1 & & & & & \multicolumn{4}{c}{} \\
\hline 2 & 8 das & 25 & 0,67927 & 1,47217 & 0,04 & 0,05889 & 0,00160 \\
3 & 8 das & 100 & 0,84063 & 1,18958 & 0,01 & 0,01190 & 0,00010 \\
4 & 8 das & 200 & 0,84271 & 1,18665 & 0,005 & 0,00593 & 0,000025 \\
5 & No dia & 25 & 0,31931 & 3,13176 & 0,04 & 0,12527 & 0,00160 \\
6 & No dia & 50 & 0,56750 & 1,76213 & 0,02 & 0,03524 & 0,00040 \\
7 & No dia & 100 & 0,54626 & 1,83065 & 0,01 & 0,01830 & 0,00010 \\
8 & No dia & 200 & 0,67568 & 1,48000 & 0,005 & 0,00740 & 0,000025 \\
9 & 5 dds & 25 & 0,38694 & 2,58440 & 0,04 & 0,10338 & 0,00160 \\
10 & 5 dds & 50 & 0,32364 & 3,08983 & 0,02 & 0,06180 & 0,00040 \\
11 & 5 dds & 100 & 0,38044 & 2,62850 & 0,01 & 0,02628 & 0,00010 \\
12 & 5 dds & 200 & 0,47023 & 2,12662 & 0,005 & 0,01063 & 0,000025 \\
13 & 10 dds & 25 & 0,06949 & 14,3907 & 0,04 & 0,57563 & 0,00160 \\
14 & 10 dds & 50 & 0,12519 & 7,98794 & 0,02 & 0,15976 & 0,00040 \\
15 & 10 dds & 100 & 0,17689 & 5,65316 & 0,01 & 0,05653 & 0,00010 \\
16 & $10 \mathrm{dds}$ & 200 & 0,14788 & 6,76208 & 0,005 & 0,03381 & 0,000025 \\
\hline
\end{tabular}

Os valores da soma das três últimas colunas foram utilizadas na eq. (39), obtendo-se o valor de $A=119,4969$. Esse mesmo valor foi obtido quando os valores $1 / N_{p d i}$ e $1 / P R R_{i}$, tomados como, respectivamente, valores dos eixos $\mathrm{X}$ e $\mathrm{Y}$, foram ajustados à eq. (33) na forma da eq. (34) no programa Table Curve. Obteve-se $q=1 / A=0,0084$.

15 Ro, a média dos 12 valores de rendimento do tratamento mantido na ausência da planta daninha foi de 966,1049 kg.ha-1.

16 das e dds são, respectivamente, dias antes e dias depois da semeadura da cultura. 
Anexo S. Dados utilizados no cálculo do coeficiente $a$ do modelo de densidade [eq. (28)]. "Método completo".15

\begin{tabular}{cccc}
\hline $\mathrm{N}^{\circ}$ Trat & Época $^{16}$ & $N_{p d i}$ & $P R R_{i}$ \\
\hline 1 & $\ldots \ldots$ & 0 & 0 \\
2 & 8 das & 25 & 0,67927 \\
3 & 8 das & 50 & 0,80097 \\
4 & 8 das & 100 & 0,84063 \\
5 & 8 das & 200 & 0,84271 \\
6 & No dia & 25 & 0,31931 \\
7 & No dia & 50 & 0,56750 \\
8 & No dia & 100 & 0,54626 \\
9 & No dia & 200 & 0,67568 \\
10 & 5 dds & 25 & 0,38694 \\
11 & 5 dds & 50 & 0,32364 \\
12 & 5 dds & 100 & 0,38044 \\
13 & 5 dds & 200 & 0,47023 \\
14 & $10 \mathrm{dds}$ & 25 & 0,06949 \\
15 & $10 \mathrm{dds}$ & 50 & 0,12519 \\
16 & $10 \mathrm{dds}$ & 100 & 0,17689 \\
17 & $10 \mathrm{dds}$ & 200 & 0,14788 \\
\hline
\end{tabular}

Os valores $N_{p d i}$ e $P R R_{i}$, tomados como, respectivamente, valores de eixo X e eixo $Y$, foram ajustados à eq. (40), com o Programa Table Curve, utilizando como valor inicial para as iterações, o valor de $a=0,0084$ obtido com o "método simplificado". Feitas as iterações, obteve-se $a=0,0114$. 
Anexo T - Dados utilizados no cálculo do coeficiente $q$ do modelo de índice de área foliar relativo [eq. (29)]. "Método simplificado". 15

\begin{tabular}{cccccccccc}
\hline $\begin{array}{c}\mathrm{N}^{\circ} \\
\text { Trat }\end{array}$ & $\begin{array}{c}\text { Épo- } \\
\text { ca }{ }^{16}\end{array}$ & $N_{p d i}$ & $P R R_{i}$ & $F_{p d i}$ & $\left(1 / F_{p d i}\right)^{2}$ & $1 / F_{p d i}$ & $1 / P R R_{i}$ & $\begin{array}{c}\text { X } \\
1 / F_{p d i}\end{array}$ & -1 \\
\hline 1 & 8 das & 25 & 0,67927 & 0,23512 & 18,0899 & 4,25323 & 1,47217 & 6,26149 & 3,25323 \\
2 & 8 das & 50 & 0,80097 & 0,32214 & 9,63652 & 3,10427 & 1,24848 & 3,87561 & 2,10427 \\
3 & 8 das & 100 & 0,84063 & 0,35689 & 7,85104 & 2,80197 & 1,18958 & 3,33313 & 1,80197 \\
4 & 8 das & 200 & 0,84271 & 0,78874 & 1,60741 & 1,26784 & 1,18665 & 1,50448 & 0,26784 \\
5 & No dia & 25 & 0,31931 & 0,05604 & 318,367 & 17,8428 & 3,13176 & 55,8796 & 16,8428 \\
6 & No dia & 50 & 0,56750 & 0,12775 & 61,2747 & 7,82782 & 1,76213 & 13,7936 & 6,82782 \\
7 & No dia & 100 & 0,54626 & 0,27288 & 13,4293 & 3,6646 & 1,83065 & 6,70860 & 2,66460 \\
8 & No dia & 200 & 0,67568 & 0,43646 & 5,24954 & 2,29119 & 1,48 & 3,39096 & 1,29119 \\
9 & 5 dds & 25 & 0,38694 & 0,01063 & 8849,98 & 94,0744 & 2,58440 & 243,126 & 93,0744 \\
10 & 5 dds & 50 & 0,32364 & 0,04594 & 473,751 & 21,7658 & 3,08983 & 67,2527 & 20,7658 \\
11 & 5 dds & 100 & 0,38044 & 0,11502 & 75,5826 & 8,69383 & 2,62850 & 22,8518 & 7,69383 \\
12 & 5 dds & 200 & 0,47023 & 0,18044 & 30,7123 & 5,54186 & 2,12662 & 11,7854 & 4,54186 \\
13 & 10 dds & 25 & 0,06949 & 0,00310 & 104321 & 322,987 & 14,3907 & 4648,01 & 321,987 \\
14 & 10 dds & 50 & 0,12519 & 0,00465 & 46255,6 & 215,071 & 7,98794 & 1717,98 & 214,071 \\
15 & 10 dds & 100 & 0,17689 & 0,02075 & 2323,27 & 48,2003 & 5,65316 & 272,484 & 47,2003 \\
10 & 10 dds & 200 & 0,14788 & 0,02698 & 1373,82 & 37,065 & 6,76208 & 250,636 & 36,0650 \\
\hline & & & & Soma & 164139 & 796,454 & 58,525 & 7328,9 & 780,45 \\
\hline & & & & & & & & &
\end{tabular}

Os valores das somas das cinco últimas colunas foram utilizados na eq. (51), obtendo-se $A=0,0392$. Valor semelhante foi obtido quando os valores das colunas $1 / F_{p d i}$ e $1 / P R R_{i}$ tomados como, respectivamente, valores dos eixos $\mathrm{X}$ e $\mathrm{Y}$ foram ajustados à eq. (45), com o programa Table Curve. Obteve-se $A=0,0399$ e $q=1 / A=25,0627$. 
Anexo U. Dados utilizados no cálculo do coeficiente $q$ do modelo de índice de área foliar relativo [eq. (29)]. "Método completo". ${ }^{15}$

\begin{tabular}{cccc}
\hline $\mathrm{N}^{\circ}$ Trat & Época ${ }^{16}$ & $F_{p d i}$ & $P R R_{i}$ \\
\hline 1 & $\ldots \ldots$ & 0 & 0 \\
2 & 8 das & 0,23512 & 0,67927 \\
3 & 8 das & 0,32214 & 0,80097 \\
4 & 8 das & 0,35689 & 0,84063 \\
5 & 8 das & 0,78874 & 0,84271 \\
6 & No dia & 0,05604 & 0,31931 \\
7 & No dia & 0,12775 & 0,56750 \\
8 & No dia & 0,27288 & 0,54626 \\
9 & No dia & 0,43646 & 0,67568 \\
10 & 5 dds & 0,01063 & 0,38694 \\
11 & 5 dds & 0,04594 & 0,32364 \\
12 & 5 dds & 0,11502 & 0,38044 \\
13 & 5 dds & 0,18044 & 0,47023 \\
14 & $10 \mathrm{dds}$ & 0,00310 & 0,06949 \\
15 & $10 \mathrm{dds}$ & 0,00465 & 0,12519 \\
16 & $10 \mathrm{dds}$ & 0,02075 & 0,17689 \\
17 & $10 \mathrm{dds}$ & 0,02698 & 0,14788 \\
\hline
\end{tabular}

Os valores $F_{p d i}$ e $P R R_{i}$, tomados como, respectivamente, valores de eixo X e eixo $Y$, foram ajustados à eq. (52), com o Programa Table Curve, utilizando como valor inicial para as iterações, o valor de $q=25,0627$ obtido com o "método simplificado". Feitas as iterações, obteve-se $q=6,2693$. 
Anexo V - Dados utilizados no cálculo do coeficiente $q$ do modelo de cobertura relativa do solo pela planta daninha [eq. (30)]. "Método simplificado". 15

\begin{tabular}{|c|c|c|c|c|c|c|c|c|c|}
\hline $\begin{array}{l}\mathrm{N}^{\circ} \\
\text { Trat }\end{array}$ & $\begin{array}{l}\text { Épo- } \\
\text { ca16 }^{16}\end{array}$ & $N_{p d i}$ & $P R R_{i}$ & $S_{p d i}$ & $\left(1 / S_{p d i}\right)^{2}$ & $1 / S_{p d i}$ & $1 / P R R_{i}$ & $\begin{array}{c}1 / P R R_{i} \\
\mathrm{x} \\
1 / S_{p d i}\end{array}$ & $\begin{array}{c}\left(1 / S_{p d i}\right) \\
-1\end{array}$ \\
\hline 1 & 8 das & 25 & 0,67927 & 0,11891 & 70,7253 & 8,40984 & 1,47217 & 12,3807 & 7,40984 \\
\hline 2 & 8 das & 50 & 0,80097 & 0,26191 & 14,5785 & 3,81818 & 1,24848 & 4,76691 & 2,81818 \\
\hline 3 & 8 das & 100 & 0,84063 & 0,30502 & 10,7481 & 3,27843 & 1,18958 & 3,89997 & 2,27843 \\
\hline 4 & 8 das & 200 & 0,84271 & 0,45329 & 4,86670 & 2,20606 & 1,18665 & 2,61782 & 1,20606 \\
\hline 5 & No dia & 25 & 0,31931 & 0,09074 & 121,444 & 11,0202 & 3,13176 & 34,5126 & 10,0202 \\
\hline 6 & No dia & 50 & 0,56750 & 0,15186 & 43,3641 & 6,58515 & 1,76213 & 11,6039 & 5,58515 \\
\hline 7 & No dia & 100 & 0,54626 & 0,23148 & 18,6624 & 4,32 & 1,83065 & 7,90840 & 3,32 \\
\hline 8 & No dia & 200 & 0,67568 & 0,23889 & 17,5230 & 4,18605 & 1,48 & 6,19535 & 3,18605 \\
\hline 9 & $5 \mathrm{dds}$ & 25 & 0,38694 & 0,03306 & 915,062 & 30,25 & 2,58440 & 78,1780 & 29,25 \\
\hline 10 & $5 \mathrm{dds}$ & 50 & 0,32364 & 0,07605 & 172,881 & 13,1484 & 3,08983 & 40,6265 & 12,1484 \\
\hline 11 & $5 \mathrm{dds}$ & 100 & 0,38044 & 0,06807 & 215,791 & 14,6898 & 2,62851 & 38,6123 & 13,6898 \\
\hline 12 & $5 \mathrm{dds}$ & 200 & 0,47023 & 0,14239 & 49,3218 & 7,02295 & 2,12662 & 14,9351 & 6,02295 \\
\hline 13 & $10 \mathrm{dds}$ & 25 & 0,06949 & 0,01226 & 6651,21 & 81,5550 & 14,3907 & 1173,63 & 80,5549 \\
\hline 14 & $10 \mathrm{dds}$ & 50 & 0,12519 & 0,01324 & 5702,59 & 75,5155 & 7,98794 & 603,213 & 74,5155 \\
\hline 15 & $10 \mathrm{dds}$ & 100 & 0,17689 & 0,01305 & 5866,33 & 76,5920 & 5,65316 & 432,987 & 75,5920 \\
\hline \multirow[t]{2}{*}{16} & $10 \mathrm{dds}$ & 200 & 0,14788 & 0,01206 & 6875,83 & 82,9206 & 6,76207 & 560,716 & 81,9206 \\
\hline & & & & Soma & 26750,9 & 425,518 & 58,5246 & 3026,78 & 409,518 \\
\hline
\end{tabular}

Os valores das somas das cinco últimas colunas foram utilizados na eq. (58), obtendo-se $A=0,098$. Valor semelhante foi obtido quando os valores das colunas $1 / S_{p d i}$ e $1 / P R R_{i}$ tomados como, respectivamente, valores dos eixos $\mathrm{X}$ e $\mathrm{Y}$ foram ajustados à eq. (57), com o programa Table Curve. Obteve-se A = 0,0987 e q = 1/A = 10,1317. 
Anexo X. Dados utilizados no cálculo do coeficiente $q$ do modelo de indice de área foliar relativo [eq. (30)]. "Método completo". ${ }^{15}$

\begin{tabular}{cccc}
\hline $\mathrm{N}^{\circ}$ Trat & Época ${ }^{16}$ & $S_{p d i}$ & $P R R_{i}$ \\
\hline 1 & $\ldots$. & 0 & 0 \\
2 & 8 das & 0,11891 & 0,67927 \\
3 & 8 das & 0,26190 & 0,80097 \\
4 & 8 das & 0,30502 & 0,84063 \\
5 & 8 das & 0,45330 & 0,84271 \\
6 & No dia & 0,090743 & 0,31931 \\
7 & No dia & 0,151857 & 0,56750 \\
8 & No dia & 0,231481 & 0,54626 \\
9 & No dia & 0,238889 & 0,67568 \\
10 & 5 dds & 0,033058 & 0,38694 \\
11 & 5 dds & 0,076055 & 0,32364 \\
12 & 5 dds & 0,068074 & 0,38044 \\
13 & 5 dds & 0,14239 & 0,47023 \\
14 & $10 \mathrm{dds}$ & 0,012262 & 0,06949 \\
15 & $10 \mathrm{dds}$ & 0,013242 & 0,12519 \\
16 & $10 \mathrm{dds}$ & 0,013056 & 0,17689 \\
17 & $10 \mathrm{dds}$ & 0,01206 & 0,14788 \\
\hline
\end{tabular}

Os valores $S_{p d i}$ e $P R R_{i}$, tomados como, respectivamente, valores de eixo X e eixo Y, foram ajustados à eq. (52), com o Programa Table Curve, utilizando como valor inicial para as iterações, o valor de $q=10,1317$ obtido com o "método simplificado". Feitas as iterações, obteve-se $q=7,7754$. 
ANEXO Z - Resumo das análises de regressão de ajuste dos dados com os métodos simplificado e completo para os três modelos empíricos de previsão de perdas de rendimento da cultura aplicados à cultura de feijão sob interferência de capimmarmelada. Análises realizadas com todas as épocas relativas de semeadura da planta daninha. ${ }^{1}$

\begin{tabular}{|c|c|c|c|c|c|c|}
\hline \multirow{2}{*}{$\begin{array}{l}\text { Fonte de } \\
\text { variação }\end{array}$} & \multicolumn{3}{|c|}{ Método simplificado } & \multicolumn{3}{|c|}{ Método completo } \\
\hline & GL & & $\mathrm{QM}$ & GL & & $\mathrm{QM}$ \\
\hline \multirow{3}{*}{$\begin{array}{c}\text { Regressão } \\
\text { Resíduo }\end{array}$} & \multicolumn{6}{|c|}{ Modelo de densidade da planta daninha $\left(N_{p d}\right)^{2}$} \\
\hline & 1 & \multicolumn{2}{|c|}{$8,3543 \mathrm{~ns}$} & 1 & \multicolumn{2}{|c|}{$0,0343 \mathrm{~ns}$} \\
\hline & 15 & \multicolumn{2}{|r|}{11,9213} & 16 & \multicolumn{2}{|c|}{0,0736} \\
\hline Ajuste & 3 & \multicolumn{2}{|r|}{$2,9745 \mathrm{~ns}$} & 4 & \multicolumn{2}{|r|}{$0,0566 \mathrm{~ns}$} \\
\hline Erro puro & 12 & \multicolumn{2}{|r|}{14,1580} & 12 & \multicolumn{2}{|r|}{0,0793} \\
\hline \multirow{5}{*}{ tan } & $\begin{array}{c}\text { Parâmetro } \\
(1 / a)\end{array}$ & $\begin{array}{c}\text { Erro } \\
\text { padrão }\end{array}$ & $\mathrm{t}$ & $\begin{array}{c}\text { Parâmetro } \\
(a)\end{array}$ & $\begin{array}{c}\text { Erro } \\
\text { padrão }\end{array}$ & $\mathrm{t}$ \\
\hline & 119,4969 & 37,4500 & 3,1908 & 0,0114 & 0,0035 & 3,2140 \\
\hline & \multicolumn{3}{|c|}{ Limites de confidência (95\%) } & \multicolumn{3}{|c|}{ Limites de confidência (95\%) } \\
\hline & 39,9015 & \multicolumn{2}{|c|}{199,0923} & 0,0039 & \multicolumn{2}{|c|}{0,0189} \\
\hline & \multicolumn{6}{|c|}{ Modelo de indice de área foliar relativa da planta daninha $\left(F_{p d}\right)^{3}$} \\
\hline \multirow{7}{*}{$\begin{array}{c}\text { Regressão } \\
\text { Resíduo }\end{array}$} & 1 & \multicolumn{2}{|c|}{$146,0709 * *$} & 1 & \multicolumn{2}{|c|}{$0,9881 * *$} \\
\hline & 15 & \multicolumn{2}{|c|}{2,7402} & 16 & \multicolumn{2}{|r|}{0,0140} \\
\hline & $\begin{array}{c}\text { Parâmetro } \\
(1 / q)\end{array}$ & $\begin{array}{c}\text { Erro } \\
\text { padrão }\end{array}$ & $\mathrm{t}$ & $\begin{array}{c}\text { Parâmetro } \\
(q)\end{array}$ & $\begin{array}{l}\text { Erro } \\
\text { padrão }\end{array}$ & $\mathrm{t}$ \\
\hline & 0,0399 & 0,0041 & 9,7239 & 6,2693 & 1,0867 & 5,7690 \\
\hline & Limites & e confidên & cia $(95 \%)$ & Limites & confidê & cia (95\%) \\
\hline & 0,0312 & & 0,0486 & 3,9608 & & 8,5778 \\
\hline & \multicolumn{6}{|c|}{ Modelo de cobertura relativa do solo pela planta daninha $\left(S_{p d}\right)$} \\
\hline \multirow{6}{*}{$\begin{array}{c}\text { Regressão } \\
\text { Resíduo }\end{array}$} & 1 & \multicolumn{2}{|c|}{$139,6093^{* *}$} & 1 & \multicolumn{2}{|r|}{$1,0789^{* *}$} \\
\hline & $\begin{array}{r}15 \\
0\end{array}$ & \multicolumn{2}{|c|}{3,1709} & 16 & \multicolumn{2}{|r|}{0,0083} \\
\hline & $\begin{array}{c}\text { Parâmetro } \\
(1 / q)\end{array}$ & $\begin{array}{l}\text { Erro } \\
\text { padrão }\end{array}$ & $\mathrm{t}$ & $\begin{array}{c}\text { Parâmetro } \\
(q)\end{array}$ & $\begin{array}{l}\text { Erro } \\
\text { Padrão }\end{array}$ & $\mathrm{t}$ \\
\hline & 0,0987 & 0,01106 & 8,9258 & 7,7754 & 0,9352 & 8,3142 \\
\hline & Limites & e confidên & cia $(95 \%)$ & Limites & confidê & icia $(95 \%)$ \\
\hline & 0,0752 & & 0,1222 & 5,7888 & & 9,7620 \\
\hline
\end{tabular}

ns, não significativo pelo teste $\mathrm{F}(\mathrm{P}>0,01)$; ** significativo pelo teste $\mathrm{F}(\mathrm{P}>0,01)$. A estimativa do parâmetro foi diferente de zero quanto $\mathrm{t}$ calculado $>\mathrm{t}$ tabela $\left(\mathrm{t}_{15(0,01)}=2,947\right.$ e $\left.\mathrm{t}_{16(0,01)}=2,921\right)$.

1. A média geral de $1 / P R R_{i}$ foi de 3,6577 e a média geral de $P R R_{i}$ foi de 0,4325.

2. No método simplificado, os valores de $1 / P R R_{i}$ foram ajustados à reta da eq. (33) e, no método completo, os valores de $P R R_{i}$ foram ajustados à hipérbole da eq. (40).

3. No método simplificado, os valores de $1 / P R R_{i}$ foram ajustados à reta da eq. (45) e, no método completo, os valores de $P R R_{i}$ foram ajustados à hipérbole da eq. (52).

4. No método simplificado, os valores de $1 / P R R_{i}$ foram ajustados à reta da eq. (57) e, no método completo, os valores de $P R R$ foram ajustados à hipérbole da eq. (59). 


\section{REFERÊNCIAS BIBLIOGRÁFICAS}

BLANCO, H.G. Ecologia das plantas daninhas; competição de plantas daninhas em culturas brasileiras. In: CONSELHO REGIONAL DE ENGENHARIA, ARQUITETURA E AGRONOMIA. Controle integrado de plantas daninhas. São Paulo, 1982. p.43-45.

BLANCO, H.G.; OLIVEIRA, D.A.; ARAUJO, J.B.M. Competição de plantas daninhas com a cultura do feijoeiro (Phaseolus vulgaris). $\mathbf{O}$ Biológico, v.35, n.12, p.304-308, 1969.

BERG, H. van den. Futuro indica mudanças no mercado do feijão. Informativo Fundação ABC, v.1, n.4, p. 15-17, 1999.

BUSSLER, B.H.; MAXWELL, B.; PUETTMANN, K.J. Using plant volume to quantify interference in corn (Zea mays) neighborhoods. Weed Science, v.43, p.586-594, 1995.

CHIKOYE, D.; SWANTON, C.J. Evaluation of three empirical models depicting Ambrosia artemisiifolia competition in white bean. Weed Research, v.35, p.421-428, 1995. 
CHRISTOFFOLETI, P.J. Controle de Brachiaria decumbens Stapf. e de Cyperus rotundus L. em área de cana-de-açúcar (Saccharum sp) através da técnica de rotação com amendoim (Arachis hypogaea) integrada ao uso de herbicidas. Piracicaba, 1988. 117p. Dissertação (Mestrado) - Escola Superior de Agricultura "Luiz de Queiroz", Universidade de São Paulo.

CHRISTOFFOLETI, P.J.; PASSINI, T. Manejo integrado de plantas daninhas na cultura de feijão. In: FANCELLI, A.; DOURADO NETO, D. (Ed.) Feijão irrigado: estratégias básicas de manejo. Piracicaba: Publique, 1999. p.80-96.

CHRISTOFFOLETI, P.J. ; VICTORIA FILHO, R. Efeitos da densidade e proporção de plantas de milho (Zea mays L.) e caruru (Amaranthus retroflexus L.) em competição. Planta Daninha, v.14, n.1. p.42-47, 1996.

CONNOLY, J. Experimental methods in plants competition research in crop-weed systems. Weed Research, v.28, n.6, p.437-441, 1988.

COUSENS, R. Aspects of the design and interpretation of competition (interference) experiments. Weed Technology, v.5, n.3, p.664-673, 1991.

DEUBER, R. Ciência das plantas daninhas: fundamentos. Jaboticabal: FUNEP, 1992. v.1, 431p.

DIELEMAN, A.; HAMILL, A.S.; WEISE, S.F.; SWANTON, C.J. Empirical models of pigweed (Amaranthus spp) interference in soybean (Glycine max). Weed Science, v.43, n.4, p.612-618, 1995. 
DOURADO NETO, D.; FANCELLI, A.L. Quimigação. In: FANCELLI, A.L.; DOURADO NETO, D. (Ed.) Tecnologia da produção do feijão irrigado. Piracicaba: ESALQ, Departamento de Agricultura, 1997. p.65-80.

FLOREZ, J.A.; FISCHER, A.J.; RAMIREZ, H.; DUQUE, M.C. Predicting rice yield losses caused by multispecies weed competition. Agronomy Journal, v.91, p.87-92, 1999.

GOLDBERG, D.E.; P.A. WERNER. Equivalence of competitors in plant communities: a null hypothesis and a field experimental approach. American Journal of Botany, v.70, n.7, p.1098-1104, 1983.

HARPER, J.L. Population biology of plants. London: Academic Press, 1977. 892p.

JASIENIUK, M.; MAXWELL, B.D.; ANDERSON, R.L.; EVANS, J.O.; LYON, D.J.; MILLER, S.D.; MORISHITA, D.W.; OGG Jr., A.G.; SEEFELDT, S.S.; STAHLMAN, P.W.; NORTHAM, F.E.; WESTRA, P.; KEBEDE, Z.; WICKS, G.A. Evaluation of models predicting winter wheat yield as a function of winter wheat and jointed goatgrass densities. Weed Science, v.49, p.48-60, 2001.

JOLLIFFE, P.A.; MINJAS, A.N.; RUNECKLES, V.C. A reinterpretation of yield relationships in replacement series experiments. Journal of Applied Ecology, v.21, n.1, p.227-243, 1984.

KISSMANN, K.G. Plantas infestantes e nocivas. São Paulo: BASF Brasileira S.A., 1991. 608p. 
KISSMANN, K.G. Uso de herbicidas no contexto no MERCOSUL. In: CONGRESSO BRASILEIRO DA CIÊNCIA DAS PLANTA DANINHAS, 22., Foz do Iguaçu, 2000. Palestras. Londrina: SBCPD, 2000. p.112-116.

KNEŽEVIĆ, S.Ž.; WEISE, S.F.; SWANTON, C.J. Comparison of empirical models depicting density of Amaranthus retroflexus L. and relative leaf area as predictors of yield loss in maize (Zea mays L.). Weed Research, v.35, p.207-214, 1995.

KRAMM M., V.E.; VIEIRA, C.; SILVA, J.F. da; CARDOSO, A.A. Efeitos da competição com plantas daninhas sobre a cultura do feijão (Phaseolus vulgaris L.). Revista Ceres, v.37, n.212, p.345-361, 1990.

KRANZ, W.M. Plantas invasoras na cultura do feijão no Estado do Paraná. In: REUNIÃO NACIONAL DE PESQUISA DE FEIJÃO, 4., Londrina, 1993. Resumos. Londrina: IAPAR, 1983. p.68

KROPFF, M.J. Modelling the effects of weeds on crop production. Weed Research, v.28, p.465-471, 1988.

KROPFF, M.J.; LOTZ, L.A.P. Systems approaches to quantify crop-weed interactions and their application in weed management. Agricultural Systems, v.40, n.1/3, p.265-282, 1992.

KROPFF, M.J.; LOTZ, L.A.P. Empirical models for crop-weed competition. In: KROPFF, M.J.; LAAR, H.H. van (Ed.) Modelling crop-weed interactions. Wallingford: CAB International, 1993. cap.2, p.9-24.

KROPFF, M.J.; SPITTERS, C.J.T. A simple model of crop loss by weed competition from early observations on relative leaf area of the weeds. Weed Research, v.31, p.97-105, 1991. 
KROPFF, M.J.; LOTZ, L.P.A.; WEAVER, S.E.; BOS, H.J.L ; WALLINGA, J.; MIGO, T. A two parameter model for prediction of crop loss by weed competition from early observations of relative leaf area of weeds. Annals of Applied Biology, v.123, n.2, p.329-346, 1995.

LORENZI, H. Plantas daninhas do Brasil: terrestres, aquáticas, parasitas, tóxicas e medicinais. 2.ed. Nova Odessa: Editora Plantanarum, 1991. 440p.

LOTZ, L.A.P.; WALLINGA, J.; KROPFF, M.J. Crop-weed interactions: quantification and prediction. In: LONG ASHTON INTERNATIONAL SYMPOSIUM ON ARABLE ECOSSYSTEMS FOR THE 21st CENTURY, 13., Bristol, 1993. Ecology and integrated farming systems. Bristol: John Wiley, 1995. p.31-45.

LOTZ, L.A.P.; KROPFF, M.J.; BOS, H.J.; WALLINGA, J. Prediction of yield loss based on relative leaf cover of weeds. In: INTERNATIONAL WEED CONTROL CONGRESS, 1., Melbourne, 1992. Proceedings. Melbourne: WSSA of Victoria, 1992. v.2, p.290-292.

LOTZ, L.A.P.; KROPFF, M.J.; WALLINGA, J.; BOS, H.J.; GROENEVELD, R.M.W. Techniques to estimate relative leaf area and cover of weeds in crops for yield loss prediction. Weed Research, v.34, n.3, p.167175, 1994.

LOTZ, L.A.P.; CHRISTENSEN, S.; CLOUTIER, D.; QUINTANILLA, C.F.; LÉGÈRE, A.; LEMIEUX, C.; LUTMAN, P.J.W.; IGLESIAS, A.P.; SALONEN, J.; SATTIN, M.; STIGLIANI, L.; TEI, F. Prediction of the competitive effects of weeds on crop yields based on the relative leaf area of weeds. Weed Research, v.36, p.93-101, 1996. 
LUNKES, J.A. Manejo integrado de plantas daninhas. In: FANCELLI, A.L.; DOURADO NETO, D. Tecnologia da produção do feijão irrigado. Piracicaba: ESALQ, Departamento de Agricultura, 1997. p.9-19.

LUTMAN, P.J.W.; RISIOTT, R.; OSTERMANN, P. Investigation into alternative methods to predict the competitive effects of weeds on crop yields. Weed Science, v.44, p.290-297, 1996.

NGOUAJIO, M.; LEMIEUX, C.; LEROUX, G.D. Prediction of corn (Zea mays) yield loss from early observations of the relative leaf area and the relative leaf cover of weeds. Weed Science, v.47, p.297-304, 1999.

OLIVER, L.R.; G.A. BUCHANAN. Weed competition and economic thresholds. In: CAMPER, N.D. (Ed.) Research methods in weed science. sl.: Southern Weed Science Society of America, 1986. cap.4, p. $72-97$.

PARKER, L.; MURDOCH, A.J. Mathematical modelling of multispecies weed competition in spring wheat. In: INTERNATIONAL WEED CONTROL CONGRESS, 2., Copenhagen, 1996. Proceedings. Copenhagen, 1996. p.153-158.

REJMÁNEK, M.; ROBINSON, G.R.; REJMÁNKOVÁ, E. Weed-crop competition: experimental designs and models for data analysis. Weed Science, v. 37, n.2, p.276-284, 1989.

ROUSH, M.L.; RADOSEVICH, S.R.; WAGNER, R.G.; MAXWELL, B.D.; PETERSEN, T.D. A comparison of methods for measuring effects of density and proportion in plant competition experiments. Weed Science, v.37, n.2, p.268-275, 1989. 
SPITTERS, C.J.T. An alternative approach to the analysis of mixed cropping experiments. 1. Estimation of competition effects. Netherland Journal of Agricultural Science., v.31, p.1-11, 1983.

SPITTERS, C.J.T.; KROPFF, M.J.; GROOT, W. Competition between maize and Echinochloa crus-galli analysed by a hyperbolic regression model. Annals of Applied Biology, v.115, p.541-551, 1989.

VANGESSEL, M.J.; SCHWEIZER, E.E.; GARRETT, K.A.; WESTRA, P. Influence of weed density and distribution on corn (Zea mays) yield. Weed Science, v.43,p.215-218, 1995.

WILKERSON, G.G.; MODENA, S.A.; COBLE, H.D. HERB: decision model for postemergence weed control in soybean. Agronomy Journal, v.83, p.413-417, 1991.

ZADOKS, J.C.; CHANG, T.T.; KONZAK, C.F. A decimal code for the growth stages of cereals. Weed Research, v.14, p.415-421, 1974.

ZIMDAHL, R.L. Weed crop competition: a review. Corvallis: International Protection Centre, 1980. 197p. 